\title{
Data Report for the Instrumented Fuel Assembly IFA-513
}

Prepared by E. R. Bradley, M. E. Cunningham, D. D. Lanning, R. E. Williford

Pacific Northwest Laboratory

Operated by

Battelle Memorial Institute

Prepared for

U.S. Nuclear Regulatory

Commission 


\title{
NOTICE
}

This report was prepared as an account of work sponsored by an agency of the United States Government. Neither the United States Government nor any agency thereof, or any of their employees, makes any warranty, expressed or implied, or assumes any legal liability or responsibility for any third party's use, or the results of such use, of any information, apparatus product or process disclosed in this report, or represents that its use by such third party would not infringe privately owned rights.

\author{
Available from \\ GPO Sales Program \\ Division of Technical Information and Document Control \\ U. S. Nuclear Regulatory Commission \\ Washington, D. C. 20555 \\ Printed copy price: $\$ 4.75$
}

and

National Technical Information Service

Springfield, Virginia 22161 
NUREG/CR-1838

PNL-3637

R3

\section{Data Report for the Instrumented Fuel Assembly IFA-513}

Manuscript Completed: January 1981

Date Published: August 1981

Prepared by

E. R. Bradley, M. E. Cunningham, D. D. Lanning, R. E. Williford

Pacific Northwest Laboratory

Richland, WA 99352

Prepared for

Division of Accident Evaluation

Office of Nuclear Regulatory Research

U.S. Nuclear Regulatory Commission

Washington, D.C. 20555

NRC FIN B2043 



\section{ABSTRACT}

This report presents the in-reactor data collected to date from the NRC/PNL Halden test assembly IFA-513. The irradiation test is part of an experimental program entitled "Experimental Support and Development of Single Rod Fue 1 Codes" sponsored by the Fuel Behavior Branch of the U.S. Nuclear Regulatory Commission (NRC). The purpose of this program is to reduce the uncertainties of predicting the thermal and mechanical behavior of an operating nuclear fuel rod.

Fue 1 centerline temperatures, cladding elongation, internal fuel rod pressures, and local powers at the thermocouple positions are shown as a function of time for the irradiation period from November 1978 to January 1980. The local powers were derived from neutron detector readings while the other variables were measured directly.

The general trends in the data as a function of burnup are presented and discussed. Detailed analysis of the data is not made, but topical reports discussing certain aspects of the data are referenced. Descriptions of the assembly, instrumentation and calibration, and data processing methods are also presented. 



\section{SUMMARY}

In-reactor data collected from the NRC/PNL/Halden test assembly IFA-513 through January 1980 are presented in this report, and the general data trends as a function of burnup are discussed. Fuel temperatures and power levels, cladding elongation, and the internal fuel rod pressures represent the primary data collected from six fuel rods that were of similar design except for fill gas composition and pressure. Rods 1,3 , and 5 were filled with pure helium at $0.1 \mathrm{MPa}$; rod 2 was filled with pure helium at $0.3 \mathrm{MPa}$; and rods 4 and 6 contained $8 \%$ and $23 \%$ xenon, respectively.

The fuel temperatures and thermal resistances for rods 1 through 5 were very similar throughout the irradiation period examined. Thus, neither increasing the initial fill gas pressure from 0.1 to $0.3 \mathrm{MPa}$ nor introducing $8 \%$ xenon into the fill gas had any effect on the thermal response of these fue 1 rods. Rod 6 , which contained $23 \%$ xenon in the fill gas, showed significantly higher temperatures and resistances than the other five rods and the differences decreased with increasing burnup. The magnitude of the initial temperature difference agrees well with the predictions from the GAPCON-THERMAL-3 computer code.

Data collected during two reactor scrams have been used to verify the steady-state trends in resistance and to compare two radial heat transfer models. The results show qualitative agreement between steady-state and transient data. The radial heat transfer model with a constant gap conductance provided the best fit to the experimental scram data, which implies that the fuel-to-cladding gap remained constant during cool-down (contrary to the conventional view of a fuel rod).

Elongation data at low power levels from the five rods with operating elongation detectors showed length increases from 0.25 to $0.50 \mathrm{~mm}$ at the end of the irradiation period examined (January 1980). Most of these length increases occurred following the first power ramp and during the third reactor operating cycle--from October 1979 to January 1980. The rod-to-rod variations in fuel rod elongation were generally related to differences in the amount of pellet-cladding interaction that occurred during power ramps. 
Small gas pressure increases were recorded for five of the six fuel rods in IFA-513. The estimated fission gas release as of January 1980 ranged from 0 to $2.2 \%$. The magnitude of the pressure increases was generally within the uncertainty of the measurements; and, therefore, meaningful rod-to-rod comparisons were not possible.

Pressure data from rod 5 were significantly different than the other five rods. Three pressure spikes were observed during the first $350 \mathrm{GJ} / \mathrm{kgU}$ (4050 MWd/MTM) of irradiation and extremely high pressures ( $2 \mathrm{MPa}$ ) were observed thereafter. Rod 5 was subsequently identified as defective and has been removed from the reactor. The high pressures indicate that the rod may have failed at about $350 \mathrm{GJ} / \mathrm{kgU}$ burnup; however, the three prior pressure spikes suggest that a small defect may have been present through most of the irradiation period. 


\section{CONTENTS}

\begin{tabular}{|c|c|c|c|c|c|c|c|c|c|c|c|c|c|c|}
\hline ABSTRACT & . & . & . & . & - & • & - & · & - & - & $\cdot$ & $\cdot$ & - & $i i i$ \\
\hline SUMMARY & - & - & - & - & - & $\cdot$ & - & . & - & - & $\cdot$ & • & - & $v$ \\
\hline INTRODUCT & ION & - & . & . & . & ${ }^{*}$ & • & - & . & ${ }^{*}$ & . & . & $\cdot$ & 1 \\
\hline \multicolumn{8}{|c|}{ ASSEMBLY DESCRIPTION AND INSTRUMENTATION } & . & - & ${ }^{\circ}$ & . & . & • & 3 \\
\hline \multicolumn{3}{|c|}{ EXPERIMENTAL DATA } & . & . & . & ${ }^{*}$ & • & . & . & $\cdot$ & . & . & - & 7 \\
\hline DISCUSSI0 & N OF & DATA & - & . & $\cdot$ & - & • & - & - & • & . & . & • & 15 \\
\hline \multicolumn{3}{|c|}{ TEMPERATURE AND } & D RES & ISTAN & & • & . & . & - & • & - & $\cdot$ & - & 15 \\
\hline \multicolumn{10}{|c|}{ Comparison of Steady-State Temperatures } & • & - & 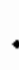 & • & 15 \\
\hline \multicolumn{15}{|c|}{ Verification of Steady-State Temperature Comparisons } \\
\hline & Via & Scram & Data & & $\cdot$ & - & . & . & . & - & • & . & . & 20 \\
\hline CLADI & DING & ELONGA & ATION & & $\cdot$ & • & • & - & - & • & $\cdot$ & $\cdot$ & $\cdot$ & 25 \\
\hline INTEI & RNAL & PRESSL & & - & - & • & • & • & - & $\cdot$ & $\cdot$ & . & $\cdot$ & 29 \\
\hline REFERENCE & & - & - & - & - & • & $\bullet$ & $\cdot$ & - & • & - & $\cdot$ & • & 35 \\
\hline APPENDIX & $A-$ & INSTRUM & MENT & DESCR & IPT & & & IBR & ION & $\bullet$ & - & 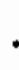 & $\cdot$ & A.1 \\
\hline APPENDIX & $B=$ & DATA PR & ROCESS & SING & $\cdot$ & $\cdot$ & • & • & • & * & . & $\bullet$ & $\cdot$ & B.1 \\
\hline APPENDIX & $C-$ & ASSEMBL & LY POI & & ALI & 11 & & $\cdot$ & • & • & • & 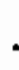 & • & C. 1 \\
\hline APPENDIX & $0=$ & DATA PL & LOTS & • & $\cdot$ & • & • & - & - & • & $\cdot$ & $\cdot$ & ${ }^{\circ}$ & D. 1 \\
\hline
\end{tabular}


FIGURES

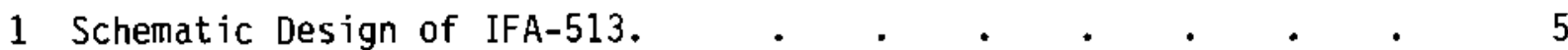

2 Experimental Data as a Function of Rod Average Burnup

for $\operatorname{Rod} 1$ of IFA-513 $\cdot$.

Experimental Data as a Function of Rod Average Burnup
for Rod 2 of IFA-513 . . . . . . . . 9

4 Experimental Data as a Function of Rod Average Burnup 10

5 Experimental Data as a Function of Rod Average Burnup

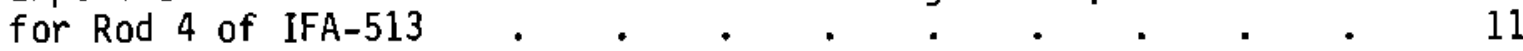

6 Experimental Data as a Function of Rod Average Burnup 12

7 Experimental Data as a Function of Rod Average Burnup

for $\operatorname{Rod} 6$ of IFA-513 . . . . . . . . . . . 13

8 Resistance of Rods 1,3 , and 5 Compared at the Lower

Thermocouple Location as a Function of Average Burnup . . . 17

9 Resistance of Rods 1 and 2 Compared at the Lower

Thermocouple Location as a Function of Average Burnup . . . 18

10 Resistance of Rods 1,4 , and 6 Compared at the Lower

Thermocouple Location as a Function of Average Burnup . . . 19

11 Resistance Trends . . . . . . . . . . . . . . 21

12 IFA-513 Scram Data. . . . . . . . . . . 22

13 Replotted IFA-513 Data . . . . . . . . . . 23

14 Resistances for Rods 2 and 6 at Approximately $30.0 \mathrm{~kW} / \mathrm{m}$. . 24

15 IFA-513, TF 11 Scram Data and Predictions

for the August 23,1979 , Scram . . . . . . . . 26

16 Internal Pressure of Rod 5 as a Function of Time

Immediately After Extended Shutdown Periods . . . . 32

A.1 Schematic of Beta-Emitter Self-Powered Neutron Detector . . A.2

A.2 Cladding Elongation Monitor (Halden Project Design) . . . A.5 
A.3 Schematic of a Bellows-Type Pressure Transducer . . A.6

B.1 Flow Diagram for Processing Halden Data.$\quad \ldots \quad$. . . . B.2

C.1 Schematic Arrangement for Assembly Power Calioration . . • C.2

D.1 Local Linear Heat Rates at Upper Thermocouple Location for Rods 1, 3, and 5 of IFA-513 from November 28, 1978, to January 26,1979

D.2 Local Linear Heat Rates at Lower Thermocouple Location for Rods 1, 3, and 5 of IFA-513 from November 28, 1978, to January 26,1979

D.3 Local Linear Heat Rates at Upper Thermocouple Location for Rods 2, 4, and 6 of IFA-513 from November 28, 1978, to January 26,1979

D.4 Local Linear Heat Rates at Lower Thermocouple Location for Rods 2, 4, and 6 of IFA-513 from November 28, 1978, to January 26, 1979

D.5 Local Linear Heat Rates at Upper Thermocouple Location for Rods 1, 3, and 5 of IFA-513 from Apri1 5, 1979,

D.6 Local Linear Heat Rates at Lower Thermocouple Location for Rods 1, 3, and 5 of IFA-513 from Apri1 5, 1979, to May 22, 1979

D.7 Local Linear Heat Rates at Upper Thermocouple Location for Rods 2, 4, and 6 of IFA-513 from April 5, 1979, to May 22, 1979

D.8 Loca] Linear Heat Rates at Lower Thermocouple Location for Rods 2, 4, and 6 of IFA-513 from Apri1 5, 1979, to May 22, 1979

D.9 Local Linear Heat Rates at Upper Thermocouple Location for Rods 1, 3, and 5 of IFA-513 from July 10, 1979, to August 23,1979

0.10 Local Linear Heat Rates at Lower Thermocouple Location for Rods 1, 3, and 5 of IFA-513 from July 10, 1979, to August 23, 1979

D.11 Local Linear Heat Rates at Upper Thermocouple Location for Rods 2, 4, and 6 of IFA-513 from July 10, 1979, to August 23,1979 
D.12 Local Linear Heat Rates at Lower Thermocouple Location for Rods 2, 4, and 6 of IFA-513 from July 10, 1979, to August 23, 1979

D.13 Local Linear Heat Rates at Upper Thermocouple Location for Rods 1, 3, and 5 of IFA-513 from October 1, 1979, to November 30,1979

D.14 Local Linear Heat Rates at Lower Thermocouple Location for Rods 1, 3, and 5 of IFA-513 from October 1, 1979, to November 30,1979

D.15 Local Linear Heat Rates at Upper Thermocouple Location for Rods 2, 4, and 6 of IFA-513 from October 1, 1979, to November 30,1979

D.16 Local Linear Heat Rates at Lower Thermocouple Location for Rods 2, 4, and 6 of IFA-513 from October 1, 1979, to November 30,1979

D.17 Local Linear Heat Rates at Upper Thermocouple Location for Rods 1, 3, and 5 of IFA-513 from December 1, 1979, to January 6, 1980

D.18 Local Linear Heat Rates at Lower Thermocouple Location for Rods 1, 3, and 5 of IFA-513 from December 1, 1979, to January 6,1980

D.19 Local Linear Heat Rates at Upper Thermocouple Location for Rods 2, 4, and 6 of IFA-513 from December 1, 1979, to January 6,1980

D.20 Local Linear Heat Rates at Lower Thermocouple Location for Rods 2, 4, and 6 of IFA-513 from December 1, 1979, to January 6,1980

0.21 Upper Thermocouple Readings for Rods 1, 3, and 5 of IFA-513 from November 28, 1978, to January 26, 1979

0.22 Lower Thermocouple Readings for Rods 1, 3, and 5 of IFA-513 from November 28, 1978, to January 26, 1979

D.23 Upper Thermocouple Readings for Rods 2, 4, and 6 of IFA-513 from November 28, 1978, to January 26,1979 . . . . . .

D.24 Lower Thermocouple Readings for Rods 2, 4, and 6 of IFA-513 from November 28,1978 , to January 26,1979 . . . .

D.25 Upper Thermocouple Readings for Rods 1 and 5 of IFA-513 from April 5, 1979, to May 22, 1979 
D.26 Lower Thermocouple Readings for Rods 1, 3, and 5 of IFA-513 from April 5, 1979, to May 22, 1979 . . . . . . . D.14

D.27 Upper Thermocoup le Readings for Rods 4 and 6 of IFA-513 from April 5, 1979, to May 22, 1979 . . . . . . . . . D.15

D.28 Lower Thermocouple Readings for Rods 2, 4, and 6 of IFA-513 from Apri1 5, 1979, to May 22, 1979 . . . . . • . . D.15

D.29 Upper Thermocouple Readings for Rods 1 and 5 of IFA-513 from July 10,1979 , to August 23,1979 . . . . . . . D.16

D.30 Lower Thermocouple Readings for Rods 1, 3, and 5 of IFA-513 from July 10,1979 , to August 23,1979 . . . . . . D.16

D.31 Upper Thermocouple Readings for Rods 4 and 6 of IFA-513 from

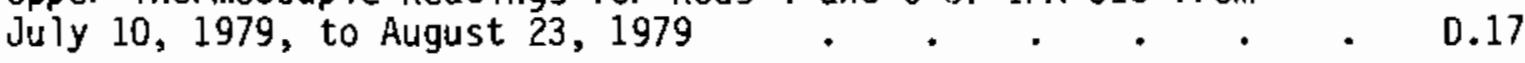

D.32 Lower Thermocouple Readings for Rods 2, 4, and 6 of IFA-513 from July 10,1979 , to August 23,1979 . . . . . . . D.17

D.33 Upper Thermocouple Readings for Rods 1 and 5 of IFA-513 from october 1, 1979, to November 30,1979 . . . . . D.18

D.34 Lower Thermocouple Readings for Rods 1, 3, and 5 of IFA-513 from October 1, 1979, to November 30,1979 . . . . . D.18

D.35 Upper Thermocouple Readings for Rods 4 and 6 of IFA-513 from October 1,1979 , to November 30,1979 . . . . . . D.19

D.36 Lower Thermocouple Readings for Rods 2, 4, and 6 of IFA-513 from

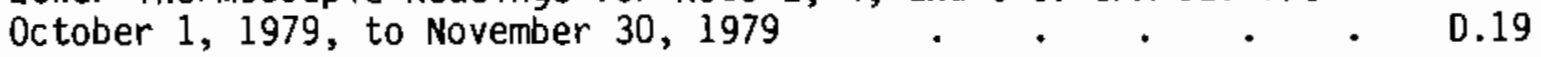

D.37 Upper Thermocouple Readings for Rods 1 and 5 of IFA-513 from December 1,1979 , to January 6,1980 . . . . . . D.20

D.38 Lower Thermocouple Readings for Rods 1, 3, anc 5 of IFA-513 from December 1,1979 , to January 6,1980 . . . . . . D.20

D.39 Upper Thermocouple Readings for Rods 4 and 6 of IFA-513 from December 1,1979 , to January 6,1980 . $\quad . \quad$. . . . 0.21

D.40 Lower Thermocouple Readings for Rods 2, 4, and 6 of IFA-513 from

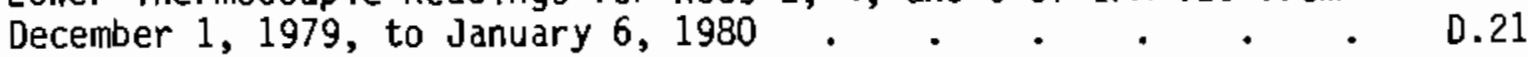

D.41 Cladding Elongation Sensor Readings for Rods 1,3 , and 5
of IFA-513 from November 18, 1978, to January 26, 1979 . $\quad 0.22$

D.42 Cladding Elongation Sensor Readings for Rods $\hat{2}, 4$, and 6
of IFA-513 from November 18,1978 , to January 26,1979 . $\quad 0.22$ 
D.43 Cladding Elongation Sensor Readings for Rods 1, 3, and 5

of IFA-513 from April 5, 1979, to May 22, 1979 . . . . 0.23

D.44 Cladding Elongation Sensor Readings for Rods 2 and 6

of IFA-513 from April 5, 1979, to May 22, 1979 . . . . D.23

D.45 Cladding Elongation Sensor Readings for Rods 1,3 , and 5

of IFA-513 from July 10,1979 , to August 23,1979 . . . $\quad$ D.24

D.46 Cladding Elongation Sensor Readings for Rods 2 and 6

of IFA-513 from Juiy 10,1979 , to August 23,1979 . . . D.24

D.47 Cladding Elongation Sensor Readings for Rods 1,3 , and 5 of IFA-513 from October 1, 1979, to November 30, 1979 . . D.25

D.48 Cladding Elongation Sensor Readings for Rods 2 and 6 of IFA-513 from October 1, 1979, to November 30, 1979 . . D.25 D.49 Cladding Elongation Sensor Readings for Rods 1, 3, and 5
of IFA-513 from December 1, 1979, to January 6, 1980 . . D.26

D.50 Cladding Elongation Sensor Readings for Rods 2 and 6
of IFA-513 from December 1,1979 , to January 6,1980 . . D.26

D.51 Internal Pressures for Rods 1,3 , and 5 of IFA-513 from
November 28, 1978, to January 26,1979 . . 0.27

D.52 Internal Pressures for Rods 2, 4, and 6 of IFA-513 from
November 28, 1978, to January 26,1979 . . . D.27

D.53 Internal Pressures for Rods 3 and 5 of IFA-513 from
April 5, 1979, to May 22, 1979 . . . . . . D.28

D.54 Internal Pressures for Rods 2, 4, and 6 of IFA-513 from
Apri] 5, 1979, to May 22, 1979 . . . . . . D.28

D.55 Internal Pressures for Rods 1,3 , and 5 of IFA-513 from July 10, 1979, to August 23,1979 . . . . . . . 0.29

D.56 Internal Pressures for Rods 2,4 , and 6 of IFA-513 from
July 10, 1979, to August 23, 1979 . . . . 0.29

D.57 Internal Pressures for Rods 1 and 3 of IFA-513 from 30

D.58 Interna 1 Pressures for Rods 2, 4, and 6 of IFA-513 from
October 1, 1979, to November 30, $1979 . \quad$. . . . 0.30

D.59 Interna1 Pressures for Rods 1 and 3 of IFA-513 from
December 1, 1979, to January 6, . . . . . 0.31 
D.60 Interna] Pressures for Rods 2, 4, and 6 of IFA-513 from December 1,1979 , to January 6,1980 . . . . . . . D.31

\section{$\underline{T A B L E S}$}

1 General Design Characteristics for NRC/PNL Test Assemb1ies . . 3

2 Experimental Matrix . . . . . . . . . 44

3 August 23, 1979, Scram Results . . . . . . . 23

4 Scram Results for Rods 2 and 6 (Lower Thermocouples) . . . 24

5 Summary of Pressure Increases and Estimated Gas Release for IFA-513 as of January 1980 .

D.1 IFA-513 Burnup Data $(\mathrm{a})$. . . . . . . . . . 0.32 


\section{ACKNOWLEDGMENTS}

The authors wish to thank the Fuel Behavior Research Branch, Office of Reactor Safety Research, U.S. Nuclear Regulatory Commission, for their continued support and encouragement of the experimental program. We also thank the Halden Reactor staff and R. W. Miller, the NRC representative at Halden, for their efforts in recording and transmitting the experimental data. Special thanks are given to $W$. $D$. Bennett, who produced the many data plots, and to $S$. K. Edler for editing this report. 


\section{INTRODUCTION}

This report presents data from the first 14 months of operation of instrifmented fuel assembly (IFA)-513, which is a heavily instrumented six-rod test assembly in the Halden bojling water reactor (HBWR) in Norway. This assembly is jointly sponsored by the Halden Project and the U.S. Nuclear Regulatory Commission (NRC) and is part of a series of irradiation tests sponsored by NRC to verify its single-rod fuel modeling computer programs. The work is being conducted by Pacific Northwest Laboratory $(P N L){ }^{(a)}$ under a related services contract.

All the rods in the four-assembly test series are of the basic BWR-6 design with variations in gap size, fuel type, fill gas composition, and fill gas pressure. The first two assemblies in the test series were IFA-431 and IFA-432 (identical six-rod assemblies), which contained the same variations of gap size and fuel pellet types but operated at different power levels and burnups. The present assembly, IFA-513, is the third in the series; its six rods are identical except for variations in fill gas composition and pressure. The fourth and last assembly, designated IFA-527, has recently been charged into the reactor to study the effects of fuel pellet cracking and relocation.

The measurements made by IF A-513 and the earlier test assemblies are made continuously and provide a record of variation with both power and burnup and include:

- fuel temperature and power (both steady-state and transient)

- total cladding elongation

- fill gas pressure.

This report also includes some discussion and analysis of the data. Detailed analysis will be presented in future topical reports.

(a) Operated for the U.S. Department of Energy (DOE) by Battelle Memorial Institute. 


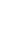




\section{ASSEMBLY DESCRIPTION AND INSTRUMENTATION}

IFA-513 was designed with three purposes in mind

- to provide instrumented, irradiated rods that are thoroughiy characterized as to fabrication parameters and thermal history for use in transient tests at the Power Burst Facility (PBF) reactor in Idaho Falls, Idaho.

- to extend the NRC Halden test series to include rods with known fill gas mixtures at several points between pure helium and pure xenon.

- to quantify the variability among rods of contemporary design that have been fabricated and operated identically.

Table 1 lists general design features of IFA-513, IFA-527, IFA-431, and IFA-432; and Table 2 lists specific variations for each rod in all four assemblies and the instrumentation for each rod. A description of the instrumentation and measurement uncertainty is given in Appendix $A$, and Figure 1 is a schematic of IFA- 513.

TABLE 1. General Design Characteristics for NRC/PNL Test Assemblies

\begin{tabular}{|c|c|c|}
\hline Item & IFA-513 and IFA-527 & IFA-431 and IFA-432 \\
\hline Number of Rods & 6 & 6 \\
\hline $\begin{array}{l}\text { Cladding: } \\
\text { Material } \\
\text { IDx00, }\end{array}$ & $\begin{array}{l}\text { Zircaloy-2 } \\
10.9 \times 12.8\end{array}$ & $\begin{array}{l}\text { Zircaloy-2 } \\
10.9 \times 12.8\end{array}$ \\
\hline Tube Length, m & 0.824 & 0.61 \\
\hline $\begin{array}{l}\text { Fuel Pellets: } \\
\text { Material } \\
\text { Enrichment, } \% 235 \mathrm{U} \\
\text { Diameter, mm } \\
\text { Pellet Length, }\end{array}$ & $\begin{array}{l}\mathrm{UO}_{2} \\
9.9 \\
10.7 \\
12.7\end{array}$ & $\begin{array}{l}\mathrm{UO}_{2} \\
10.0 \\
10.7 \\
12.7\end{array}$ \\
\hline Active Pellet Column Length, $m$ & 0.78 & 0.57 \\
\hline Pellet Density, \%TD & 95 & 95,92 \\
\hline $\begin{array}{l}\text { Fuel Rod: } \\
\text { Plenum Length, mm } \\
\text { Poison Pellet Length } \\
\text { (each end), mm }\end{array}$ & $\begin{array}{l}29 \\
7\end{array}$ & $\begin{array}{l}19 \\
7\end{array}$ \\
\hline
\end{tabular}


TABLE 2. Experimental Matrix

\begin{tabular}{|c|c|c|c|c|c|c|c|c|c|c|c|c|c|}
\hline \multirow{2}{*}{$\begin{array}{l}\text { Assembiy } \\
\text { and Rod }\end{array}$} & \multirow{2}{*}{$\begin{array}{c}\text { Power, (a) } \\
\mathrm{kw/m} \\
\end{array}$} & \multirow{2}{*}{$\begin{array}{l}\text { Fue } 1 \text { (b) } \\
\text { Type }\end{array}$} & \multirow{2}{*}{$\begin{array}{l}\text { Oiametra } \\
50-75 \\
\end{array}$} & \multirow{2}{*}{\multicolumn{2}{|c|}{$\frac{1}{231}$}} & \multicolumn{2}{|c|}{ Initial Fill Gas } & $q \times \mathrm{e} \mathrm{at}$ & \multicolumn{5}{|c|}{ Detectors $(c)$} \\
\hline & & & & & & $0.1 \mathrm{MPa}$ & $\geq 0.1 \mathrm{MPa}$ & $0.1 \mathrm{MPa}$ & UTC & LTC & ES & PT & SPND \\
\hline $\begin{array}{c}\text { IFA-431 } \\
1 \\
2 \\
3 \\
4 \\
5 \\
6\end{array}$ & $35 / 25$ & $\begin{array}{l}95 S \\
95 S \\
95 S \\
95 S \\
92 S \\
92 U\end{array}$ & $x$ & $\begin{array}{l}x \\
x \\
x \\
x\end{array}$ & $x$ & $\begin{array}{l}x \\
x \\
x \\
x \\
x\end{array}$ & & $100 x$ & $\begin{array}{l}x \\
x \\
x \\
x \\
x \\
x\end{array}$ & $\begin{array}{l}x \\
x \\
x \\
x \\
x \\
x\end{array}$ & $\begin{array}{l}x \\
x \\
x \\
x \\
x \\
x\end{array}$ & $\begin{array}{l}x \\
x\end{array}$ & 7 \\
\hline $\begin{array}{c}\text { IFA-432 } \\
1 \\
2 \\
3 \\
4 \\
5 \\
6\end{array}$ & $50 / 35$ & $\begin{array}{l}95 S \\
95 S \\
95 S \\
955 \\
92 S \\
92 U\end{array}$ & $x$ & $\begin{array}{l}x \\
x \\
x \\
x\end{array}$ & $x$ & $\begin{array}{l}x \\
x \\
x \\
x \\
x\end{array}$ & & $100 x$ & $\begin{array}{l}x \\
U T \\
X \\
x \\
x \\
X\end{array}$ & $\begin{array}{l}x \\
x \\
x \\
x \\
x \\
x\end{array}$ & $\begin{array}{l}x \\
x \\
x \\
x \\
x \\
x\end{array}$ & $\begin{array}{l}x \\
x\end{array}$ & 7 \\
\hline $\begin{array}{c}\text { IFA-513 } \\
1 \\
2 \\
3 \\
4 \\
5 \\
6\end{array}$ & $40 / 28$ & $\begin{array}{l}95 S \\
95 S \\
95 S \\
955 \\
95 S \\
95 S\end{array}$ & & $\begin{array}{l}x \\
x \\
x \\
x \\
x \\
x\end{array}$ & & $\begin{array}{l}x \\
x \\
x\end{array}$ & $0.3 \mathrm{MPa}$ & $\begin{array}{r}8 x \\
23 x\end{array}$ & $\begin{array}{l}x \\
x \\
x \\
x \\
x \\
x\end{array}$ & $\begin{array}{l}x \\
x \\
x \\
x \\
x \\
x\end{array}$ & $\begin{array}{l}x \\
x \\
x \\
x \\
x \\
x\end{array}$ & $\begin{array}{l}x \\
x \\
x \\
x \\
x \\
x\end{array}$ & 9 \\
\hline $\begin{array}{c}\text { IFA-527 } \\
1 \\
2 \\
3 \\
4 \\
5 \\
6\end{array}$ & $14 / 10$ & $\begin{array}{l}95 S \\
45 S \\
95 S \\
95 S \\
95 S \\
95 S\end{array}$ & $x$ & $\begin{array}{l}x \\
x \\
x \\
x \\
x\end{array}$ & & & & $\begin{array}{l}100 \% \\
100 \% \\
100 \% \\
100 \% \\
100 \% \\
100 \%\end{array}$ & $\begin{array}{l}x \\
x \\
x \\
x \\
x \\
x\end{array}$ & $\begin{array}{l}x \\
x \\
x \\
x \\
x \\
x\end{array}$ & $\begin{array}{l}y \\
x \\
x \\
x \\
x \\
x\end{array}$ & $\begin{array}{l}y \\
x \\
x \\
x \\
x \\
x\end{array}$ & 9 \\
\hline
\end{tabular}

(a) Linear power is given for upper and lower thermocouple positions, respectively.

(b) Three fuel types are used; all are enriched to $10 x 235_{\mathrm{u}}$

$95 S=95 \%$ TD, Stable

$92 \mathrm{~S}=92 \times \mathrm{TD}$, Stable

$92 \mathrm{U}=92 \mathrm{x}$ T0, Unstable

(c) UTC = Upper Thermocouple

LTC = Lower Thermocouple

$E S=$ Elongation Sensor

$\mathrm{PT}=$ Pressure Transducer

SPND = Self-Powered Neutron Detector

UT = UItrasonic Thermometer 


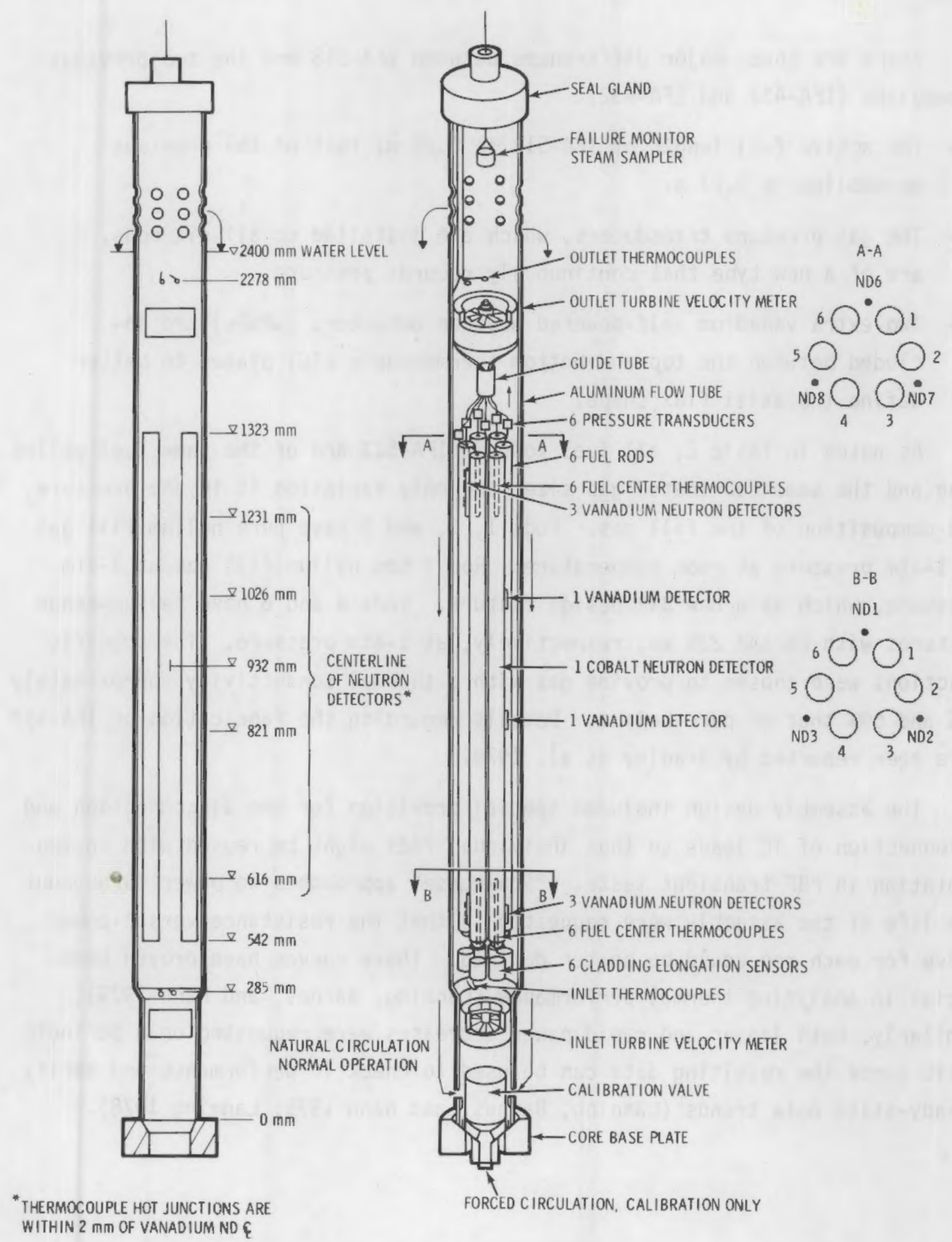

FIGURE 1. Schematic Design of IFA-513. (Note that neutron detectors 4 and 5 are in line with detectors 1 and 6. ) 
There are three major differences between IFA-513 and the two previous assemblies (IFA-431 and IFA-432).

- The active fuel length of IFA-513 is $0.78 \mathrm{~m}$; that of the previous assemblies is $0.57 \mathrm{~m}$.

- The gas pressure transducers, which are installed on all six rods, are of a new type that continuously records pressure.

- Two extra vanadium self-powered neutron detectors (SPNDs) are included between the top and bottom thermocouple (TC) planes to better define the axial flux shape.

As noted in Table 2, all fuel rods in IFA-513 are of the same fuel pellet type and the same fabricated gap size; the only variation is in the pressure and composition of the fill gas. Rods 1,3 , and 5 have pure helium fill gas at 1 -atm pressure at room temperature. Rod 2 has helium fill gas at 3 -atm pressure, which is a new BWR design feature. Rods 4 and 6 have helium-xenon mixtures with $8 \%$ and $23 \% \mathrm{Xe}$, respectively, at 1 -atm pressure. The specific fractions were chosen to provide gas with a thermal conductivity approximately 75\% and 50\% that of pure helium. Details regarding the fabrication of IFA-513 have been reported by Bradley et al. 1979.

The assembly design included special provision for the disconnection and reconnection of TC leads so that individual rods might be reused with instrumentation in PBF transient tests. "Staircase" approaches to power throughout the life of the assembly were requested so that the resistance-versus-power curve for each rod could be better defined. These curves have proven beneficial in analyzing thermal performance (Lanning, Barnes, and Hann 1979). Similarly, both linear and rapid power decreases were requested on a periodic basis since the resulting data can be used to check TC performance and verify steady-state data trends (Lanning, Barnes, and Hann 1979; Lanning 1978). 


\section{EXPERIMENTAL DATA}

Experimental data are collected by the Halden IBM/1800 on-line computer acquisition system. Measurements are taken at 15-min intervals and stored on magnetic tape. Upon receipt of the data tapes from Halden, the data were translated, corrected, and stored on a disk file for further processing. Data processing details are given in Appendix B, and the assembly calibration procedures are described in Appendix C.

The primary data stored on the disks include the linear heat rate and fue 1 centerline temperature at the upper and lower TC positions, the total cladding elongation, and internal fuel rod gas pressures. Oata were taken daily and are presented graphically, in Appendix D. The linear heat rates were calculated from the neutron detector readings as discussed in Appendix $B$; the other data were processed at Halden to convert the electronic signals to the desired readings. The data shown in Appendix $D$ represent all of the data received from Halden at power levels above $25 \mathrm{~W} / \mathrm{cm}$. No further editing of the data has been done.

Experimental data as a function of rod average burnup are shown in Figures 2 through 7, respectively, for the six fuel rods in IFA-513. Linear heat rates and fuel temperatures at both upper and lower TC positions are shown in each figure. Linear heat rates and temperatures were higher at upper TC positions, except at those regions indicated by arrows in the figures. During these periods, control rod positioning depressed the linear heat rates at the upper TC location.

Examination of the data in Figures 2 through 7 shows that some of the instrumentation failed during irradiation. The various detectors are discussed below.

Neutron Detectors. All nine neutron detectors operated satisfactorily throughout the irradiation period (November 28, 1978, to January 6, 1980).

Fuel Thermocouples. Both the upper and lower TCs of rods 1, 4, and 6 operated throughout the irradiation period. The upper TC of rod 1 showed 

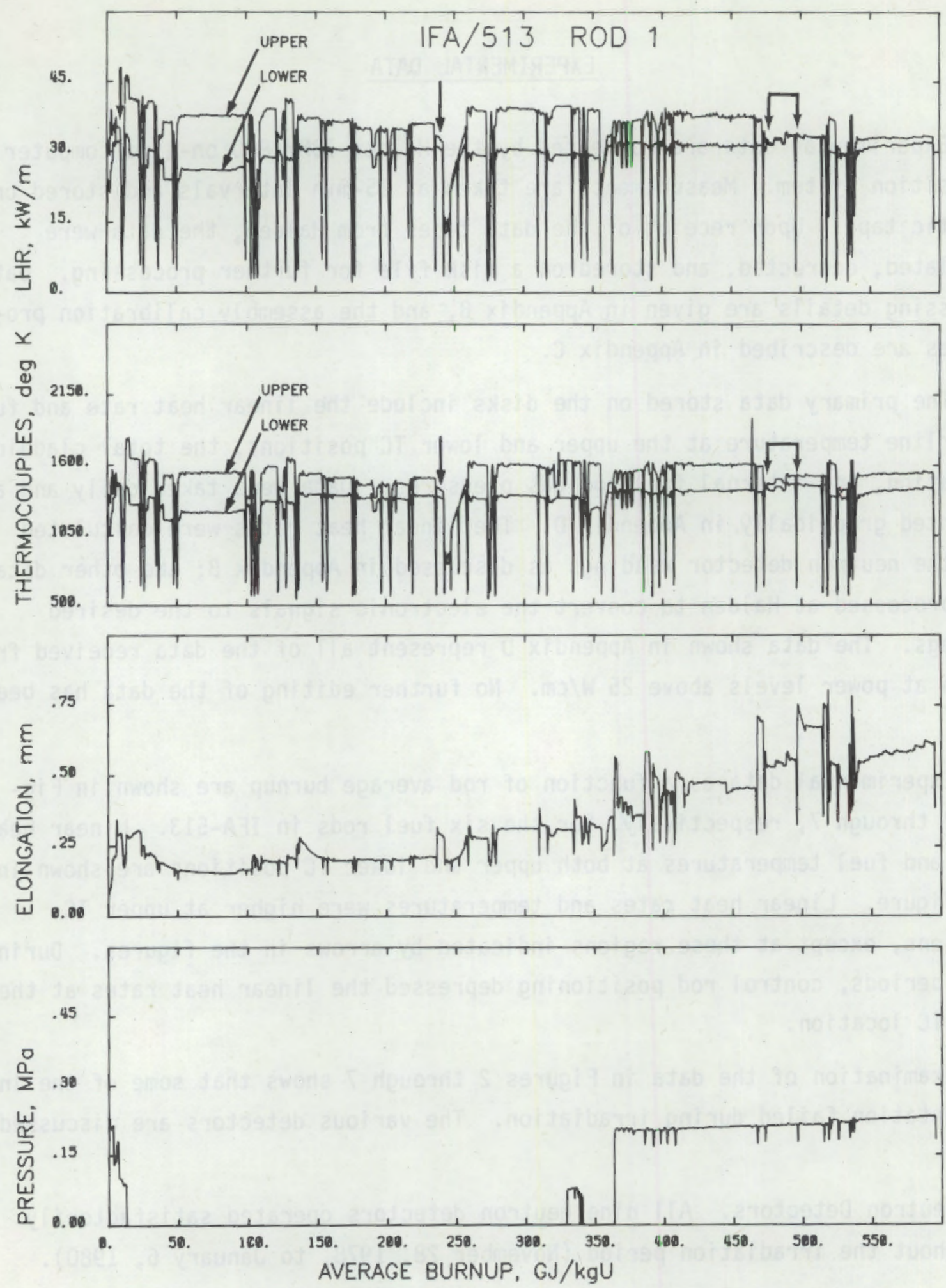

FIGURE 2. Experimental Data as a Function of Rod Average Burnup for Rod 1 of IFA-513. Arrows indicate regions where the relative position of the curves at the upper and lower TC locations are reversed. 

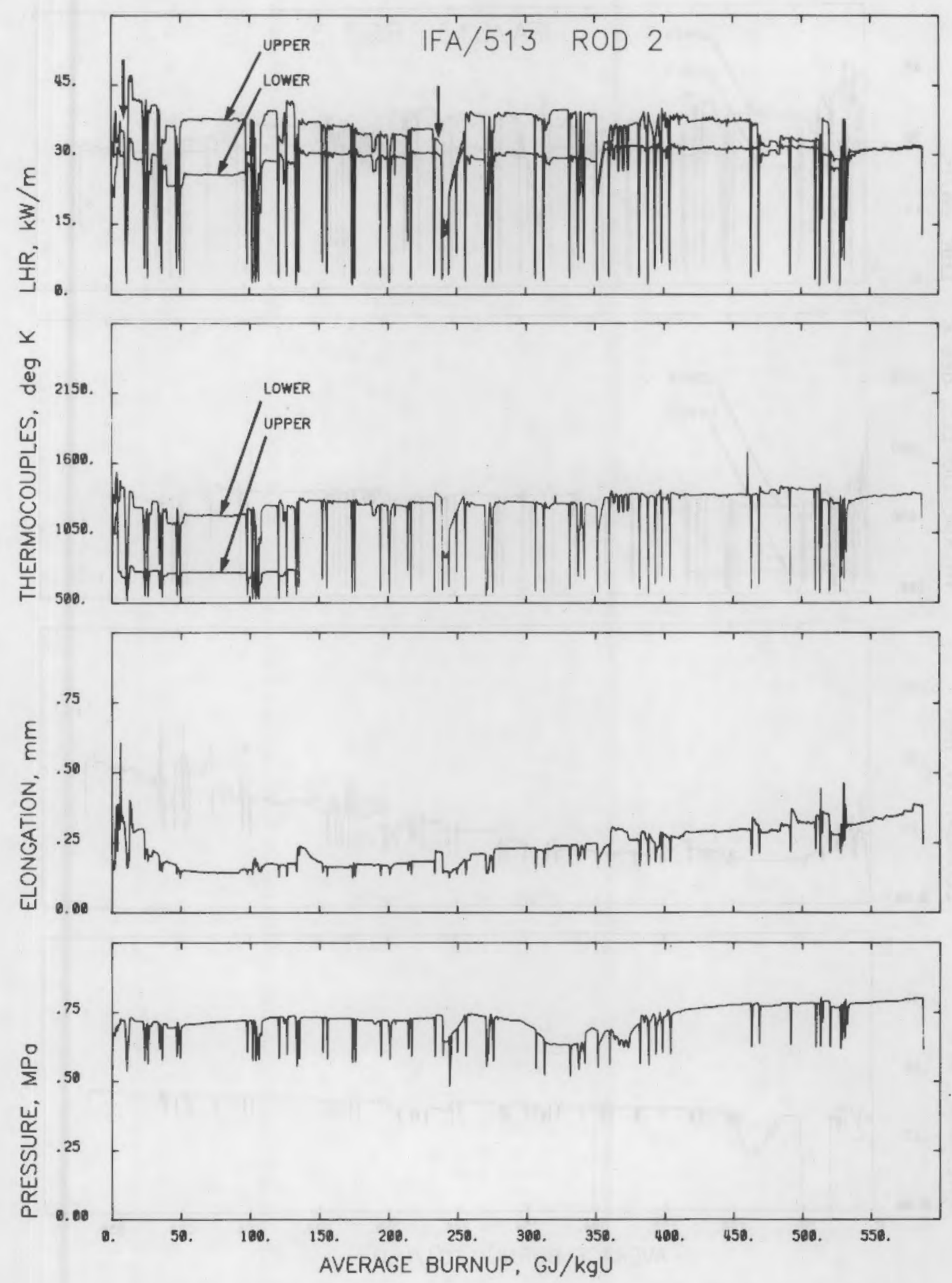

FIGURE 3. Experimental Data as a Function of Rod Average Burnup for Rod 2 of IFA-513. Arrows indicate regions where the relative position of the curves at the upper and lower TC locations are reversed. 

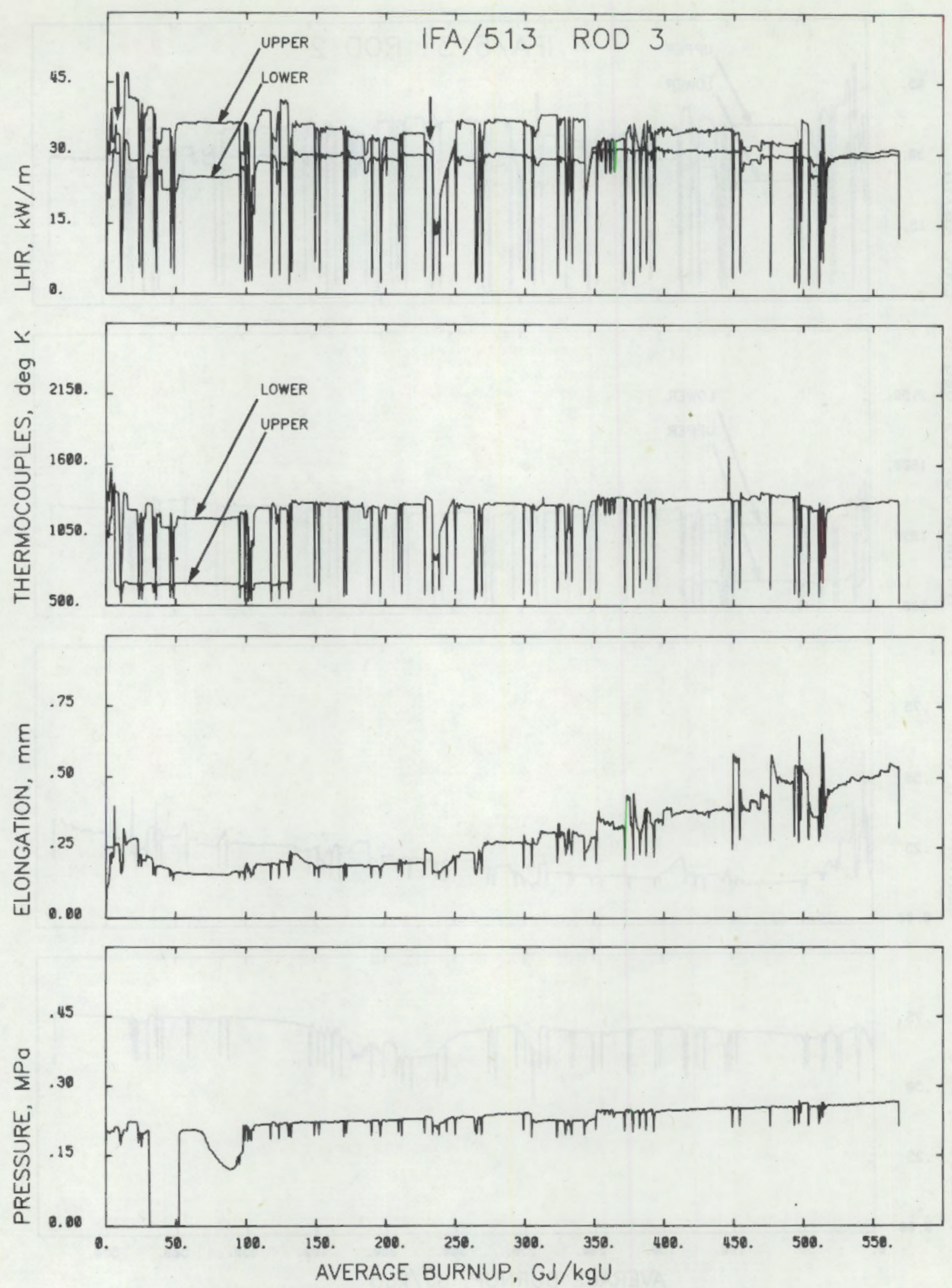

FIGURE 4. Experimental Data as a Function of Rod Average Burnup for Rod 3 of IFA-513. Arrows indicate regions where the relative position of the curves at the upper and lower TC locations are reversed. 

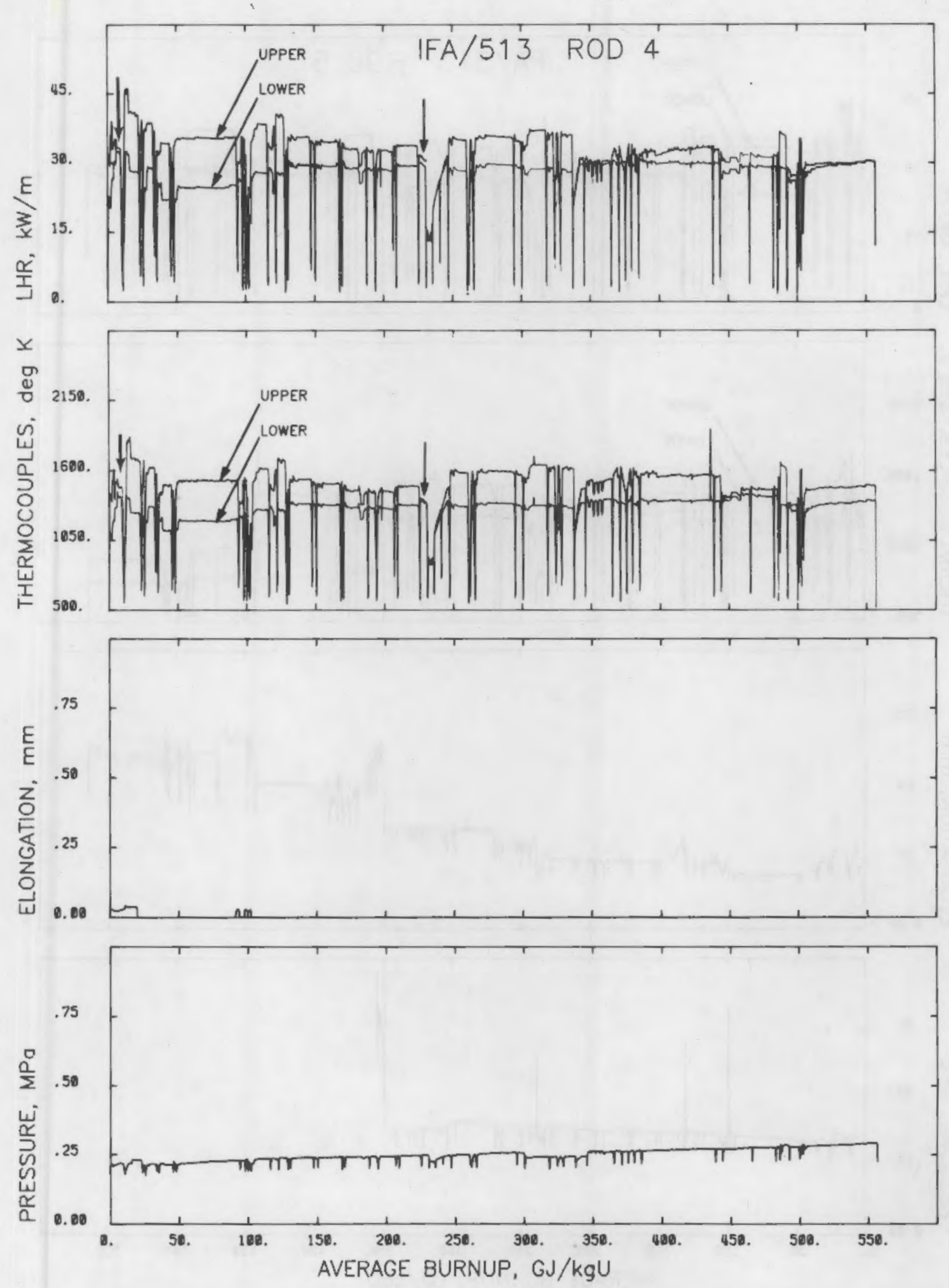

FIGURE 5. Experimental Data as a Function of Rod Average Burnup for Rod 4 of IFA-513. Arrows indicate regions where the relative position of the curves at the upper and lower TC locations are reversed. 

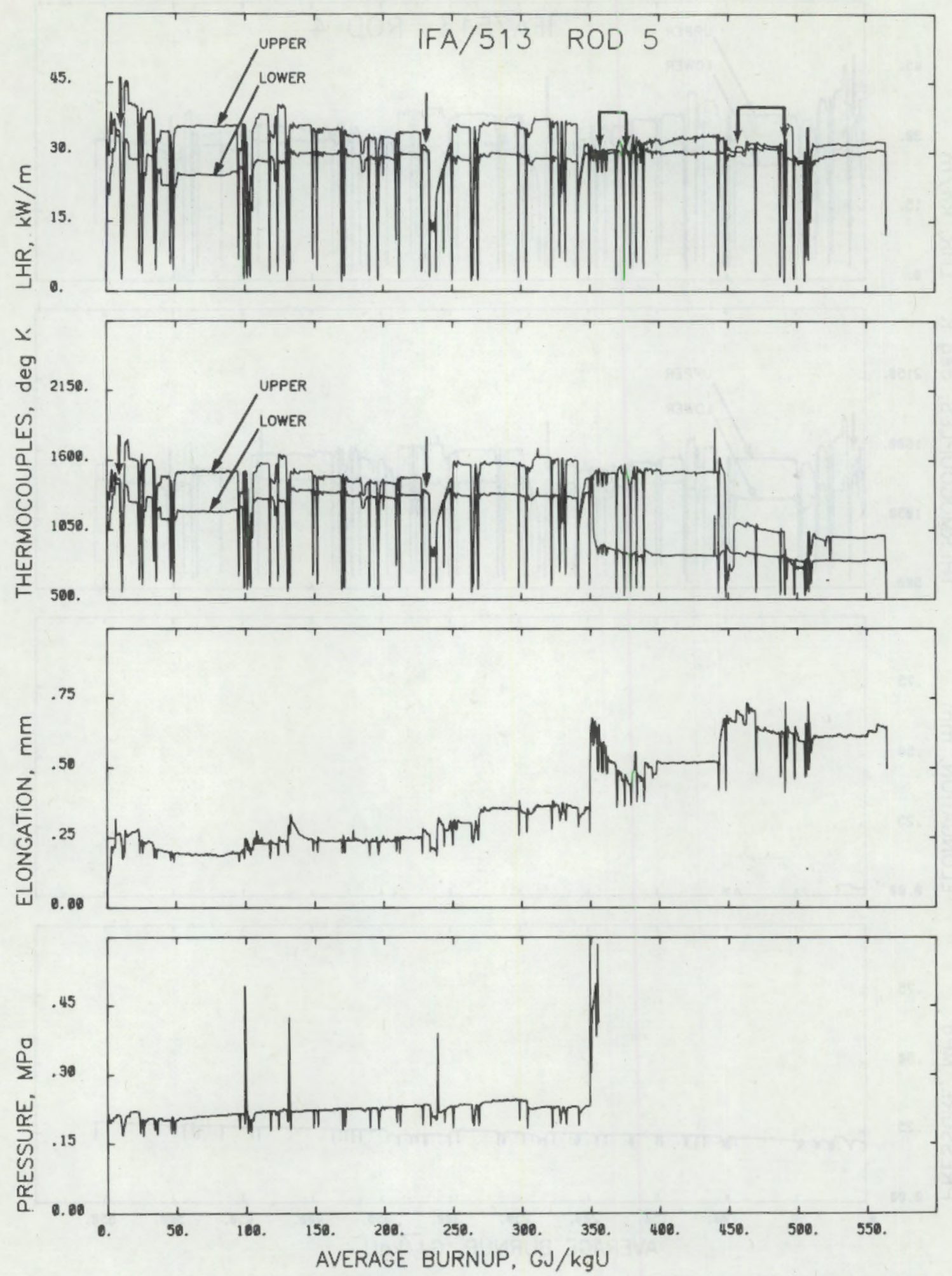

FIGURE 6. Experimental Data as a Function of Rod Average Burnup for Rod 5 of IFA-513. Arrows indicate regions where the relative position of the curves at the upper and lower TC locations are reversed. 

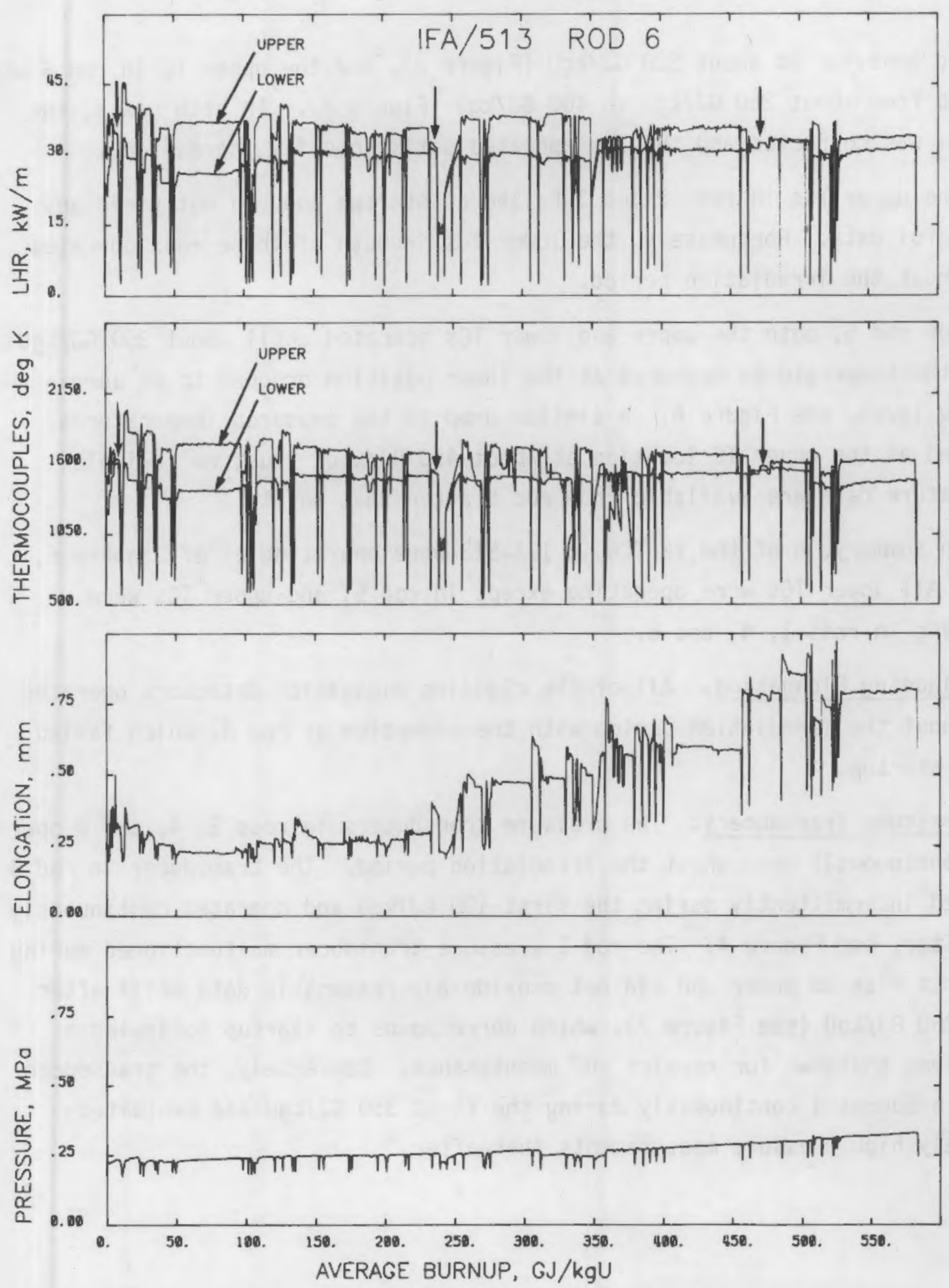

FIGURE 7. Experimental Data as a Function of Rod Average Burnup for Rod 6 of IFA-513. Arrows indicate regions where the relative position of the curves at the upper and lower TC locations are reversed. 
erratic behavior at about $320 \mathrm{GJ} / \mathrm{kgU}$ (Figure 2), and the upper TC in rod 6 was erratic from about $250 \mathrm{GJ} / \mathrm{kgU}$ to $400 \mathrm{GJ} / \mathrm{kgU}$ (Figure 7). In both cases, the problem was corrected and the TCs operated satisfactorily thereafter.

The upper TCs in rods 2 and 3 failed at startup and did not yield any meaningful data. "Fortunately, the lower TCs in both of these rods operated throughout the irradiation period.

For rod 5, both the upper and lower TCS operated until about $350 \mathrm{GJ} / \mathrm{kgU}$ where the temperatures measured at the lower position dropped to an unreasonable leve1, see Figure 6 . A similar drop in the measured temperatures occurred at the upper TC location at about $450 \mathrm{GJ} / \mathrm{kgU}$; thus, no reliable temperature data are available from rod 5 after that point.

In sumary, 8 of the 12 TCS in IFA-513 were operating as of January 6 , 1980. All lower TCS were operating except in rod 5; and upper TCs were operating in rods 1,4 , and 6 .

Cladding Elongation. All of the cladding elongation detectors operated throughout the irradiation period with the exception of rod 4 , which failed during startup.

Pressure Transducers. The pressure transducers in rods 2, 4, and 6 operated continuously throughout the irradiation period. The transducer in rod 3 operated intermittently during the first $100 \mathrm{GJ} / \mathrm{kgU}$ and operated continuously thereafter, see Figure 4 . The rod 1 pressure transducer malfunctioned during the first rise to power and did not provide any reasonable data until after about $360 \mathrm{GJ} / \mathrm{kgU}$ (see Figure 2), which corresponds to startup following a month-long shutdown for repairs and maintenance. Conversely, the transducer in rod 5 operated continuously during the first $350 \mathrm{GJ} / \mathrm{kgU}$ and exhibited extremely high pressure measurements thereafter. 
Fuel rod thermal characteristics, cladding elongation, and internal pressures as a function of burnup are discussed in this section. Primary emphasis is placed on the general trends of the experimental data rather than specific details. Detailed analyses of specific aspects of the data have been reported elsewhere (Lanning and Cunningham 1979; Williford et al. 1980; Cunningham, Lanning, and Montgomery 1979).

\section{TEMPERATURE AND RESISTANCE}

Fue 1 temperatures and corresponding local linear heat rate histories for the six rods of IFA-513 were shown in Figures 2 through 7. As expected, fuel temperatures generally followed local linear heat generation rates. Fuel temperatures from rods 1 through 5 all fall within a $100 \mathrm{~K}$ band throughout the irradiation period when compared at the same TC position. The temperatures from rod 6, which contained $23 \% \mathrm{Xe}$ in the fill gas, were 100 to $200 \mathrm{~K}$ hotter than the other five rods; and the difference decreased with increasing burnup.

Rod-to-rod comparisons of the steady-state temperatures will be made in the following subsection. These comparisons will be followed by a subsection where the data taken during reactor scrams are used to verify some of the steady-state comparisons.

Comparison of Steady-State Temperatures

Some of the rod-to-rod variations in temperature could be due to small differences in the local linear heat generation rates. To minimize these differences, we have found it beneficial to compare fuel rod resistances rather than temperatures, where resistance $(R)$ is defined by

$$
R=\frac{T_{\text {center }}-T_{\text {coolant }}}{\text { Power }}
$$

These comparisons have additional value because the resistance is sensitive to changes in gap size and fill gas composition as discussed by Lanning, Barnes, and Hann (1979). 
Rods 1,3 , and 5 were fabricated identically to assess the amount of rodto-rod variations in irradiation response. The resistances of these three rods at the lower TC location as a function of average burnup are compared in Figure 8 . The resistances of all three rods show an initial adjustment early in the irradiation and remain nearly constant thereafter. Rods 1 and 5 show identical resistances whereas the resistance of rod 3 is about $6 \%$ lower. These differences are not considered significant, and the data from these rods compare very well with the resistances measured for rod 1 of both IFA-431 and IFA-432, which contained a similar fuel and fuel-to-cladding gap.

Rod 2 in IFA-513 was identical in design to rods 1,3 , and 5 except that the initial fill gas pressure was $0.3 \mathrm{MPa}$ rather than $0.1 \mathrm{MPa}$. The resistance at the lower position from this rod is compared to that of rod 1 in Figure 9. The resistance of rod 2 remains fairly constant during the irradiation period with the values about $8 \%$ lower than for rod 1 but identical to those obtained for rod 3 (see Figure 8 ). Consequently, the higher helium content in rod 2 does not significantly affect the thermal characteristics of fuel rods operating at relatively low temperatures and low burnup. A significant effect of fill gas pressure would be expected at higher fuel temperatures or high burnup where higher initial helium content would suppress the effects of fission gas release on the thermal conductivity of the gap gas.

The effects of gas composition on thermal resistance can be assessed by comparing rods 4 and 6 --which initially contained $8 \%$ and $23 \%$ xenon, respectively, in the fill gas with the rods containing pure helium. Such a comparison at the lower position is shown in Figure 10 where rod 1 is used for reference. The resistances for rods 1 and 4 are identical throughout the irradiation period, indicating that a $25 \%$ decrease in the thermal conductivity of the fill gas is not sufficient to produce a significant increase in the calculated thermal resistance.

The resistance of rod 6 is significantly different than the other five rods in both magnitude and burnup dependence: from $17 \%$ to $27 \%$ higher than the other five rods during the first $450 \mathrm{GJ} / \mathrm{kgU}$ exposure. This increase compares favorably with the $24 \%$ resistance increase that is calculated by the 


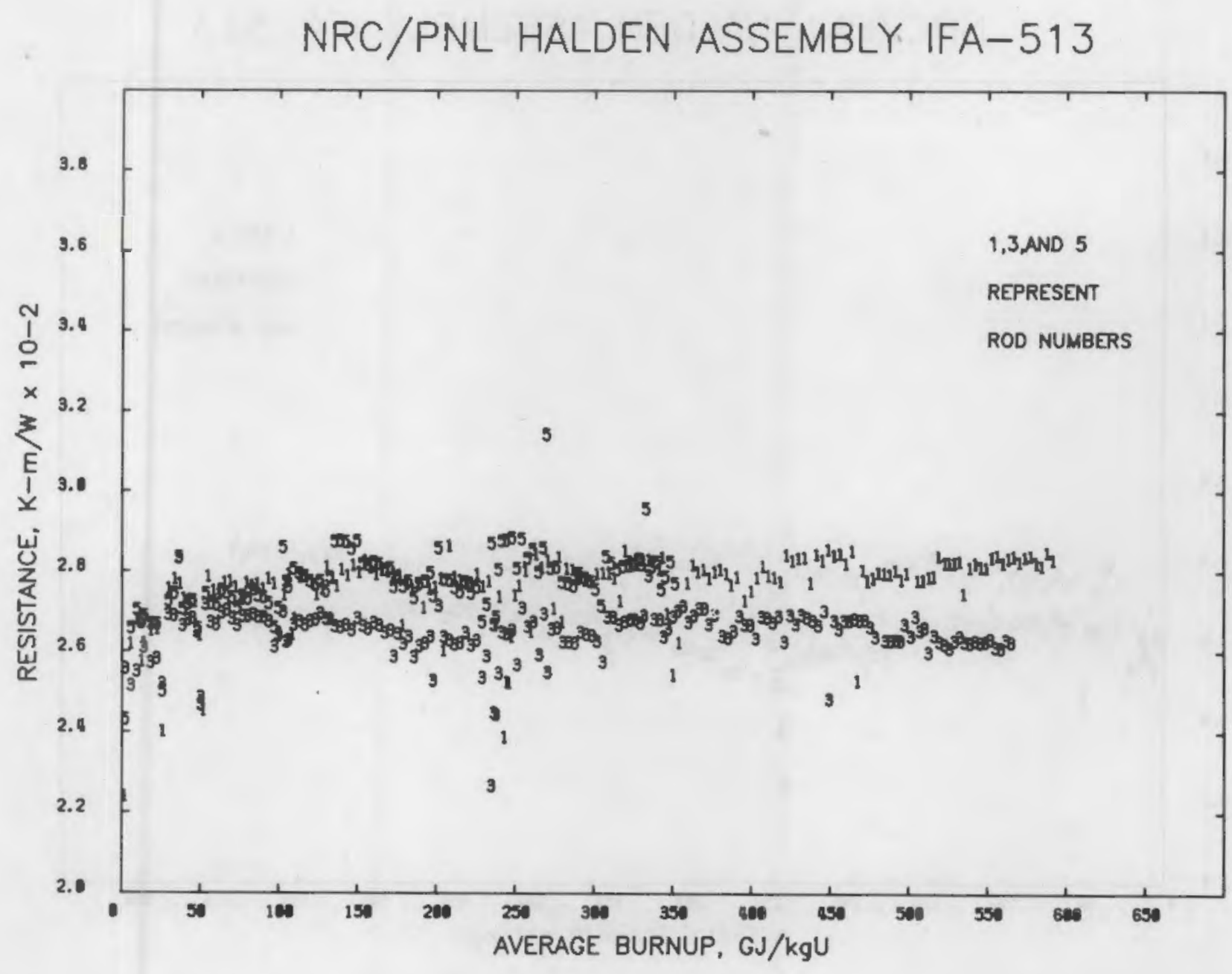

FIGURE 8. Resistance of Rods 1,3, and 5 Compared at the Lower Thermocouple Location as a Function of Average Burnup

GAPCON-THERMAL-3 (GT3) computer code (Lanning et al. 1978) when the xenon concentration in the gap gas is increased from 0 to $23 \%$.

The second unique feature of the rod 6 resistance curve is the decrease that occurs following about $450 \mathrm{GJ} / \mathrm{kgU}$. A resistance decrease suggests that outward movement of the fuel, i.e., gap closure, possibly occurred during this period. The gap closure could be associated with several phenomenon, including fuel swelling, mechanical relocation of the fuel, temperature distributions within the fuel, and cladding creepdown. It is not presently possible to determine the cause of the resistance decrease; however, it is interesting 


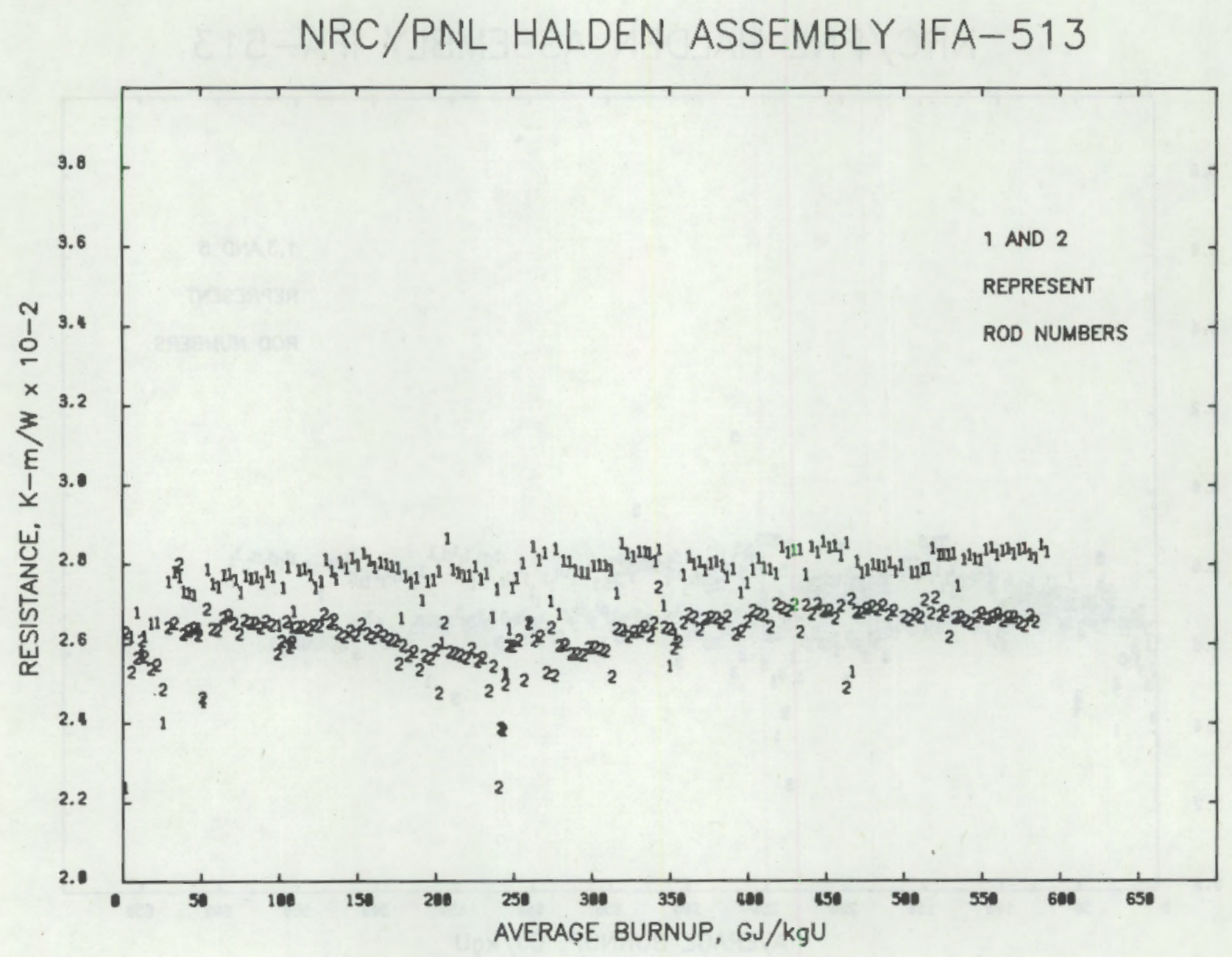

FIGURE 9. Resistance of Rods 1 and 2 Compared at the Lower Thermocouple Location as a Function of Average Burnup

to note that the decrease occurred between 460 and $520 \mathrm{GJ} / \mathrm{kgU}$, which corresponds to a period when the linear heat rates at the upper and lower TC positions were nearly identical (see Figure 7). Extensive interaction between the fuel and cladding also occurred during this period as evidenced by the magnitude of the fuel rod elongations that occurred during power increases.

Changing the axial power profile and having extensive fuel-cladding interactions could cause the fuel and cladding to move radially relative to one another and thereby decrease the gap size in accordance with the decrease in resistance for rod 6 . The other rods did not show the resistance decrease, 


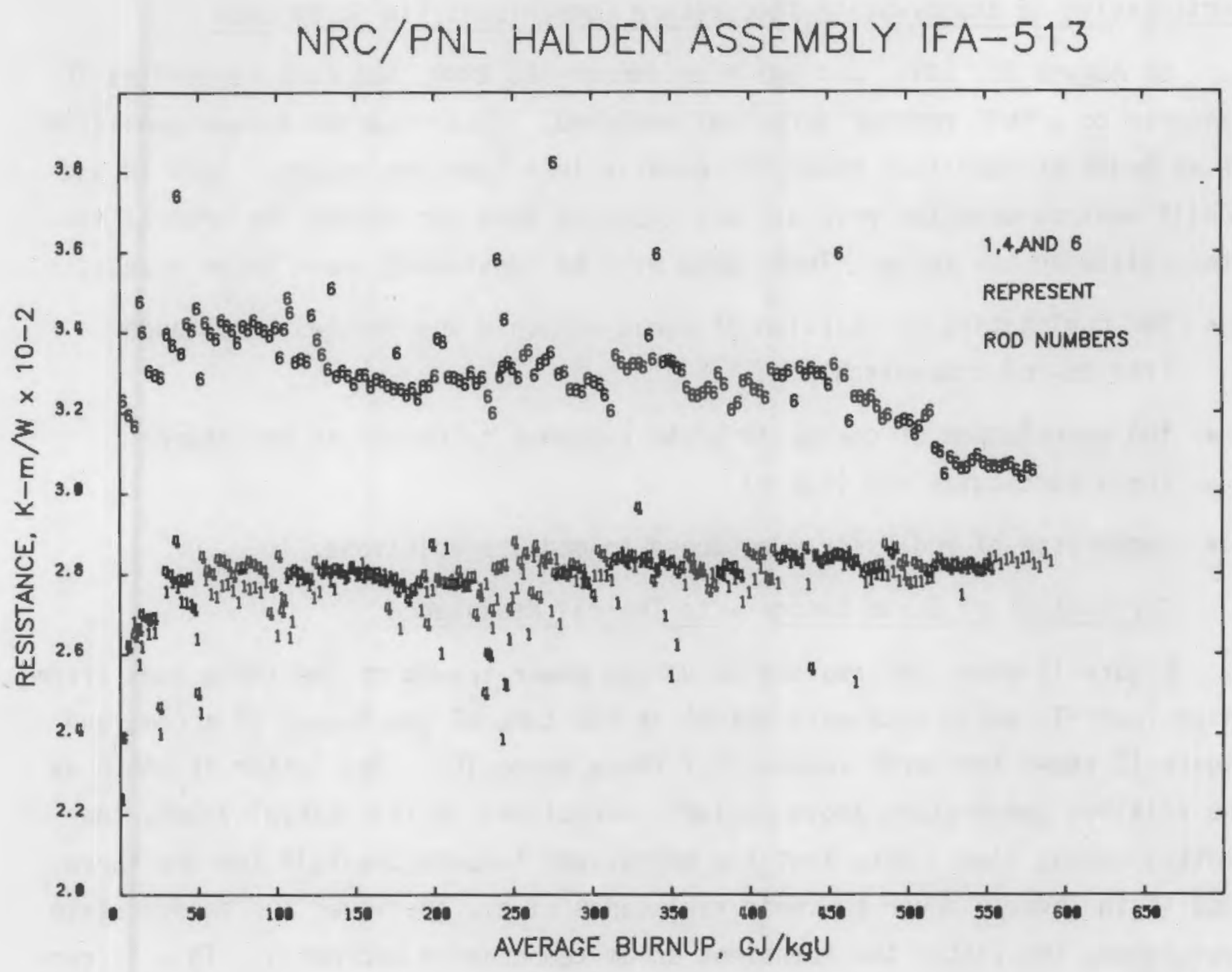

FIGURE 10. Resistance of Rods 1,4 , and 6 Compared at the Lower Thermocouple Location as a Function of Average Burnup

which is correlated with smaller elongations in these rods and, more importantly, to the lower sensitivity of the resistance to changes in gap size in rods containing pure helium.

In summary, fuel temperatures and resistances for rods 1 through 5 were very similar throughout the irradiation period. Thus, neither increasing the fill gas pressure from 0.1 to $0.3 \mathrm{MPa}$ nor introducing $8 \%$ xenon into the fill gas had any significant effect on the thermal characteristics of these fuel rods. In contrast, introducing $23 \%$ xenon into the fill gas significantly increased both fuel temperature and thermal resistance. 
Verification of Steady-State Temperature Comparisons Via Scram Data

On August 23, 1979, and again on January 6, 1980, the fuel centerline TC response to a full reactor scram was recorded. These reactor scrams consisted of an order-of-magnitude power decrease in less than one second. Fuel TC and cobalt neutron detector response was recorded once per second for several minutes following the scram. These data will be considered under three aspects:

- the qualitative correlation of scram response and initial resistance (rod-to-rod comparison)

- the correlation of change in scram response to change in resistance for a particular rod (rod 6)

- comparison of rod 6 scram response to model predictions.

\section{Correlation of Scram Response to Thermal Resistance}

Figure 11 shows the resistance versus power trends of the three rods (from which lower TC scram data were taken) at the time of the August $23 \mathrm{scram}$, and Figure 12 shows the scram response of these three TCs. The latter is shown as the relative temperature above coolant, normalized to its initial value, and plotted versus time. Note that the normalized temperature fall for the three rods is in inverse order to their resistance (i.e., the lower the steady-state resistance, the faster the transient scram temperature decrease). This is certainly in line with intuitive expectations and tends to confirm the rod-to-rod resistance comparisons. In Figure 13 the data from Figure 12 are replotted in terms of the logarithm of normalized temperature versus time. The latter curves can be summarized by a gross parameter--the slope of the curve in the most linear range ( $\sim-20$ seconds). Table 3 summarizes these slopes and compares them to the initial resistances. (Again note that the slopes and resistances vary inversely.) These slopes were used because they tend to be independent of the TC time constant and of errors in zero time (Cunningham, Lanning, and Montgomery 1979). 


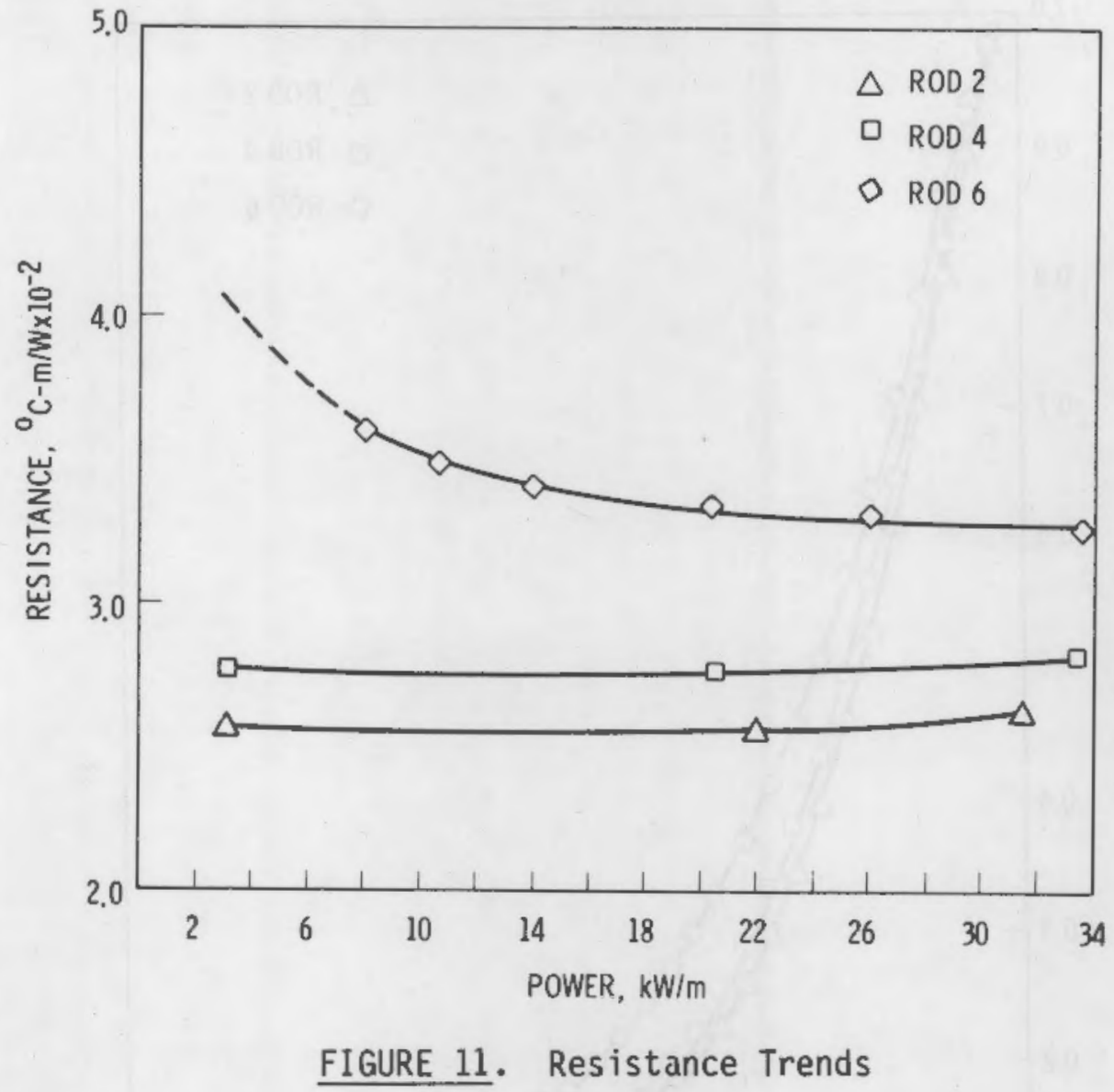

Correlation of Scram Response Change to Resistance Change (Rod 6)

The resistance versus burnup histories of rods 2 and 6 (lower TCs) are compared in Figure 14. Over the time span between the two scrams, the resistance of rod 6 fell while that of rod 2 stayed constant. Table 4 lists the scram data for the two rods for both scrams. Note that the time constant of rod 6 increases whereas that of rod 2 is approximately the same. This provides at least qualitative confirmation of the resistance decrease in rod 6 .

\section{Comparison of Rod 6 Scram Response to Model Predictions}

The two models of heat transfer are compared to the scram data, as was also done with $20 \%$ rapid power drops on this assembly by Lanning and Cunningham (1979). These two models are described as follows: 


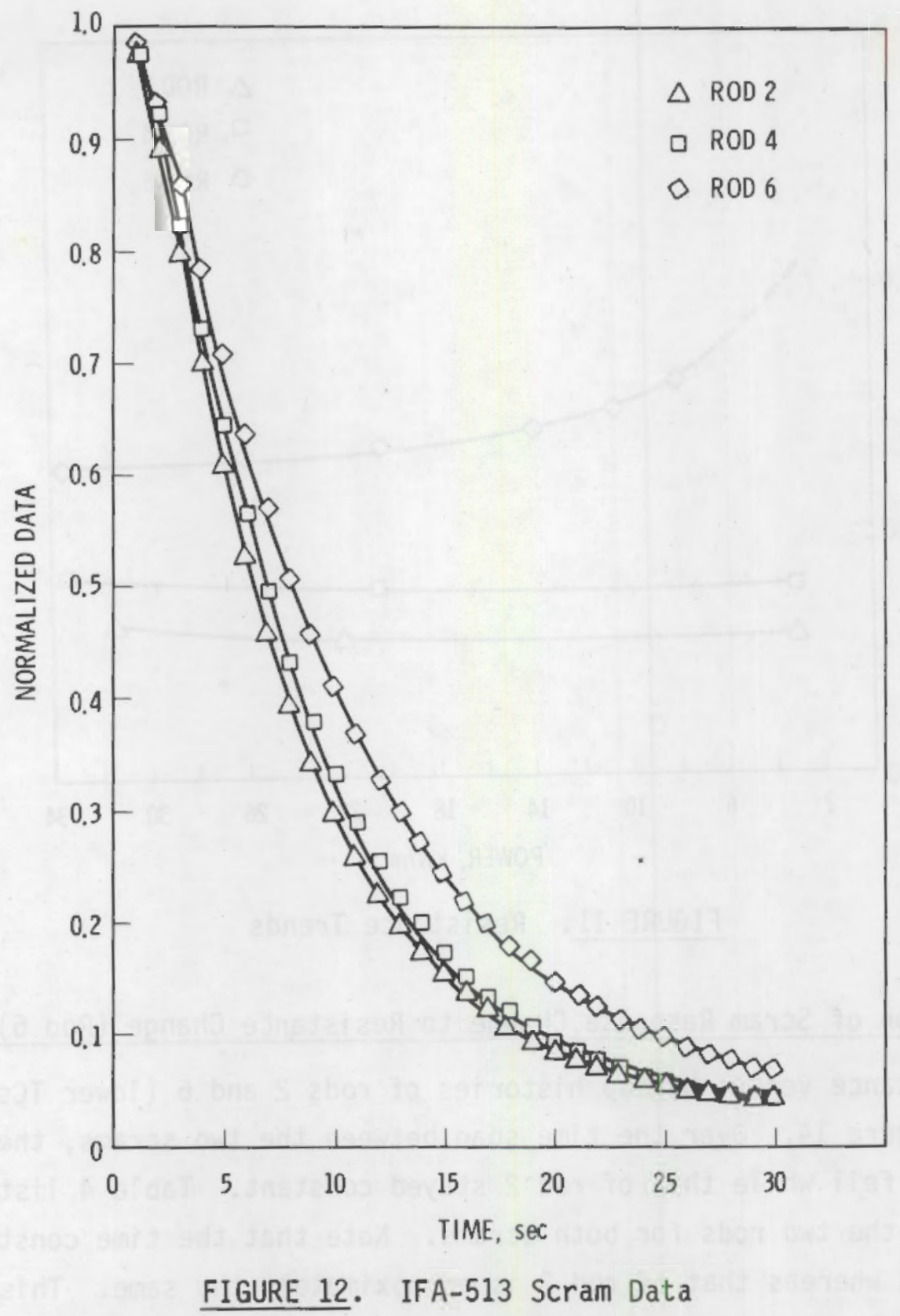




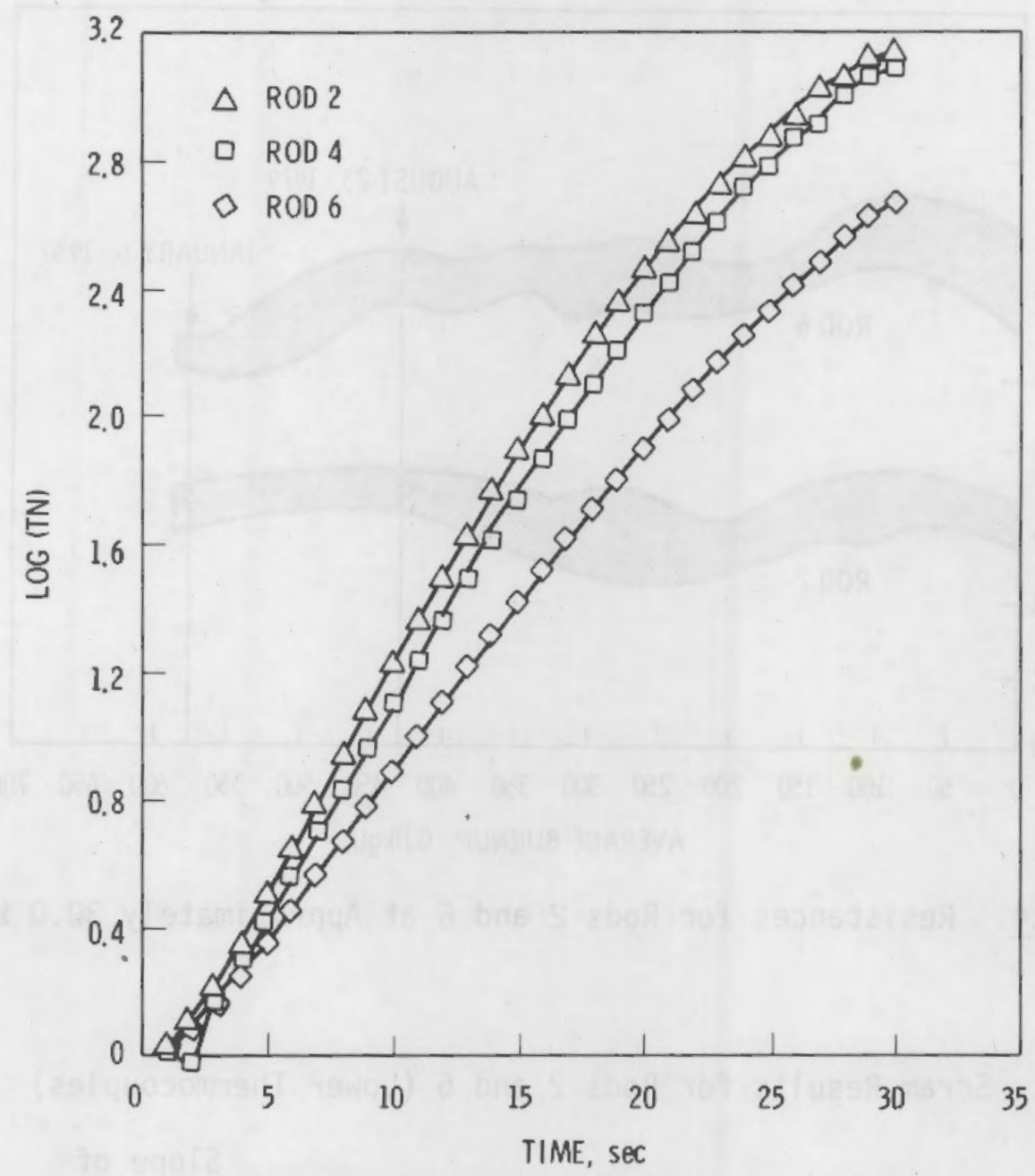

FIGURE 13. Replotted IFA-513 Data

TABLE 3. August 23, 1979, Scram Results

\begin{tabular}{|c|c|c|c|}
\hline Rod Number & Fill Gas & $\begin{array}{c}\text { Initial } \\
\text { Resistance, } \\
\mathrm{K}-\mathrm{m} / \mathrm{W} \\
\end{array}$ & $\begin{array}{c}\text { Slope of } \\
-\operatorname{In}(T N) \text { Versus } \\
\text { Time, } \mathrm{sec}^{-1} \\
(5-20 \mathrm{sec})\end{array}$ \\
\hline 2 & $100 \% \mathrm{He}$ & 0.0262 & 0.131 \\
\hline 4 & $8 \% \times \mathrm{X}, 92 \% \mathrm{He}$ & 0.0280 & 0.126 \\
\hline 6 & $23 \% \mathrm{Xe}, 77 \% \mathrm{He}$ & 0.0326 & 0.103 \\
\hline
\end{tabular}




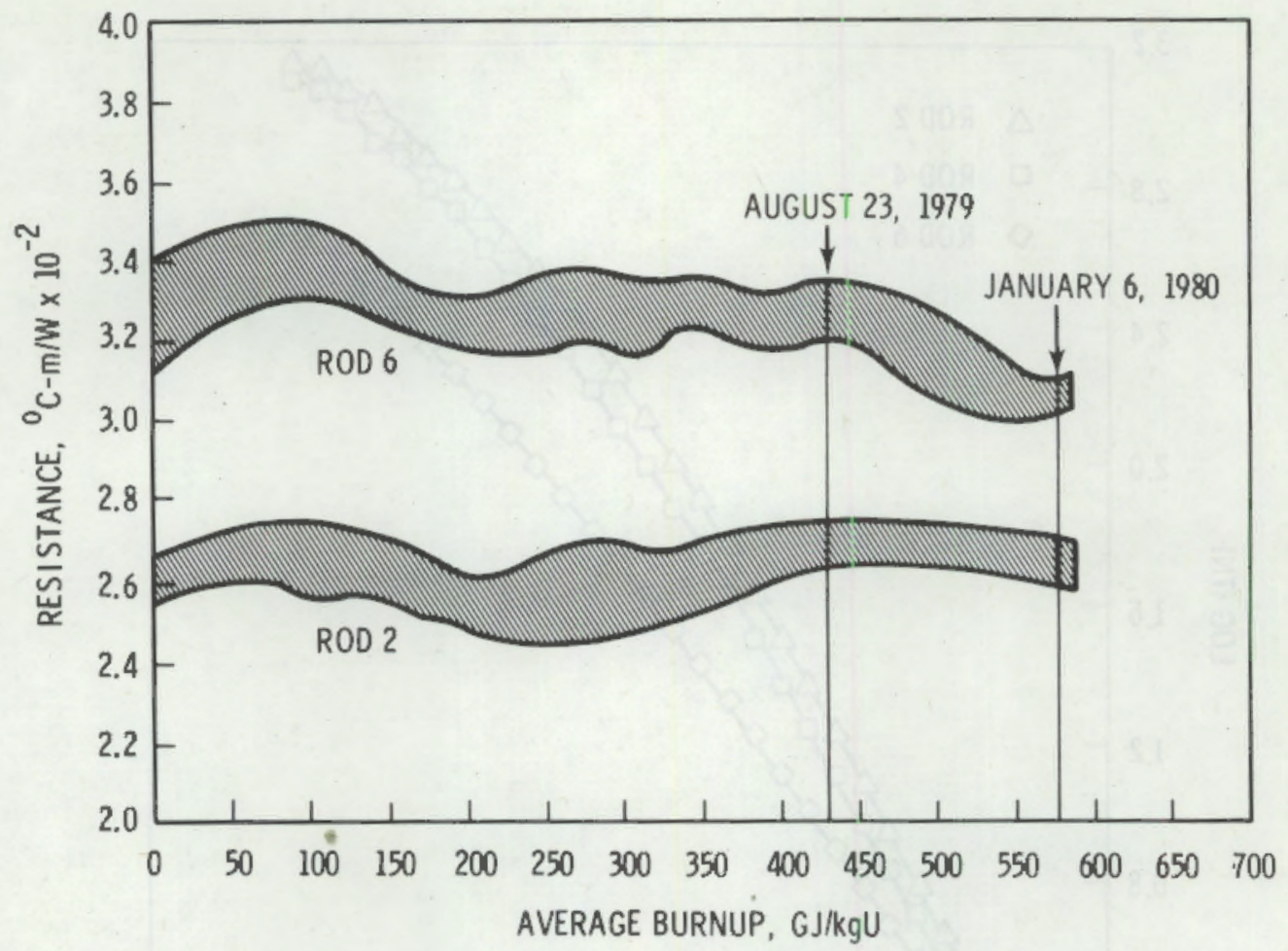

FIGURE 14. Resistances for Rods 2 and 6 at Approximately $30.0 \mathrm{~kW} / \mathrm{m}$

TABLE 4. Scram Results for Rods 2 and 6 (Lower Thermocouples)

\begin{tabular}{|c|c|c|c|}
\hline Scram Date & $\begin{array}{c}\text { Rod } \\
\text { Number }\end{array}$ & $\begin{array}{c}\text { Initial } \\
\text { Resistance, } \\
\mathrm{K}-\mathrm{m} / \mathrm{W} \\
\end{array}$ & $\begin{array}{c}\text { Slope of } \\
-\ln (\mathrm{TN}) \text { Versus } \\
\text { Time, } \mathrm{sec}^{-1} \\
(5-20 \mathrm{sec}) \\
\end{array}$ \\
\hline August 23,1979 & 2 & 0.0262 & 0.131 \\
\hline January 6,1980 & 2 & 0.0255 & 0.130 \\
\hline August 23,1979 & 6 & 0.0326 & 0.103 \\
\hline January 6,1980 & 6 & 0.0294 & 0.107 \\
\hline
\end{tabular}

- Mode1 1 - This is the conventional view of the fuel rod where the fuel thermal conductivity is a laboratory-determined function of temperature (we use the Lyons form for $95 \%$ dense $\mathrm{UO}_{2}$ ). No crack factor modifies this conductivity. Steady-state temperature/power data are used to infer gap conductance values associated with several 
power levels. To feed into a path-dependent transient temperature calculation, simply tabulate these conductances and the associated fuel volume-average temperature. During the course of the transient, interpolate within this table to establish the gap conductance for the next time step. (This is the explicit forward method.)

- Model 2 - In this model, the gap conductance is fixed at an arbitrary value (usually the model 1 initial condition value); and most nonlinearity is lumped into the conductivity of the fuel, which has a multiplicative temperature-dependent crack factor. For several steady-state power levels, the crack factor is defined as that number that will modify (multiply) the Lyons conductivity function to yield the measured fuel center temperature given the arbitrary gap conductance value. This crack factor can be tabulated as a function of the associated volume-average fuel temperature, and that table is used during a scram calculation (much as the conductance table is used in model 1).

The results of these two models as processed through the transient code MWRAM (Cunningham, Lanning, and Montgomery 1979) are shown in Figure 15 . The cracked fuel model 2 is definitely favored, implying that the conductance may be remaining fairly constant. This is the same result obtained for $20 \%$ power drops, but it is interesting that it should be attained for full scrams. It implies an inability of the fuel to shrink back from the cladding.

\section{CLADDING ELONGATION}

Cladding elongation data were obtained throughout the irradiation period for all of the fuel rods except rod 4 (the elongation detector failed during startup). The data from these rods were plotted in Figures 2 through 7 as a function of rod average burnup. In the following discussion, the general trends in the data as a function of burnup will be presented, and specific observations regarding the data will be made. Detailed analys is of the data will be presented in future reports. 


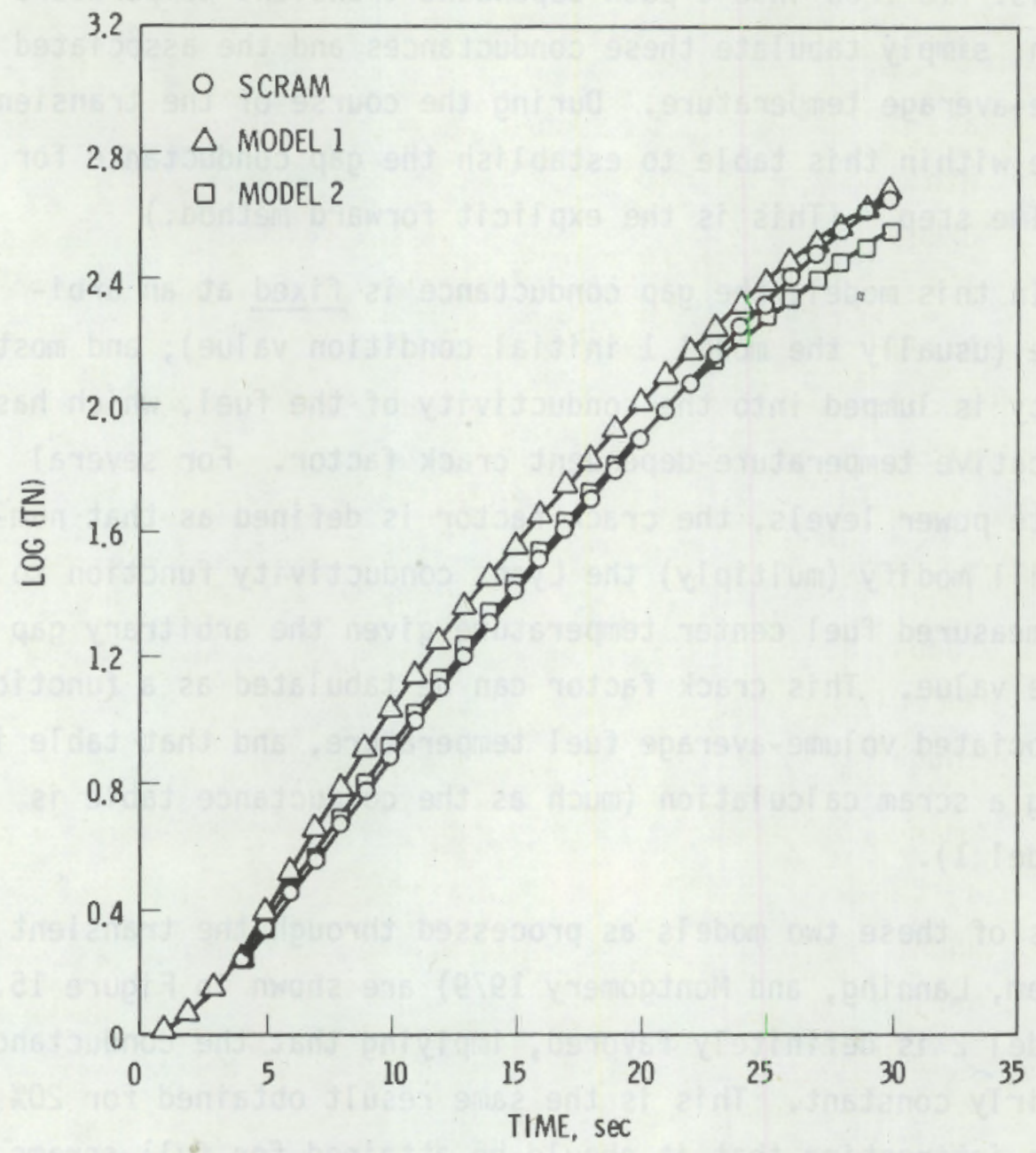

FIGURE 15. IFA-513, TF11 Scram Data and Predictions for the August 23, 1979, Scram

Cladding elongation measurements are obtained from linear variable differential transformers (LVDTs) that are positioned at the bottom of the fuel rods. The LVDTs are electrically zeroed after the coolant is heated to $513 \mathrm{~K}$ and prior to the initial startup. Therefore, elongation data at low power provide a measure of the permanent fuel rod elongations while the amount of pellet cladding interaction is directly related to the length difference between measurements at low and full reactor power. For a detailed analysis of elongation data, consideration must be given to temperature gradients within the assembly, irradiation growth of the support rods, and decalibration of the LVDTs. The 
effects of these variables are difficult to quantify, but they need to be addressed before using elongation data quantitatively.

Elongation data in Figures 2 through 7 show similar trends that can be broadly divided into three burnup regimes: 0 to $50 \mathrm{GJ} / \mathrm{kgU}, 50$ to $250 \mathrm{GJ} / \mathrm{kgU}$, and 250 to $\sim 570 \mathrm{GJ} / \mathrm{kgU}$. (a) The first regime ( 0 to $50 \mathrm{GJ} / \mathrm{kgU}$ ) is characterized by a large increase in the fuel rod length at low power levels after the first power cycle. An additional small increase in length at low power occurs after the second power cycle and then the length decreases with additional cycles until about $50 \mathrm{GJ} / \mathrm{kgU}$ burnup. Interactions between the fuel and cladding also decrease dramatically following the second power cycle.

The relatively large elongations--0.16 to 0.19 mn--measured after the first power cycle could be caused by primary creep of the cladding, plastic yielding, fuel-induced elastic stresses remaining at low power levels, or a combination of mechanisms.

Using the primary creep correlation for Zircaloy-2 presented by Fidleris (1978) and assuming that axial stresses are uniformly distributed along the fuel column, permanent elongations can be calculated that are $25 \%$ to $30 \%$ of those measured experimentally. Concentrating the axial elastic stresses in localized segments leads to higher local creep rates but does not significantly influence the overall elongation of the fuel rods.

Further concentration of the axial stresses could produce localized yielding and subsequent plastic deformation of the cladding due to strong mechanical interactions between the fuel and cladding in isolated regions along the fuel column from random cracking and movement of the fuel during the first power ramp. However, for such a random process, one would expect greater rod-to-rod variations than measured experimentally; and, thus, localized plastic deformation following yielding is not considered the predominant cause of the measured elongations after the first power ramp.

An increase in fuel rod length could also occur after the first power cycle if axial stresses remain after the reduction in power. The magnitude of

(a) Small rod-to-rod variations in burnup exist because of the flux tilt across the assembly. 
the stresses at low power is generally considered to be very small; therefore, the contribution from this mechanism should not be significant. However, it is interesting to note that the reduction in fuel rod length $(\sim 0.04 \mathrm{~mm})$ that occurred after the first two power cycles is consistent with a reduction in the axial stresses due to rearrangement or creep of the fuel during this period.

None of the above mechanisms by themselves satisfactorily account for the elongations observed after the first power cycle. The interactions between the fuel and cladding during reactor operation are extremely complex and make identification of a specific mechanism or a combination of mechanisms very difficult. In addition, some of the axial elongation observed after the first power cycle could have been caused by mechanical or thermal stabilization of the assembly during this initial operating period. At present, there is insufficient information to allow the responsible mechanisms to be identified.

The second burnup regime $(50-250 \mathrm{GJ} / \mathrm{kgU})$ corresponds to the end of the second reactor operating cycle and is characterized by small variations in the low power elongation data and generally small differences in length between the data taken at low and full reactor power. There are two power ramps during this period that show larger amounts of fuel-cladding interactions. The first occurred at about $140 \mathrm{GJ} / \mathrm{kgU}$ and corresponds to the first power ramp following a long reactor shutdown for maintenance and refueling. The second ramp, which produced larger elongations, occurred at about $230 \mathrm{GJ} / \mathrm{kgU}$ and corresponds to a period when the local power level at the upper TC location was lower than at the lower position due to control rod movements.

The third burnup regime extends from $250 \mathrm{GJ} / \mathrm{kgU}$ to the end of the irradiation period. All of the fuel rods showed an increase in length at low power levels during this period. There was also a significant increase in the elongation that accompanies power increases, and the elongation differences between low and full power generally increase with increasing burnup.

The higher activity during the period 250 to $350 \mathrm{GJ} / \mathrm{kgU}$ can be attributed to the increased powers and temperatures at upper TC locations. This period corresponds to the third complete operating cycle between shutdowns for maintenance and refueling; the power levels at both upper and lower locations remained fairly constant during this period. 
During the final reactor operating period, the difference in fuel rod length between low and full reactor power was considerably greater than previously observed. This increased activity may be associated with changes in the axial power profile because of extensive control rod movements near the top of the fuel rods.

The first power ramp of the final operating period produced more cladding elongation in each respective rod than any ramp since the initial startup of the assembly. This is especially evident in rod 5 where the elongation was three times larger than observed in the preceding operating period. It is interesting to note that the lower TC in rod 5 failed at this time and the internal pressures increased dramatically. When rod 5 was subsequently identified as leaking, it was removed from the reactor.

Examining the elongation data reveals a general correspondence between the amount of pellet-cladding interaction as measured by the elongation that occurred during power ramps and the permanent elongation that was measured at the end of the irradiation period. The only exception is rod 5, which generally showed less pellet-cladding interaction than rod 1 but a larger total elongation. This apparent discrepancy can be mostly attributed to the large elongation observed in rod 5 during the first power ramp of the fourth reactor operating cycle, which resulted in about $0.08-\mathrm{mm}$ permanent elongation for this rod.

The direct correlation between pellet-cladding interaction and the low power elongation data suggests that plastic deformation of the cladding is responsible for fuel rod length increases. The cladding creep rates should be lower in this higher burnup regime; and, thus, a larger contribution from localized plastic yielding is expected.

\section{INTERNAL PRESSURE}

Internal pressure data as a function of burnup were shown in Figures 2 through 7, respectively, for the six fuel rods in IFA-513; and, in general, pressures increased gradually with irradiation. However, there were regions where the data are inconsistent with the expected data trends, especially in rod 2 where the pressures decreased and then increased during the interval 
from 270 to $400 \mathrm{GJ} / \mathrm{kgl}$. Based on fuel behavior, there is no physical explanation for this pressure anomaly; and it is assumed that it has an electronic origin. Since the pressure measurements from rod 2 taken after $400 \mathrm{GJ} / \mathrm{kgU}$ are consistent with earlier data, it appears that the problem has been corrected.

Another example of anomalous pressure measurements is seen in the data from the other rods in the interval from $\sim 300$ to $350 \mathrm{GJ} / \mathrm{kgU}$. An abrupt pressure drop of about $0.02 \mathrm{MPa}$ is observed during this period that is not consistent with the measured fuel rod power levels or temperatures. This pressure drop may be associated with the data acquisition system because all of the fuel rods showed identical behavior. Except for rod 5, pressure data taken after $350 \mathrm{GJ} / \mathrm{kgU}$ are consistent with earlier data; and, therefore, the problem has apparently been corrected.

The pressure data from rod 5 show three pressure spikes during the first $350 \mathrm{GJ} / \mathrm{kgU}$ of irradiation and extremely high pressure ( $2 \mathrm{MPa}$ ) thereafter (see Figure 6 ). As mentioned previously this rod was recently identified as being defective and was removed from the assembly. The extremely high pressures recorded since the start of the fourth reactor operating cycle (350 $\mathrm{GJ} / \mathrm{kgU})$ indicate that the rod may have failed during the first power ramp of this cycle due to pellet-cladding interactions. However, the three prior pressure spikes suggest that a small defect may have been present through most of the irradiation.

All three of the pressure spikes occurred after the reactor was shut down for an extended period of time and the moderator cooled to about 350k. Figure 16 shows the internal pressure as a function of time immediately after each shutdown period. These data were taken after the moderator had been heated to $513 \mathrm{~K}$ and with the reactor power level increasing with time for about 5 hours and constant thereafter. As can be seen, the majority of the pressure increase occurred during the initial reactor heatup as evidenced by the high pressures recorded at time zero. The pressures continued to increase as the reactor was taken to full power and then decreased to values consistent with the initial fill gas pressure. It required about 15 hours to reach equilibrium. 
The characteristics of the pressure spikes are consistent with a small amount of water entering the fuel rod during the extended shutdowns. Upon heating to $500 \mathrm{~K}$, the water vaporized and produced the high pressure reading observed at time zero. 'The subsequent pressure increase is directly related to the reactor power level while the pressure decrease can be attributed to chemical reactions with the fuel and cladding that remove the water vapor and its components from the gas phase. A detailed kinetic study has not been attempted, but 15 hours seems a reasonable time to remove a small amount of water vapor from the system.

To estimate fission gas release from internal pressure measurements, it is desirable to use data taken at zero reactor power where temperature gradients along the fuel rod are minimized. Since reliable data for zero power operation are not available, low power data will be used to estimate fission gas release. Using these data and assuming that the internal temperature equals the moderator temperature produces a slightly higher estimate for fission gas release because actual temperatures are higher than the assumed temperature. This results in an overestimate of the moles of gas present in the fuel rod.

The pressure increase at low reactor power and the estimated release fractions are given in Table 5 . The data for rod 5 have been omitted from the table because of the extremely high pressures that were observed in this rod after October 1979. Before this time, the pressure increase in rod 5 was similar to the other five rods.

The estimated release fractions were based on the difference between two pressure measurements; and, thus, the repeatability of the measurements is of concern in determining the uncertainty of the estimates. Halden personnel have suggested the repeatability of the pressure transducers is $\pm 1.5 \%$ or $\sim 0.003 \mathrm{MPa}$ at $0.2 \mathrm{MPa}$. However, examination of the data obtained during calibration of the pressure transducers in IFA- 513 shows differences up to $0.024 \mathrm{MPa}$ between repeat pressurizations and somewhat greater differences during depressurization. These differences are thought to be associated with the mechanical behavior of the bellows and could decrease with continued operation. However, each transducer was given at least 10 pressurization 
cycles prior to calibration as a preconditioning treatment, which should have minimized these effects. Therefore, we will assume the repeatability of the measurements is about $0.02 \mathrm{MPa}$.

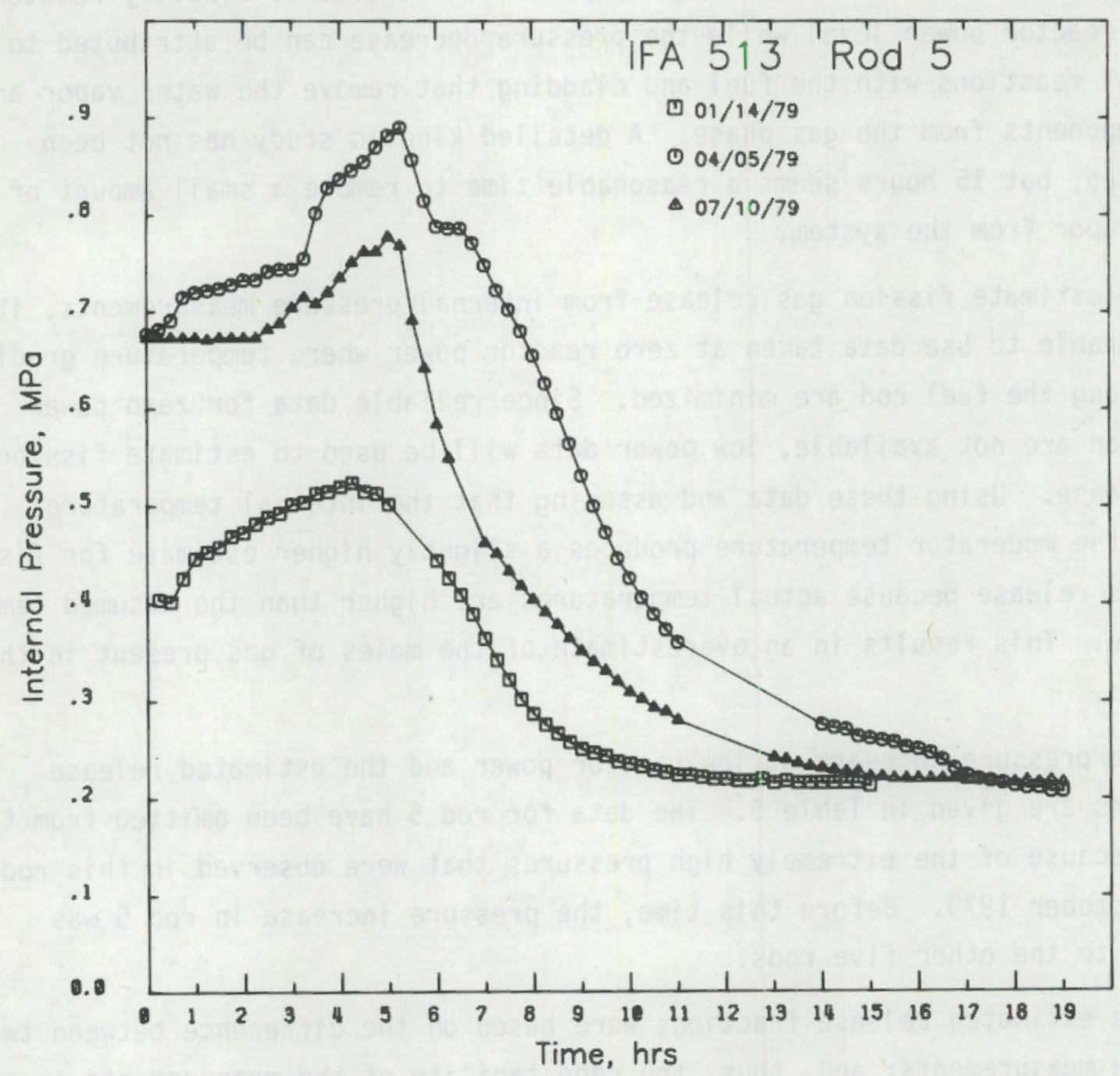

FIGURE 16. Internal Pressure of Rod 5 as a Function of Time Immediately After Extended Shutdown Periods 
TABLE 5. Surmary of Pressure Increases and Estimated Gas Release for IFA-513 as of January 1980

\begin{tabular}{cll} 
Rod Number & $\Delta P, M P a$ & $\begin{array}{l}\text { Fission } \\
\text { Release }\end{array}$ \\
\cline { 3 - 3 } 1 & 0.0 & 0.0 \\
2 & 0.069 & 2.2 \\
3 & 0.031 & 0.9 \\
4 & 0.043 & 1.4 \\
6 & 0.063 & 2.0
\end{tabular}

The total pressure increases at the end of the irradiation period (Table 5) do not greatly exceed the assumed repeatability of the measurements. This leads to large uncertainties in the estimated fission gas release, which in some cases exceeded $100 \%$ at the $3 \sigma$ confidence level. These large uncertain ties preclude making meaningful comparisons between the fuel rods in IFA-513. The fission gas release appears to be in the range of $1 \%$ to $2 \%$, which is reasonable for fuel temperatures below 1700K. 



\section{REFERENCES}

Bradley, E. R., et al. November 1979. Precharacterization Report for Instrumented Nuc lear Fuel Assembly IFA-513. NUREG/CR-1077, PNL-3156, Pac if ic Northwest Laboratory, Richland, Washington.*

Cunningham, M. E., D. D. Lanning, and S. D. Montgomery. October 1979. A Procedure for the Qualitative Interpretation of Fuel Centerline Thermocouple Response to Step-Power Decreases. NUREG/CR-1012, PNL-3096, Pac if ic Northwest Laboratory, Richland, Washington.*

Fidleris, V. 1978. "Primary Creep of Zircaloy-2 Under Irradiation." Fourth International Conference on Zirconium in the Nuclear Industry, June 27-29, 1978, Stratford-Upon-Avon, England.

Lanning, D. D. November 1978. "Qualitative Confirmation of Steady-State Fuel Center Line Thermocouple Data from Transient Response." ANS Transactions 30.

Lanning, D. O., B. O. Barnes, and C. R. Hann. January 1979. Manifestations of Nonlinearity in Fuel Center Line Thermocouple Steady-State and Transient Data: Implications for Data Analysis. NUREG/CR-0220, PNL-2602, Pacific Northwest Laboratory, Richland, Washington.*

Lanning, D. D., et al. 1978. GAPCON-THERMAL-3 Code Description. PNL-2434, Pacific Northwest Laboratory, Richland, Washington.

Lanning, D. D., and M. E. Cunningham. July 1979. Startup Data Report for NRC/PNL Halden Assembly IFA-513. NUREG/CR-0862, PNL-2948, Pacif ic Northwest Laboratory, Richland, Washington.*

Williford, R. E., et al. April 1980. The Analysis of Fuel Relocation for the NRC/PNL Halden Assemblies IFA-431, IFA-432, and IFA-513. NUREG/CR-0588, PNL-2709, Pac if ic Northwest Laboratory, Richland, Washington.*

FAvailable for purchase from the NRC/GPO Sales Program, U.S. Nuclear Regulatory Commission, Washington, DC 20555, and/or the National Technical Information Service, Springfield, VA 22161. 

APPENDIX A

INSTRUMENT DESCRIPTIONS AND CALIBRATION 
APPENDIX A

\section{INSTRUMENT DESCRIPTIONS AND CALIBRATION}

Instrumented fuel assembly (IFA) - 513 was equipped with a comprehensive array of in-pile instrumentation to collect data. These instruments are located as shown in text Figure 1, page 5. The most important of these instruments are:

- 8 vanadium beta-emitter self-powered neutron detectors (SPNDs)

- 1 cobalt fast-response SPND

- 12 W5\%Re/W26\%Re-sheathed fuel centerline thermocouples (TCS)

- 6 linear variable differential transformer (LVDT) cladding elongation monitors

- 6 bellows-type pressure transducers.

Each of these is briefly discussed below. The accuracy and uncertainty of their respective outputs is discussed more completely by Hann et al. 1977.

\section{NEUTRON DETECTORS}

IFA-513 was equipped with eight vanadium beta-emitter SPNDs to monitor the power in the fuel assembly after the initial thermal-hydraulic calibration (see Figure A.1). Each vanadium neutron detector was $100 \mathrm{~mm}$ (3.93 in.) long, and the centers of three detectors were located on essentially the same plane as each of the two TC junctions. The remaining two detectors were positioned at different levels between the two TC locations to determine the axial flux profile.

The neutron detectors used in IFA-513 were not calibrated. Their precision was based on the results of 30 similar vanadium neutron detectors in the Studsvik R2-0 Reactor in Sweden that had been irradiated in a thermal neutron flux of $1.1 \times 10^{10} \mathrm{n} / \mathrm{cm}^{2}-\mathrm{s}$. The error limits for the detector outputs were estimated to be $\pm 2.5 \%$. 


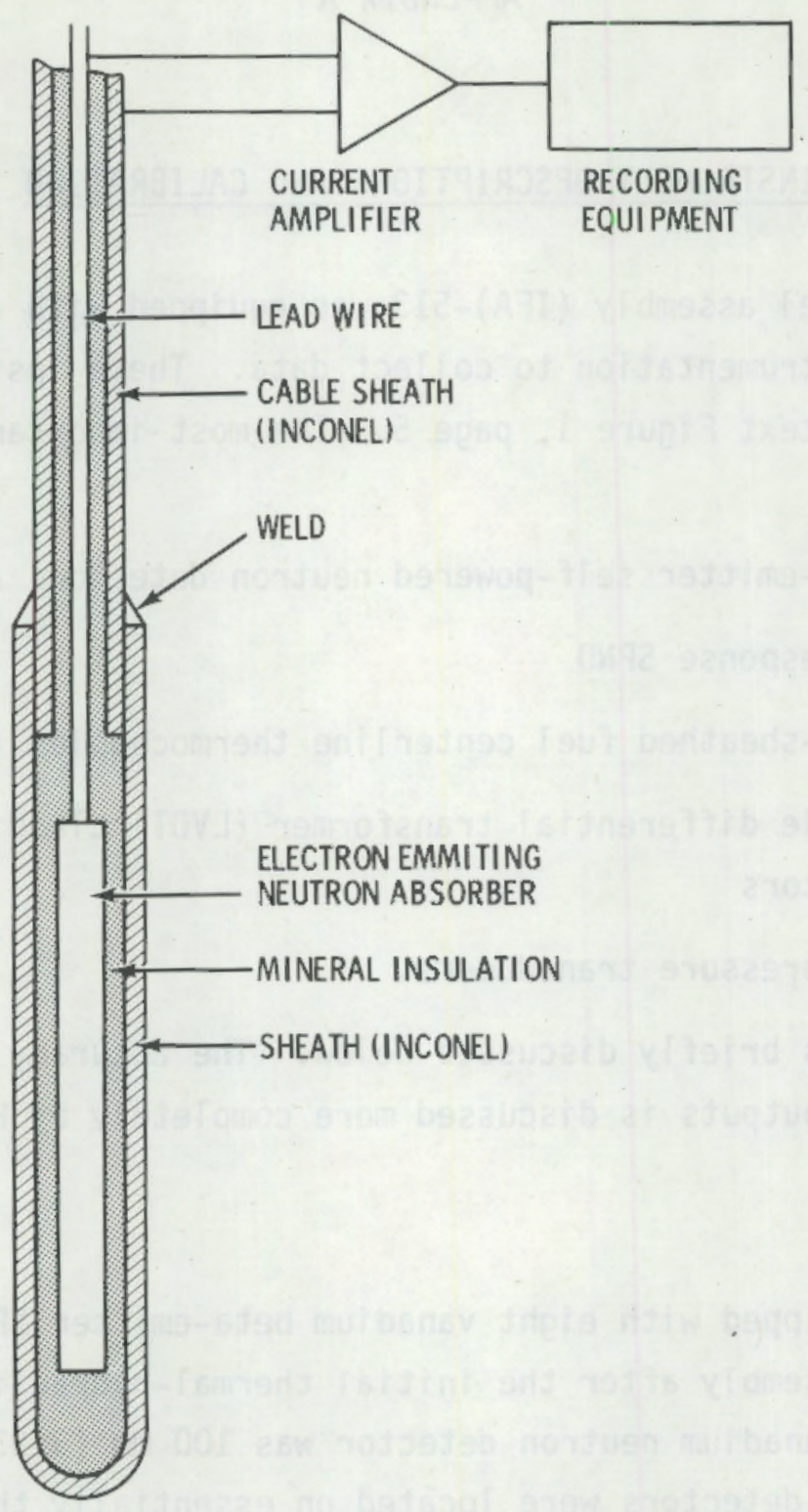

FIGURE A.1. Schematic of Beta-Emitter Self-Powered Neutron Detector

In addition to correlating the detector outputs to the neutron flux in the Studsvik reactor, Halden has conducted long-term tests of similar neutron detectors in the Halden boiling water reactor (HBWR). These long-term tests have established that the detectors are reliable and accurate instruments without a measurable change in sensitivity at higher flux levels in the HBWR. 
The sensitivities of the test assembly neutron detectors were calculated from the sensitivities of the calibrated detectors and the physical characteristics of the test assembly detectors supplied by the manufacturer. Since Halden considers gamma sensitivity to be negligible, it was not measured.

The vanadium detectors have a calculated burnup rate of $0.013 \%$ /month at a neutron flux of $1 \times 10^{13} \mathrm{n} / \mathrm{cm}^{2}-\mathrm{s}$. Based on this rate, the neutron detector end-of-life (EOL) burnup for IFA-513 is $0.3 \%$. Because of this low value, the neutron detector outputs were not corrected for burnup.

A disadvantage of the vanadium detectors is their slow response time to power changes ( $5.5 \mathrm{~min}, 0$ to $63 \%$ ). Consequently, during up and down power ramps, a correction factor should be considered for the output values.

A cobalt detector, similar in appearance to the vanadium detectors but $200 \mathrm{~mm}$ long, was placed in the center of the assembly to monitor average assembly power during transient tests (Lanning and Hann 1977).

\section{FUEL THERMOCOUPLES}

Twe lve W5\%Re/W26\%Re TCs were used in IFA-513 to measure the central fuel temperatures. They were not calibrated because of the embrittling effect of temperature on TC materials and the subsequent high probability of breakage during fuel rod assembly. They are supposed to have initial accuracies that are within $\pm 1 \%$ of the appropriate calibration table up to $2273 \mathrm{~K}$ and with in $\pm 2 \%$ above that. These accuracies have been confirmed by Halden in some calibration tests.

Additional uncertainties caused by dissimilar metal junctions in the measuring system and the instrumentation are estimated to be within $\pm 6 \mathrm{~K}$. This is substantially less than the uncertainty introduced by not calibrating each TC individually.

Finally, temperature and irradiation-induced decalibration of the TC needs to be considered. Data from IFA-432 at $1890 \mathrm{GJ} / \mathrm{kgU}$ suggest a decalibration rate of approximately $-0.01 \%$ per GJ/kgU ( $1 \%$ per 1000 MWd/MTM). This rate is about $20 \%$ higher than the $-4 \%$ year decalibration rate suggested by Halden, which indicates the difficulty of determining TC decalibration. However, the 
importance of TC decalibration increases with exposure and needs to be considered when using the high burnup data given in this report.

\section{CLADDING ELONGATION MONITORS}

Figure A.2 is a schematic of the LVDT cladding elongation sensors used in IFA-513. These instruments are mounted upside down at the bottom of the assembly, and the core extension contacts the lower end plug of the rod. The ferromagnetic core is attached to the extension and moves inside a coil system with the central primary coil carrying 50-mA 400- $\mathrm{Hz}$ excitation. A secondary coil consisting of two balanced halves flanks the primary coil. The output voltage is zero when the core is in its central position and increases linearly when the cladding elongation moves the core. Sample calibration curves for these instruments may be found in the report by Hann et al. (1978).

\section{PRESSURE TRANSDUCERS}

A schematic of the bellows-type pressure transducers that were used to monitor the internal fuel rod pressures is shown in Figure A.3. The transducer consists of a magnetic core connected to an evacuated bellows. The position of the core depends on the internal fuel rod pressure and is monitored by a differential transformer.

Each transducer was preconditioned by a series of pressure cycles and calibrated at 513K prior to fuel rod assembly. The sensitivity of the transducers was determined by pressurizing in $0.1-\mathrm{MPa}$ increments and measuring the output of the differential transformer. Measurements were also taken during depressurization to establish bellows hysterisis and during an additional pressure cycle to check for repeatability. The combined results from the two calibration runs are within $\pm 0.02 \mathrm{MPa}$ for each of the six transducers. 


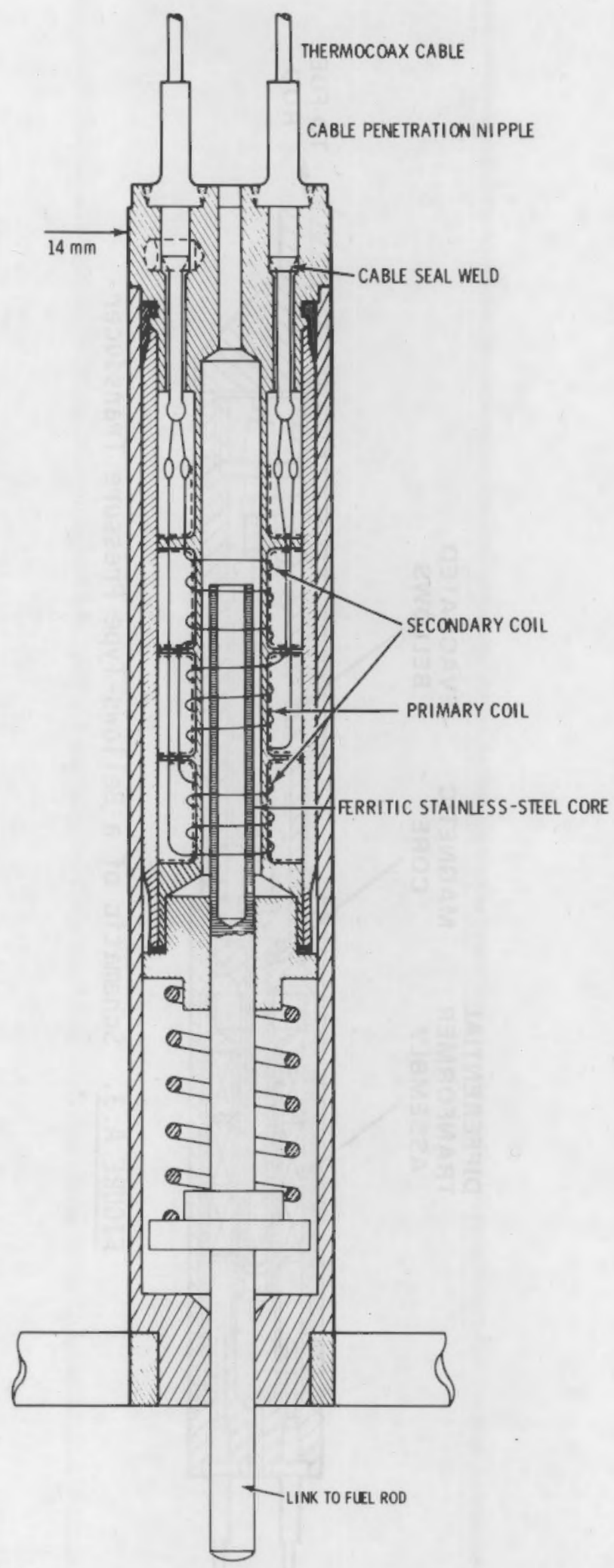

FIGURE A.2. Cladding Elongation Monitor (Halden Project Design) 
DIFFERENTIAL

TRANFORMER

MAGNETIC
CORE

ASSEMBLY

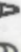

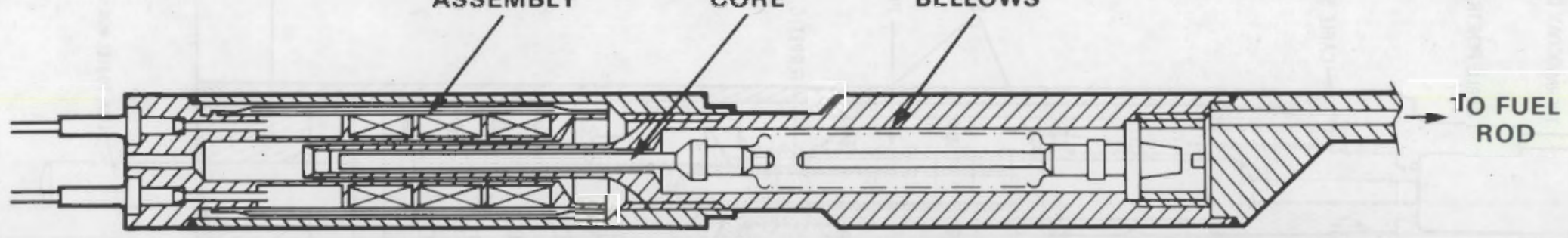

FIGURE A.3: Schematic of a Bellows-Type Pressure Transducer 
In-core calibration consists of measuring the internal pressure at $513 \mathrm{~K}$ and correcting this measured value to be equal to the calculated pressure at this temperature. All subsequent pressures are determined by the relation:

$$
P=\frac{\text { output }}{\text { sensitivity }}+\text { correction }
$$

\section{REFERENCES}

Hann, C. R., et al. February 1977. A Method for Determining the Uncertainty of Gap Conductance Deduced from Measured Fuel Center line Temperatures. BNWL-2091, Pac ific Northwest Laboratory, Richland, Washington.

Hann, C. R., et al. June 1978. Data Report for the NRC/PNL Halden Assembly IFA-431. PNL-2494, Pac ific Northwest Laboratory, Richland, washington.

Lanning, D. D., and C. R. Hann. April 1977. Verification of Fuel Centerline Thermocouple Readings Through Response to Linear Power Decreases. BNWL-2189, Pacific Northwest Laboratory, Richland, Washington. 

APPENDIX B

DATA PROCESSING 
APPENDIX B

\section{DATA PROCESSING}

Processing of the data received from Halden on magnetic tape proceeds as shown in Figure B.1. The data tape must first be translated from the Halden IBM/1800 language (EBCDIC) to the PDP11/45 language (ANSI); the translated version is stored on tape. This tape is reformatted so that all data from a particular time on a particular date are in one block. This is simultaneously stored on a disk file.

Once the raw data are stored on disk, another program is applied to each block of data to evaluate the rod local heat ratings at the thermocouple (TC) positions. The eight vanadium neutron detectors in instrumented fuel assembly (IFA)-513 provide a measure of the axial fiux profile and the radial flux tilt at the upper and lower TC planes. Pseudo neutron flux profiles for each rod are determined by translating the measured flux profiles to the appropriate position in each fuel rod. This is followed by defining a calibration factor as the ratio of the assembly power to the sum of the flux integrals over the individual rods. Local power is then the product of the calibration factor and the local pseudo flux.

When this step is complete, another program corrects the burnups and heat ratings for depletion of ${ }^{235} \mathrm{U}$. Plutonium buildup is not taken into account.

After the data are corrected, four paths are possible and are usually simultaneously executed. The data are plotted, relative flux profiles and mean power histories are calculated for input to safety-related codes, an error analysis is performed on the corrected data, and data are analyzed by subsets (i.e., transient, steady state) to separate the effects of the major variables. 


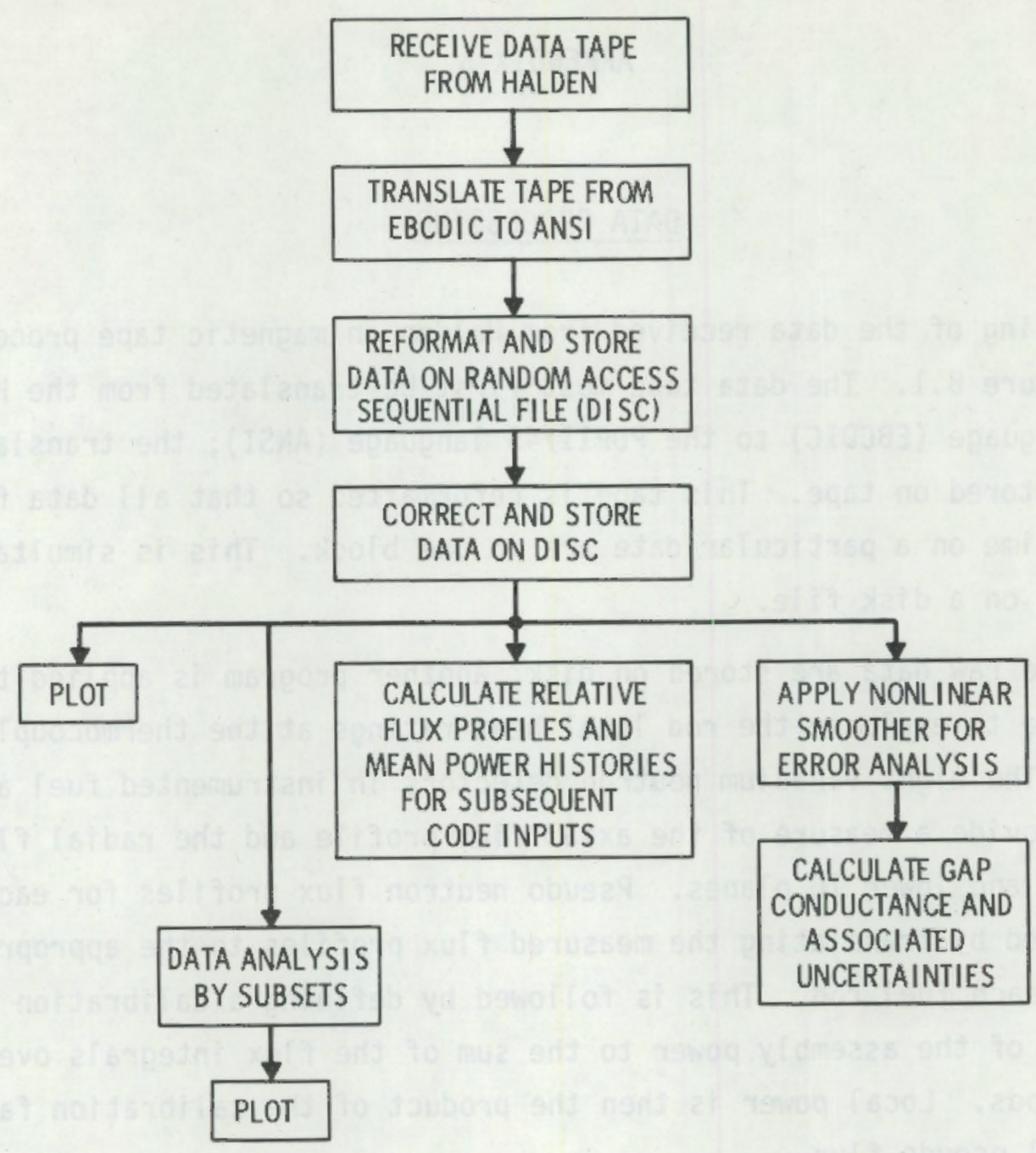

FIGURE B.1. Flow Diagram for Processing Halden Data 
APPENDIX C

ASSEMBLY POWER CALIBRATION 
APPENDIX C

\section{ASSEMBLY POWER CALIBRATION}

\section{FUEL ASSEMBLY POWER}

At the beginning of the first irradiation cycle, the total power in the test assembly is calibrated thermal-hydraulically under forced convection cooling and is related to the average of the neutron detector currents. After this calibration, the assembly is operated under natural circulation cooling; and the assembly power and individual fuel rod linear heat ratings are deduced from the neutron detector currents. The calibration is not repeated.

The test assembly inlet ports near the bottom of the assembly (see text Figure 1, page 5) are closed for the forced convection calibration run by activating the calibration valve. Forced circulation cooling is introduced from the subcooled plenum chamber and boiling is established in the channel as shown schematically in Figure C.1.

The assembly is operated at a constant power that is controlled by the neutron detector readings while the subcooling is varied. The boiling power is computed and plotted versus the measured subcooled power. The plots of boiling power versus subcooled power are very close to a straight line. The intersection of the extrapolated plots and the abscissa gives the minimum subcooled power required to suppress boiling in the channel under ideal conditions. The subcooled power is equal to the total channel power, which is corrected for the moderator heating effect to give the channel power associated with the assembly.

The calibration method is based on assuming a constant slip factor during a subcooled power ramp. The results of the measurements give a plot of boiling power versus subcooled power that is very close to a straight line, indicating that the assumption is valid.

The effects of void volume on assembly power calibration have been calculated by Halden to be $0.044 \% /$ percent void volume, which represents an 


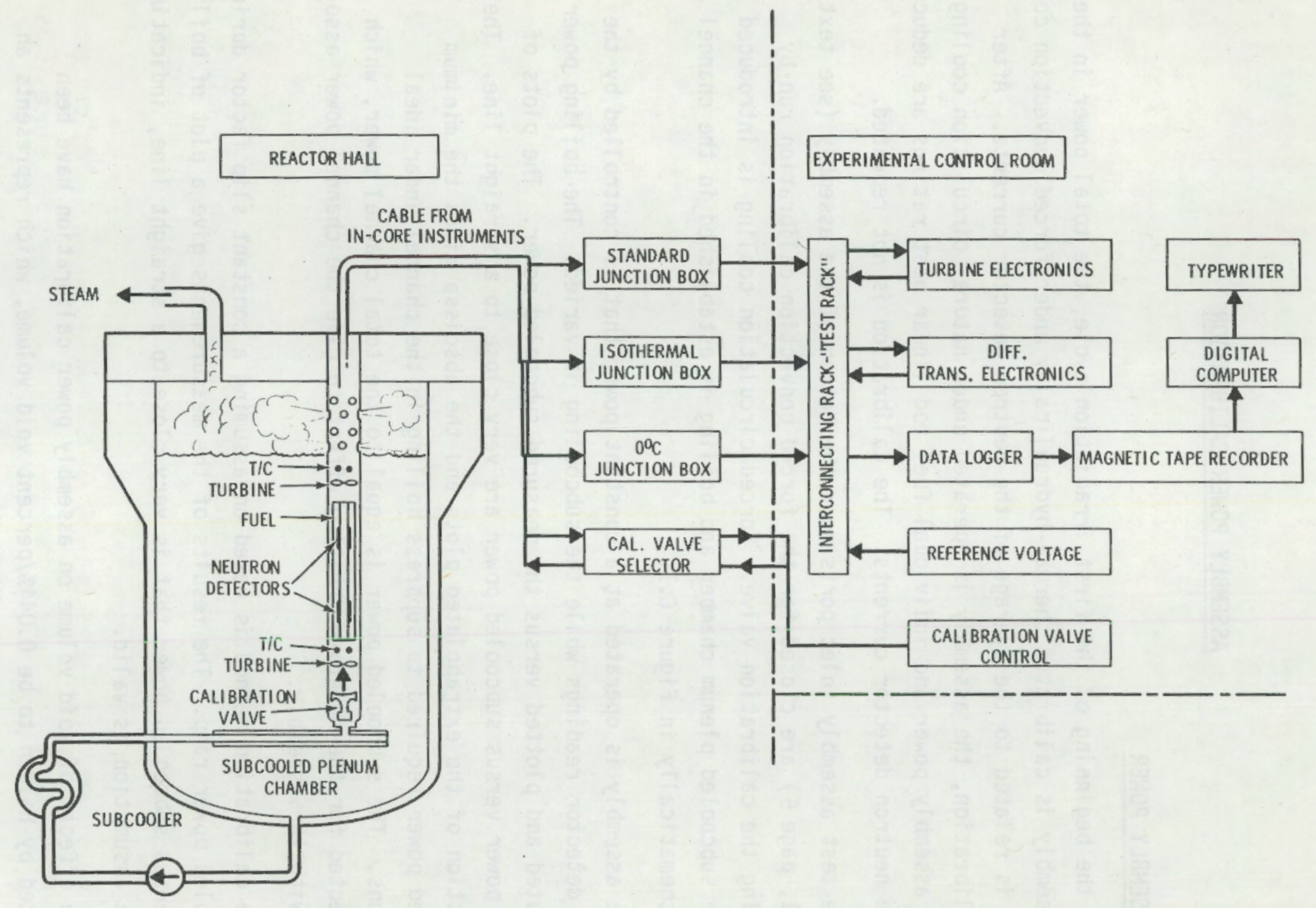

FIGURE C.1. Schematic Arrangement for Assembly Power Calibration 
increase in the $\mathrm{Kg}$ factor (ratio of thermohydraulic power to neutron detector signa1) for instrumented fuel assembly (IFA)-513. The difference between the percent void volume during calibration and operation is not well known and is not included in this analysis.

The accuracy of the assembly power determination depends on the following factors:

- calibration of inlet and outlet turbine flowmeters

- calibration of coolant thermocouples (TCS)

- temperature profile across the coolant channel where the, inlet and outlet TCs are located

- influx of heat from the moderator into the coolant channel

- slip factor constancy

- signal-to-noise ratio

- accuracy of data-handling equipment.

The outlet turbine accuracy is very good (better than $\pm 0.5 \%$ ) while the inlet turbine calibration is more doubtful due to the short and complicated inlet section. Comparison with the outlet turbine immediately prior to measurements gives good control, however; and the accuracy obtained is estimated to be better than $\pm 2 \%$.

The calibration of coolant TCS is very good--about $\pm 2 \mu \mathrm{V}$. A 10K temperature $r$ ise in the channel has an accuracy of $\pm 0.5 \%$.

The nonuniform temperature distribution across the inlet to the channel is negligible because there is excellent mixing before the coolant enters the assembly. The distribution across the outlet, however, is difficult to determine as there is little information available. The best estimate is obtained by studying the consistency of the measurements and the degree of agreement between the various calibration methods.

The influence of the heat flux from the moderator is small. It can amount to as much as $10 \mathrm{~kW}$ at low channel power and high subcooling; but since it is 
taken into account, the overall error contribution is very small (probably less than $\pm 0.5 \%$ ) even if some error is involved in determining the heat flux.

The signal-to-noise ratio does not normally cause any difficulty with sound instruments. The noise is easily filtered out.

There is always full control with the performance of the data-handling system; therefore, errors caused in this equipment can be neglected compared to errors from other sources.

Another factor that influences the accuracy of assembly power indication by the beta current neutron detectors is the specificity of the power indicators themselves. Part of the neutron flux registered by these instruments originates in other fuel assemblies, and this portion of the signal will depend on the flux distribution in the core.

Taking the above factors into account, Halden estimates that the inreactor assembly power measurements have accuracies in the $\pm 3 \%$ to $\pm 5 \%$ range. A value of $\pm 4-1 / 2 \%$ was selected for the IFA-513 assembly power accuracy. 


\section{APPENDIX D}

DATA PLOTS 


\section{APPENDIX D}

\section{DATA PLDTS}

Figures D.1 through 0.60 show the in-reactor data collected from instrumented fuel assembly (IFA)-513 during its irradiation period from November 1978 to January 1980. All data were obtained by the Halden IBM/1800 on-line computer data acquisition system. Data densities (versus time) vary from 15 minutes to 12 hours, depending on whether the reactor was experiencing transient (startup, power cycling) or steady-state conditions.

In each figure, the rod number for each curve appears in the upper lefthand corner. The relative position of the rod number corresponds to the relative position of the curve in each figure. The data are arranged as follows:

\begin{tabular}{lll}
\multicolumn{1}{c}{ Measurement } & & Figure Number \\
\cline { 1 - 1 } Power Histories & & 0.1 to $D .20$ \\
Temperature Histories & & 0.21 to 0.40 \\
Elongation Histories & & 0.41 to $D .50$ \\
Pressure Histories & & 0.51 to $D .60$
\end{tabular}

Table D.1 shows the calculated burnup at each thermocouple (TC) location for each rod. These are the local burnups at the end of each month of operation and were calculated by numerically integrating the power history over time and then correcting for the depletion of ${ }^{235} \mathrm{U}$. Comparisons of results using this method and postirradiation examination (PIE) data for Rod 6 of IFA-431 show good agreement. 


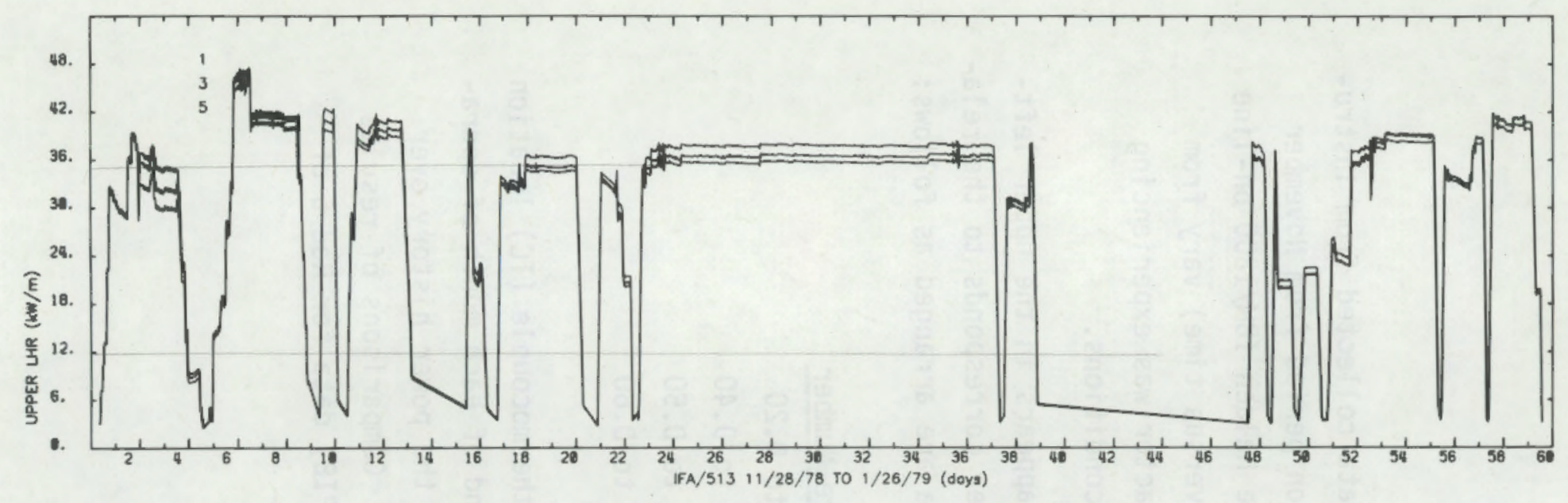

FIGURE D.1. Local Linear Heat Rates at Upper Thermocouple Location for Rods 1, 3, and 5 of IFA-513 from November 28, 1978, to January 26, 1979

$\stackrel{\square}{\text { iv }}$

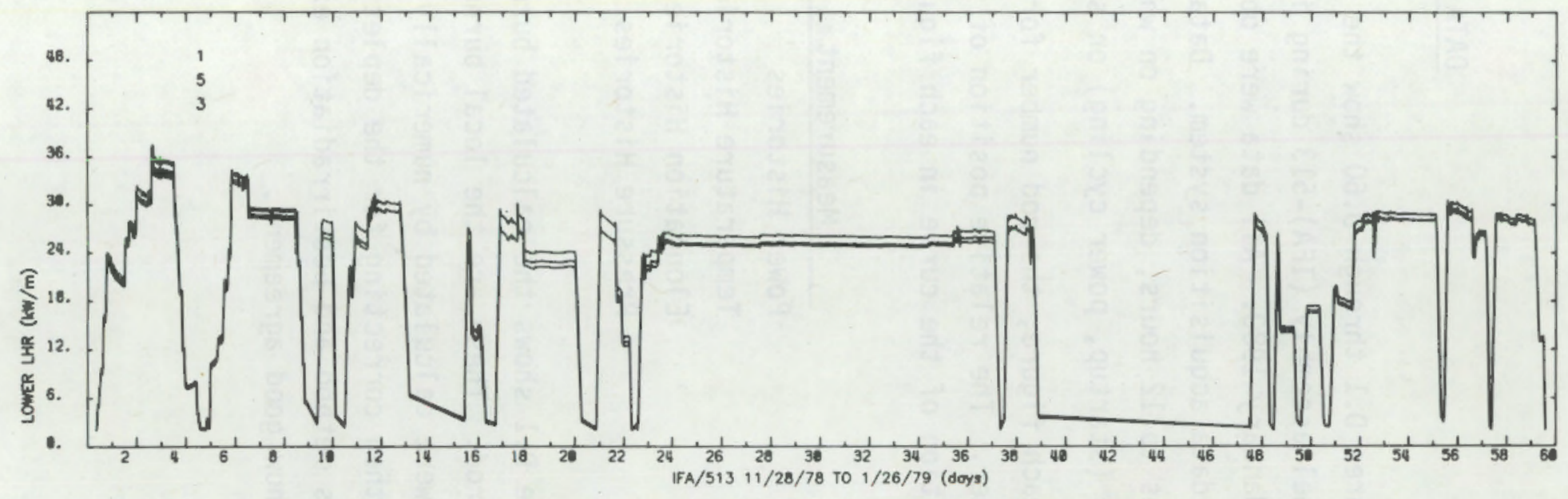

FIGURE D.2. Local Linear Heat Rates at Lower Thermocouple Location for Rods 1,3 , and 5 of IFA-513 from November 28, 1978, to January 26, 1979 


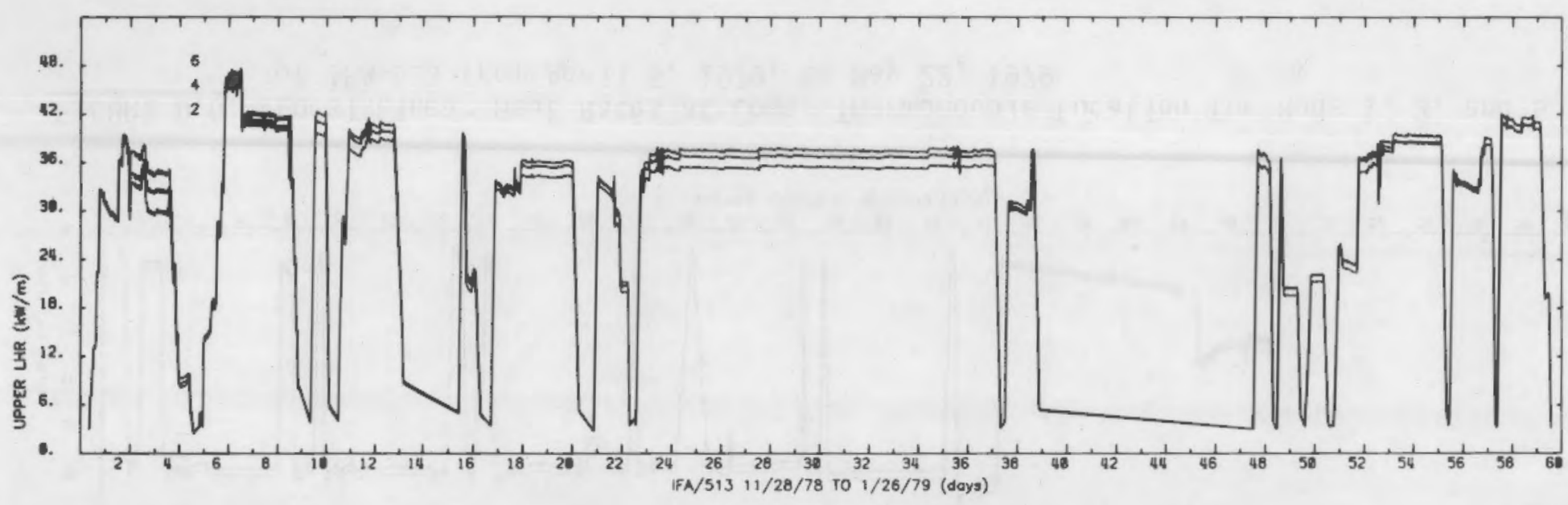

FIGURE 0.3. Local Linear Heat Rates at Upper Thermocouple Location for Rods 2, 4, and 6 of IFA-513 from November 28, 1978, to January 26, 1979

$\stackrel{\circ}{\omega}$

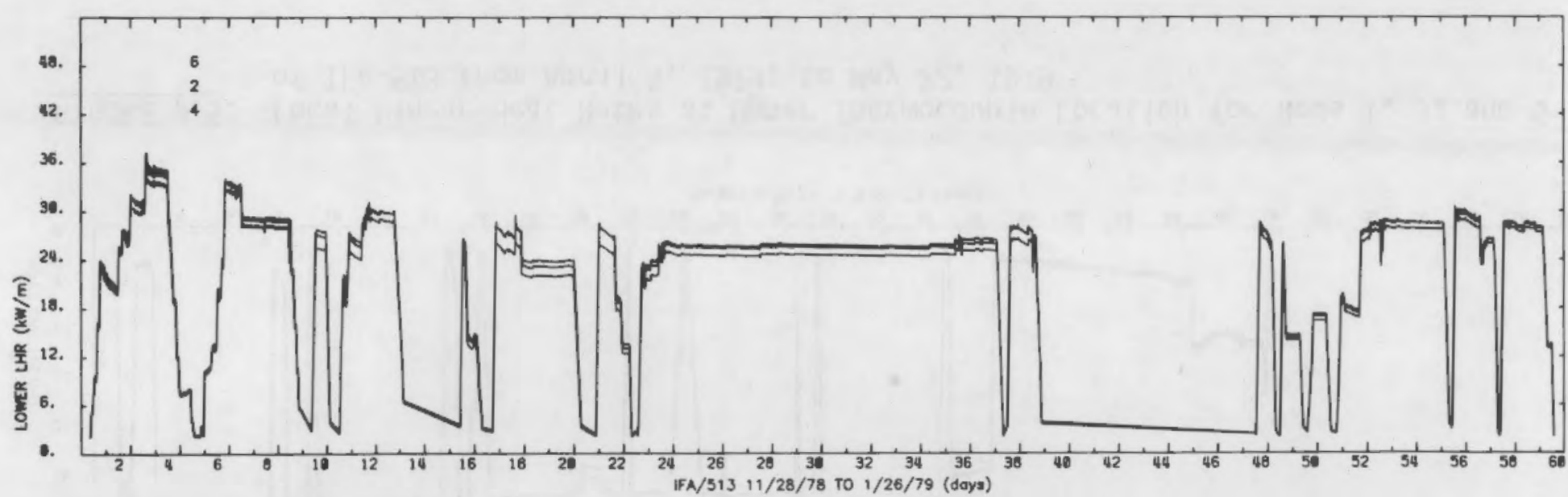

FIGURE D.4. Local Linear Heat Rates at Lower Thermocouple Location for Rods 2, 4, and 6 of IFA-513 from November 28, 1978, to January 26, 1979 


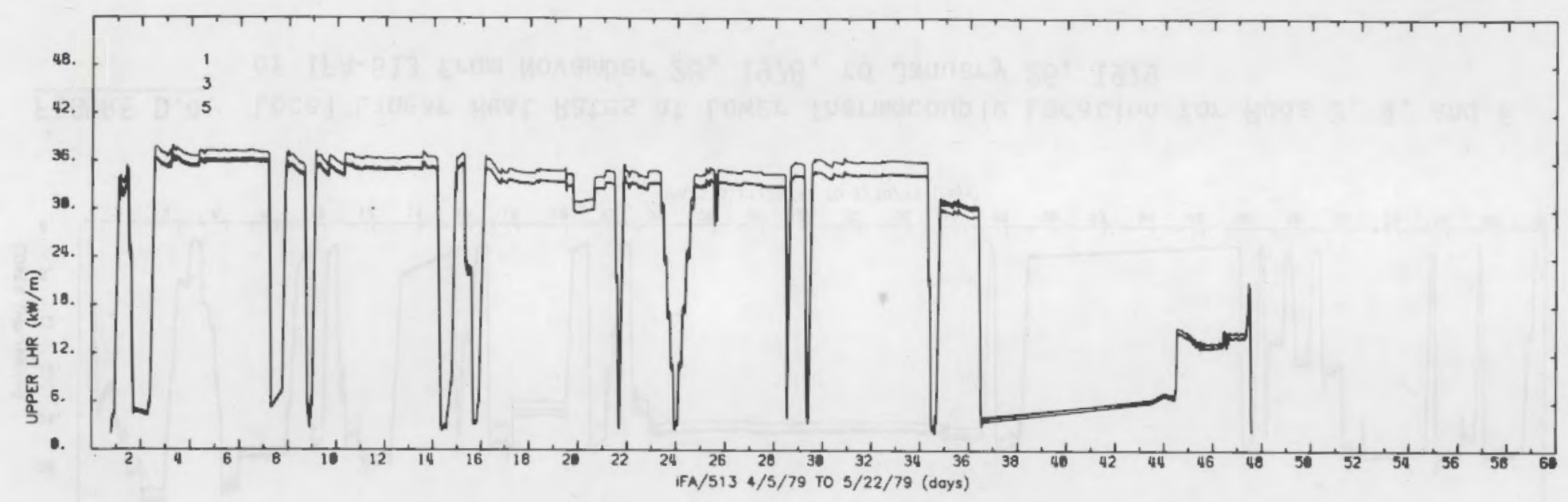

FIGURE 0.5. Local Linear Heat Rates at Upper Thermocouple Location for Rods 1, 3, and 5 of IFA-513 from Apri1 5, 1979, to May 22, 1979

is

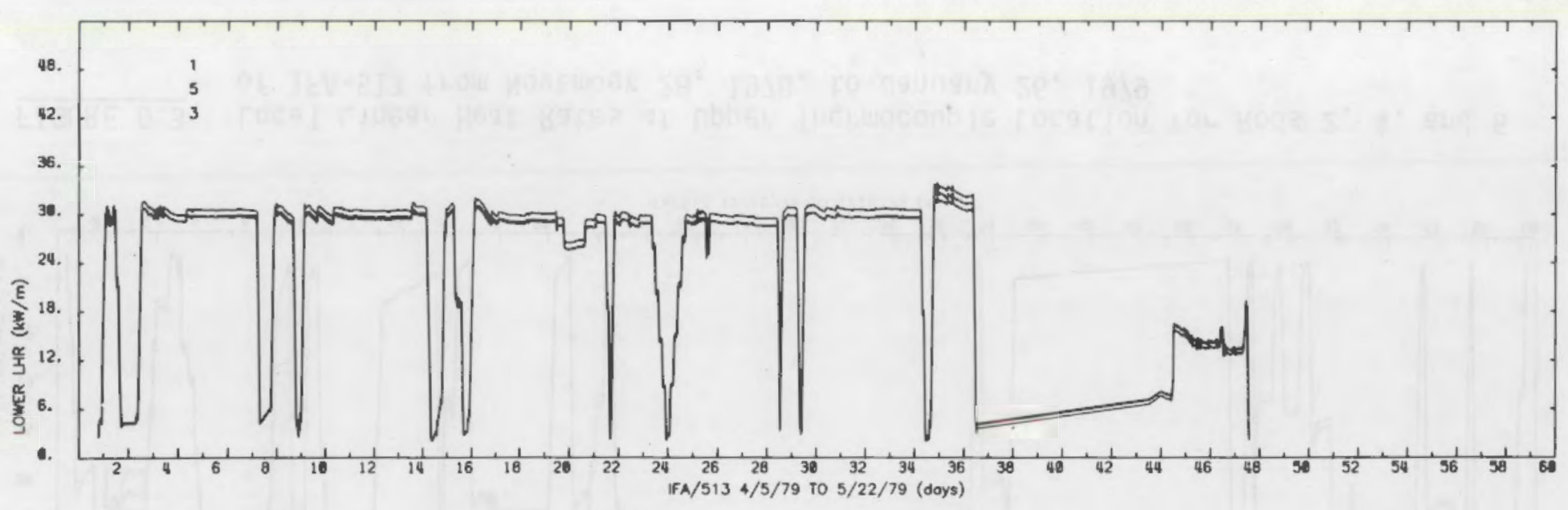

FIGURE 0.6. Local Linear Heat Rates at Lower Thermocouple Location for Rods 1, 3, and 5 of IFA-513 from Apri1 5, 1979, to May 22, 1979 


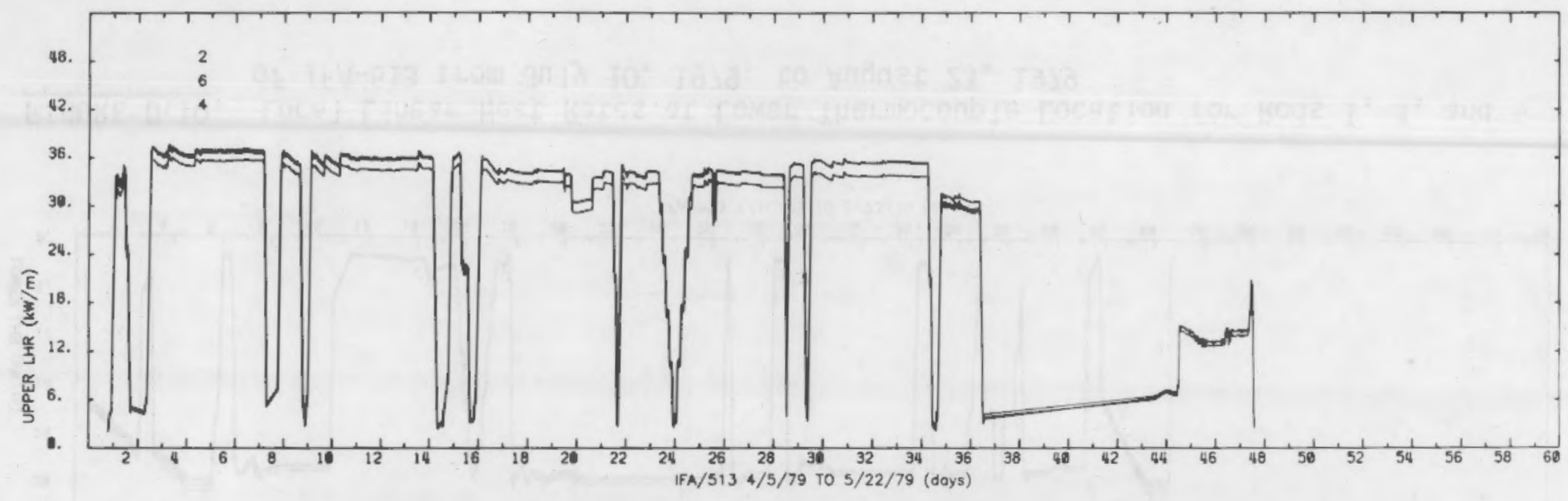

FIGURE 0.7. Local Linear Heat Rates at Upper Thermocouple Location for Rods 2, 4, and 6 of IFA-513 from April 5, 1979, to May 22, 1979

ir

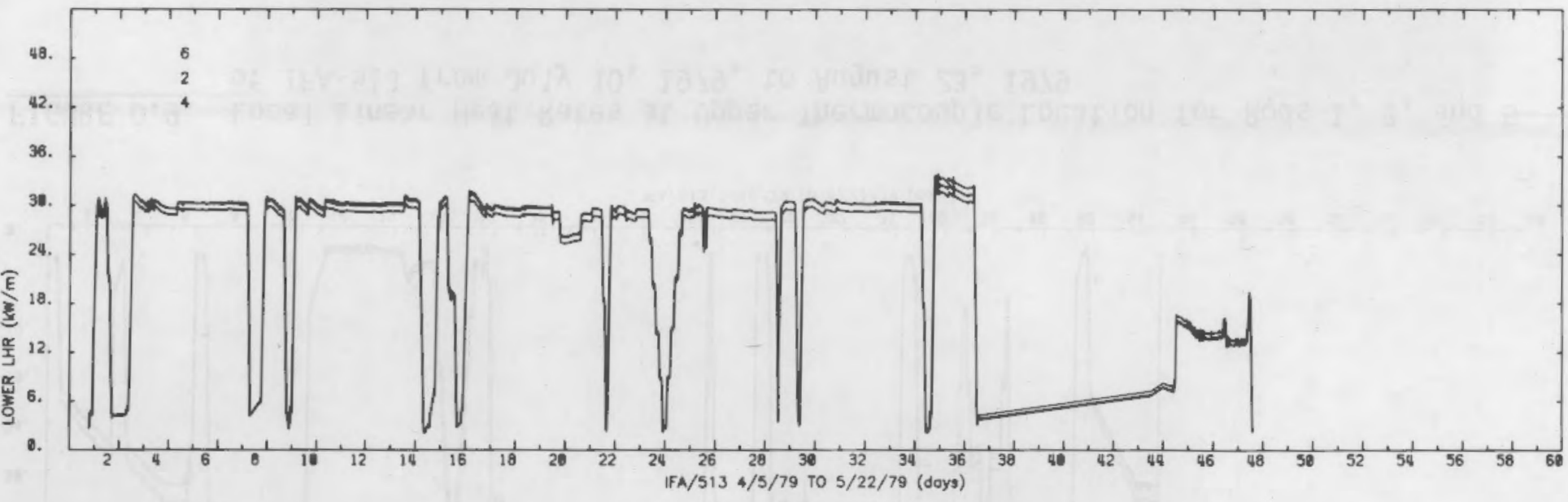

FIGURE 0.8. Local Linear Heat Rates at Lower Thermocouple Location for Rods 2, 4, and 6 of IFA-513 from April 5, 1979, to May 22, 1979 


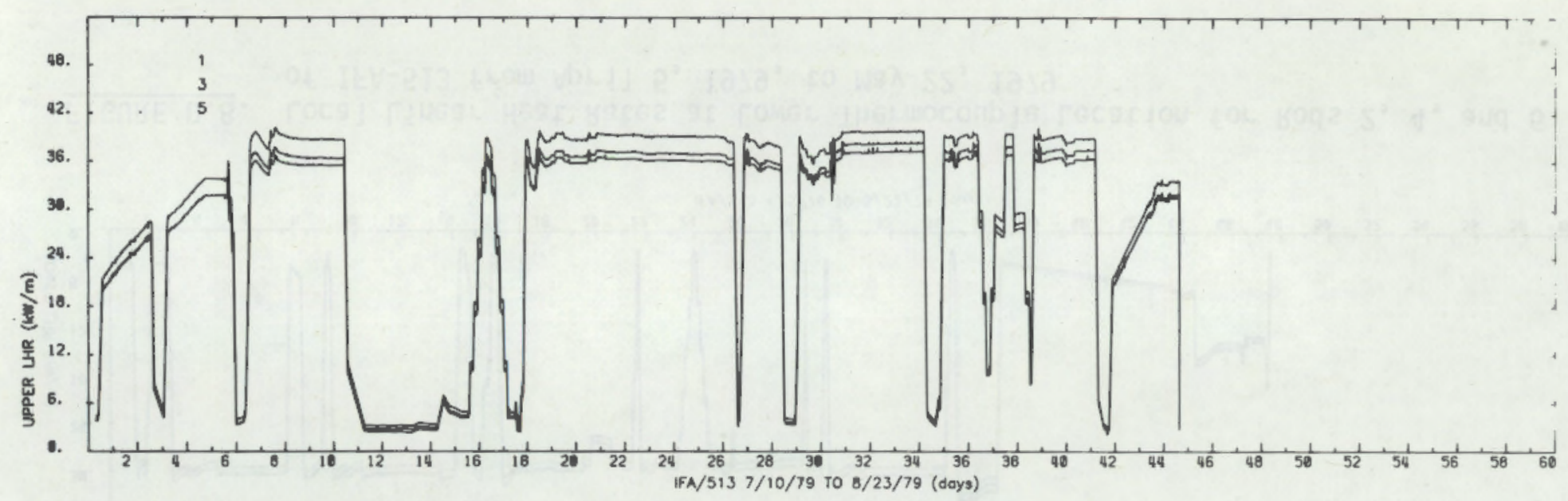

FIGURE 0.9. Local Linear Heat Rates at Upper Thermocouple Location for Rods 1, 3, and 5 of IFA-513 from July 10, 1979, to August 23, 1979

$\dot{\circ}$

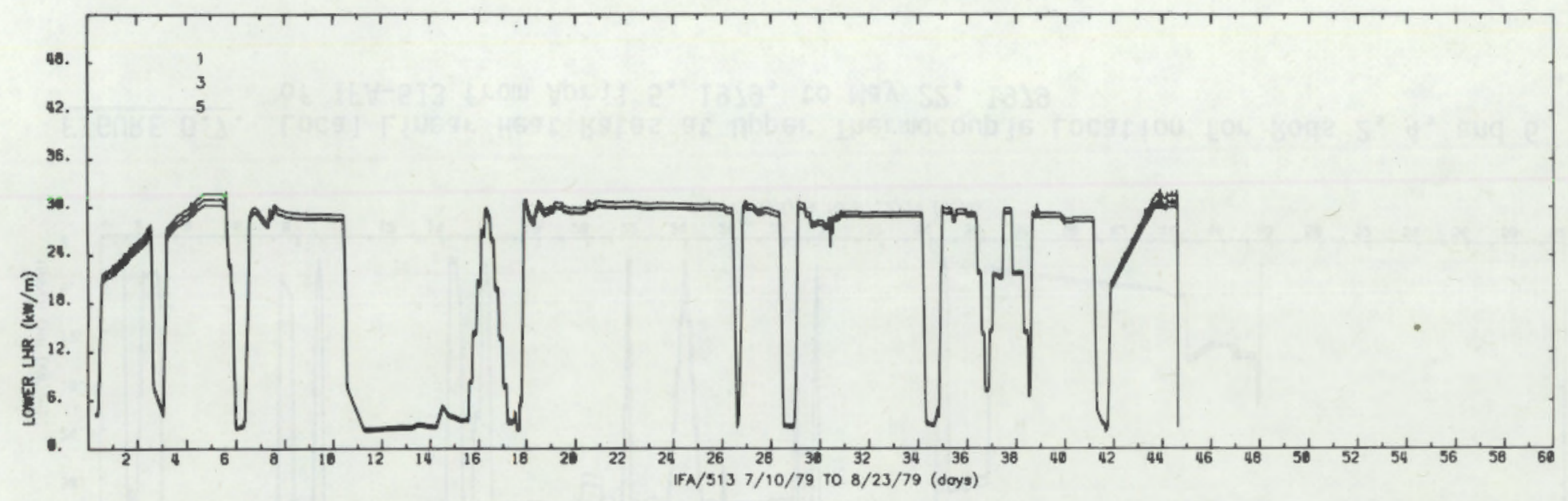

FIGURE 0.10. Local Linear Heat Rates at Lower Thermocouple Location for Rods 1, 3, and 5 of IFA-513 from July 10, 1979, to August 23, 1979 


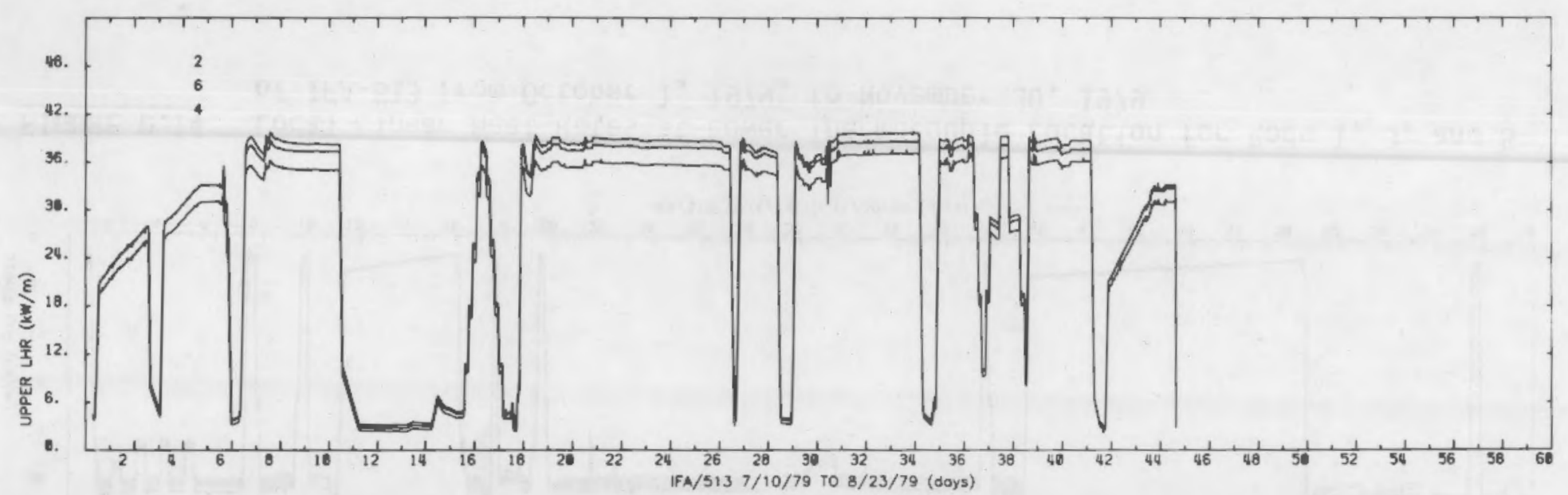

FIGURE 0.11. Local Linear Heat Rates at Upper Thermocouple Location for Rods 2, 4, and 6 of IFA-513 from July 10, 1979, to August 23, 1979

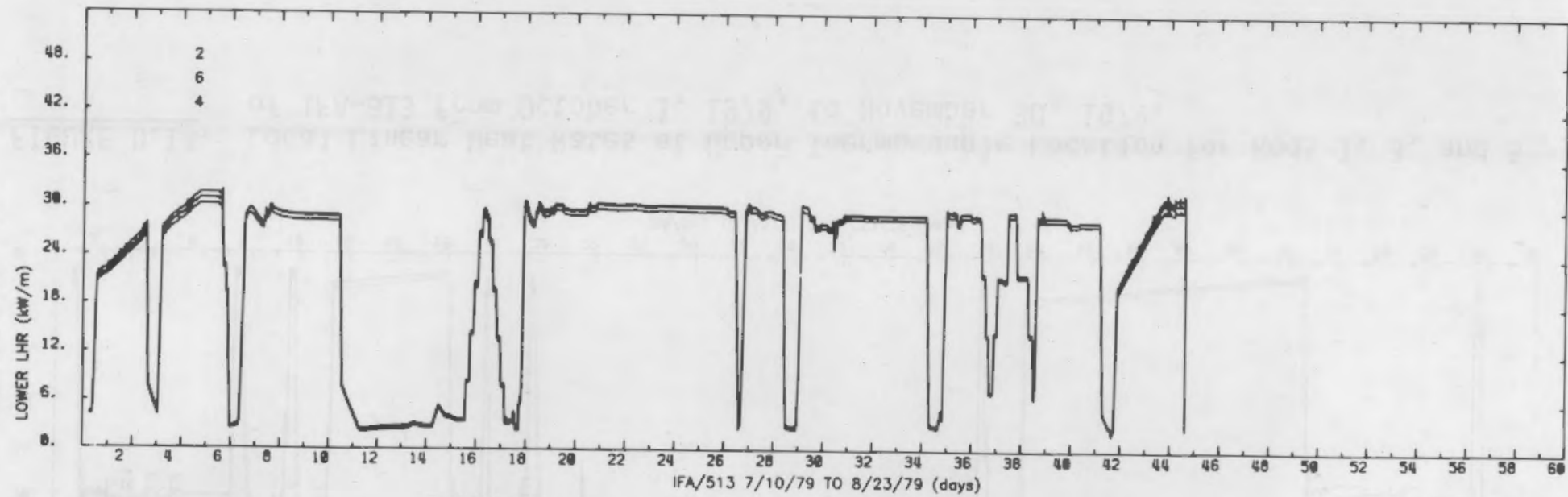

FIGURE 0.12. Local Linear Heat Rates at Lower Thermocouple Location for Rods 2, 4, and 6 of IFA-513 from July 10, 1979, to August 23, 1979 


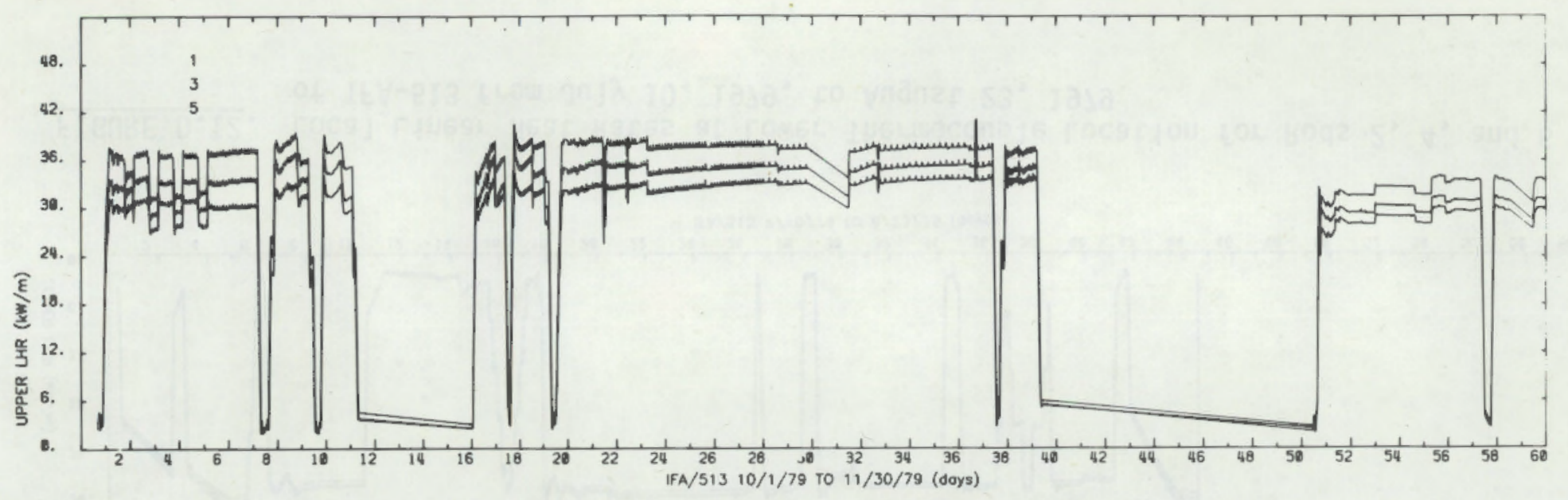

FIGURE D.13. Local Linear Heat Rates at Upper Thermocouple Location for Rods 1, 3, and 5 of IFA-513 from October 1, 1979, to November 30, 1979.

$\oplus_{\infty}^{\infty}$

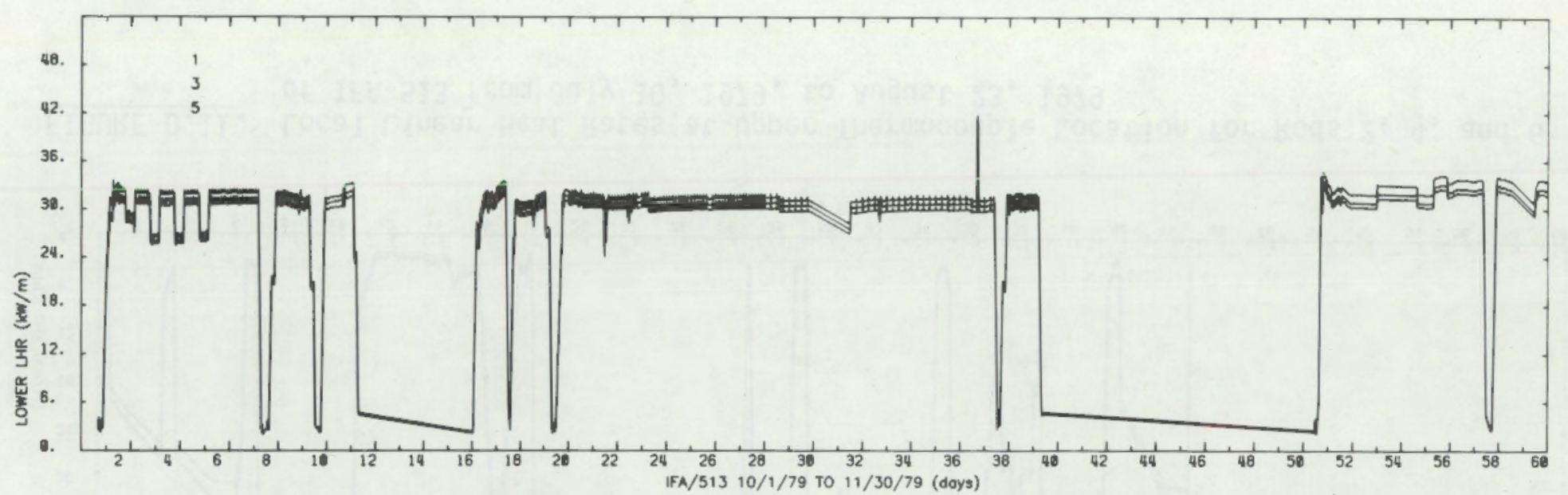

FIGURE D.14. Local Linear Heat Rates at Lower Thermocouple Location for Rods 1,3 , and 5 of IFA-513 from October 1, 1979, to November 30, 1979 


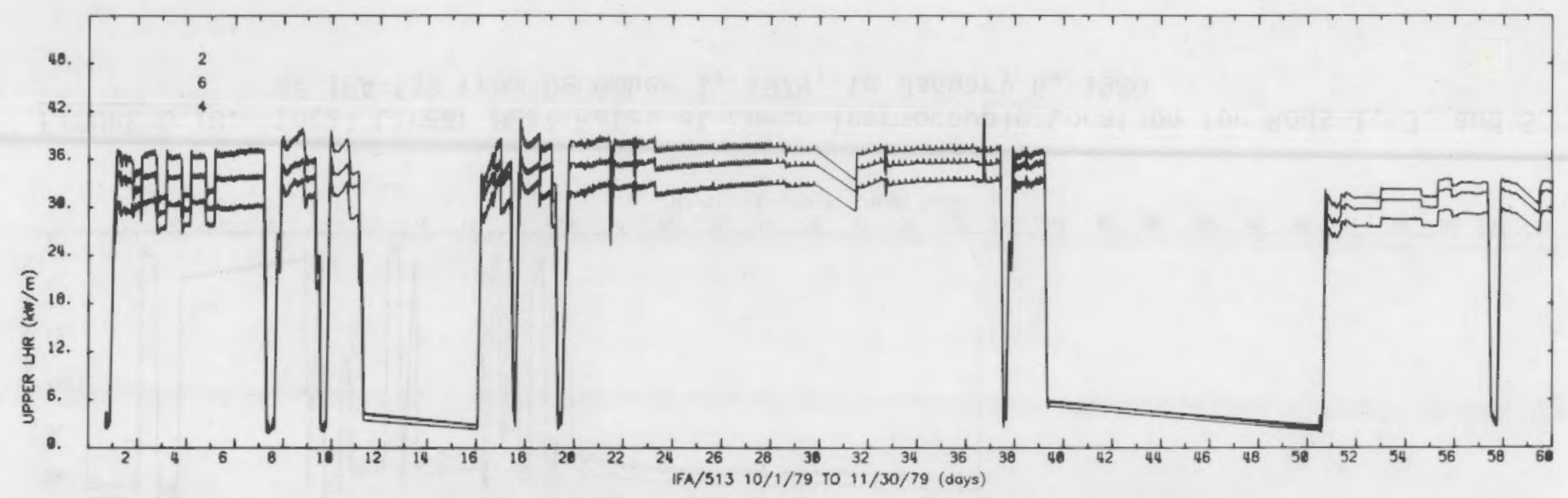

FIGURE 0.15. Local Linear Heat Rates at Upper Thermocouple Location for Rods 2, 4, and 6 of IFA-513 from October 1, 1979, to November 30, 1979

i.

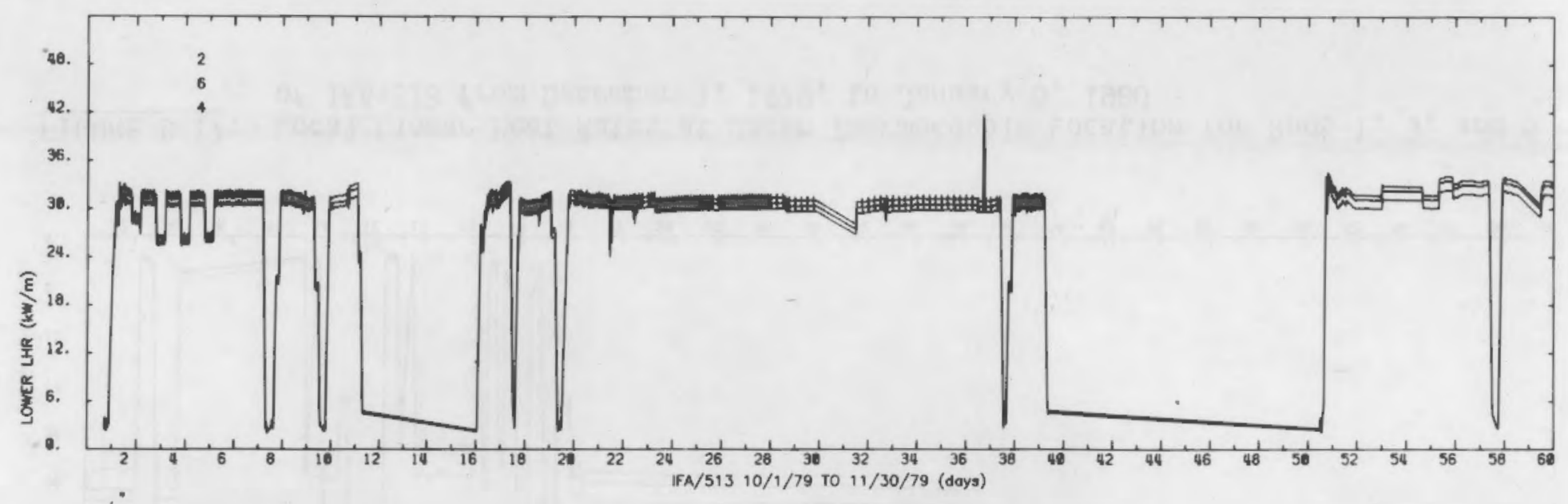

FIGURE 0.16. Local Linear Heat Rates at Lower Thermocouple Location for Rods 2, 4, and 6 of IFA-513 from October 1, 1979, to November 30, 1979 


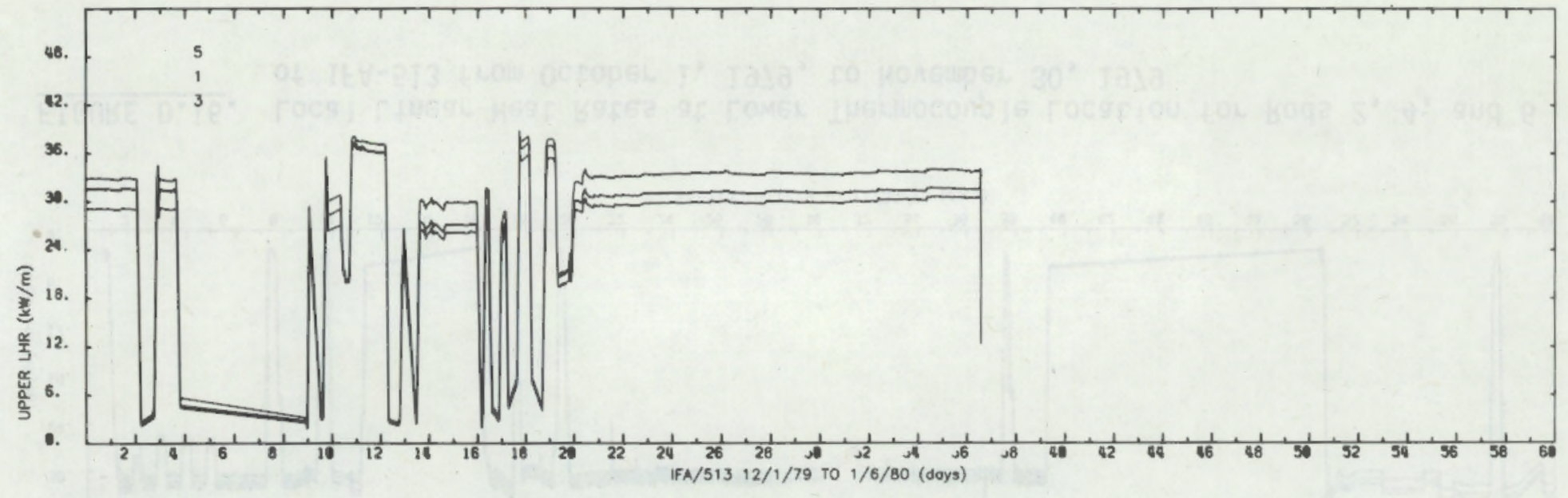

FIGURE 0.17. Local Linear Heat Rates at Upper Thermocouple Location for Rods 1, 3, and 5 of IFA-513 from December 1, 1979, to January 6, 1980

i

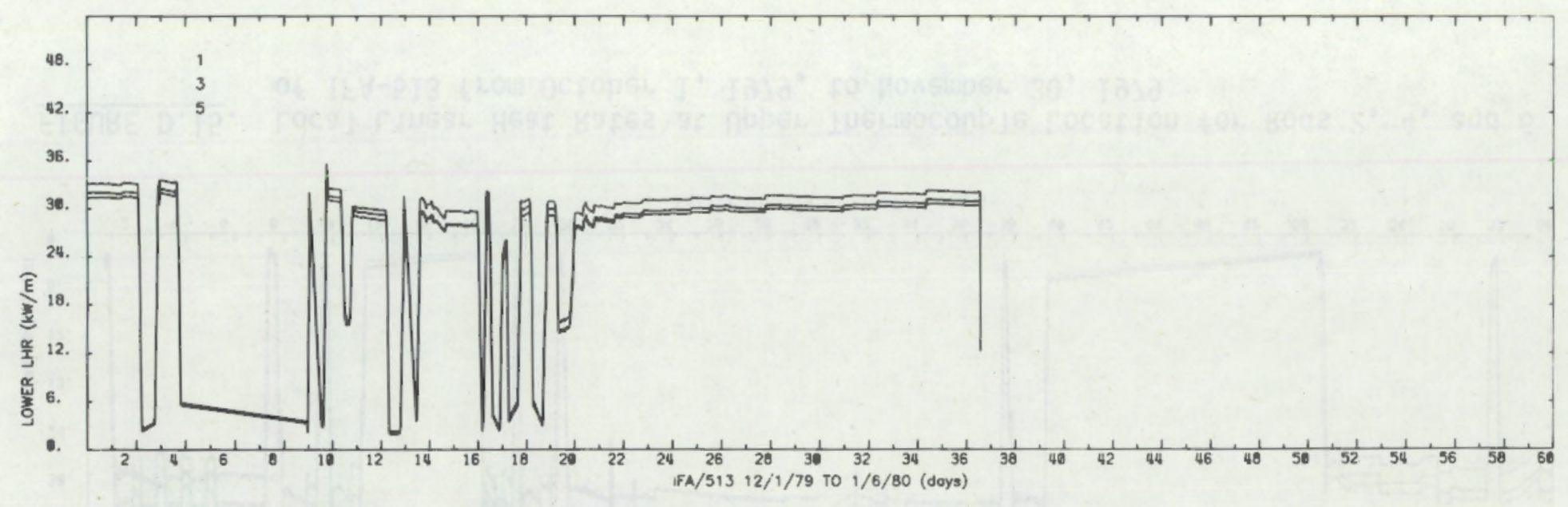

FIGURE D.18. Local Linear Heat Rates at Lower Thermocouple Location for Rods 1, 3, and 5 of IFA-513 from December 1, 1979, to January 6, 1980 


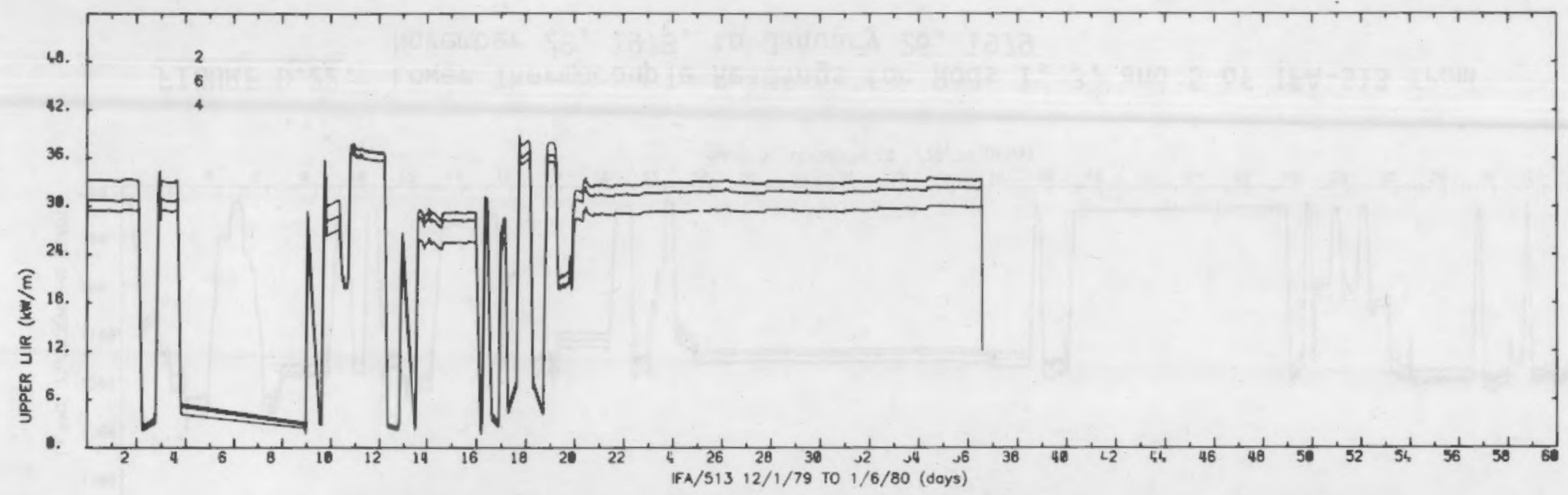

FIGURE 0.19. Local Linear Heat Rates at Upper Thermocouple Location for Rods 2, 4 , and 6 of IFA-513 from December 1, 1979, to January 6, 1980

号

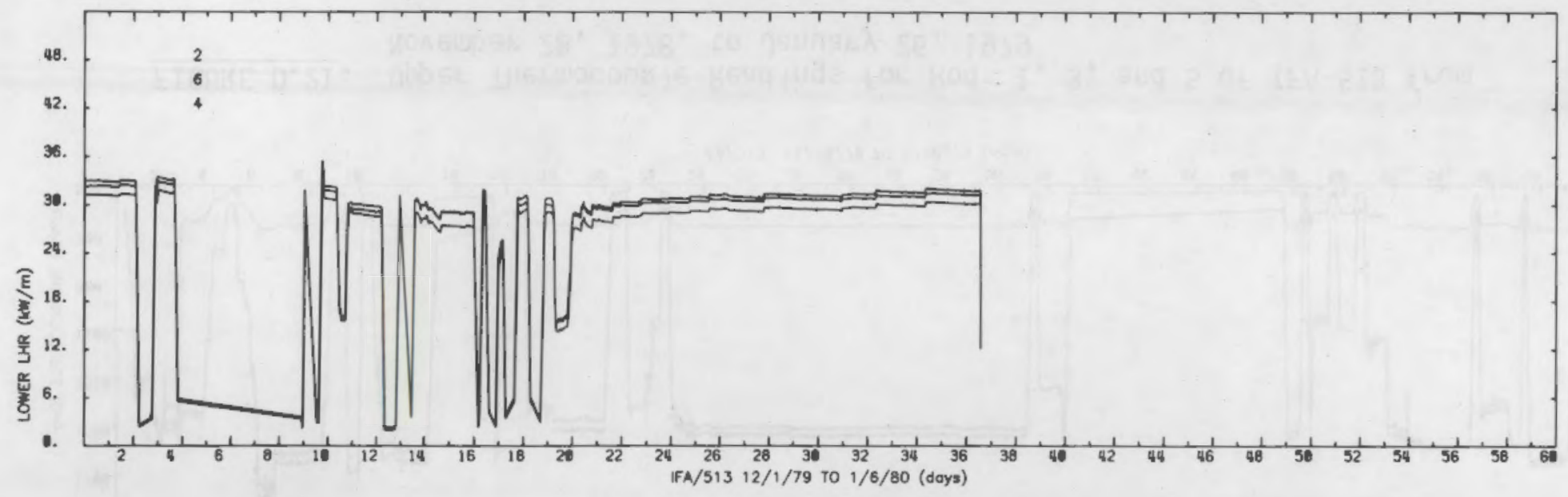

FIGURE 0.20. Local Linear Heat Rates at Lower Thermocouple Location for Rods 2, 4, and 6 of IFA-513 from December 1, 1979, to January 6, 1980 


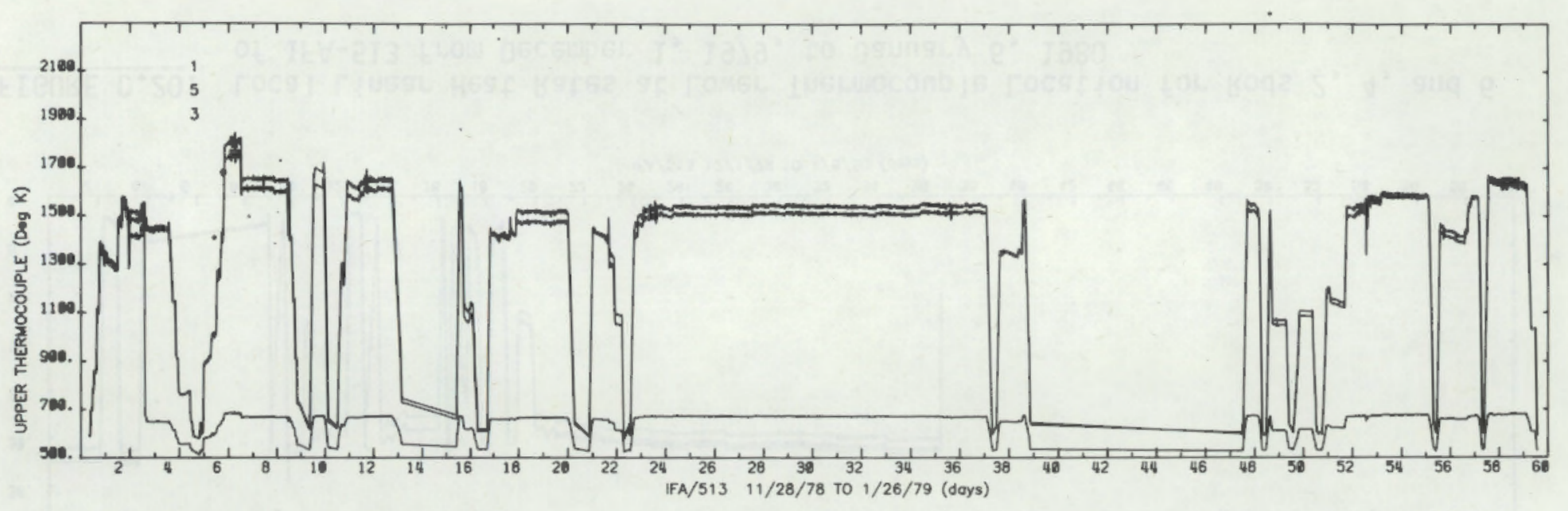

FIGURE 0.21 . Upper Thermocouple Readings for Rods 1,3 , and 5 of IFA-513 from November 28, 1978, to January 26, 1979

$\stackrel{D}{\stackrel{D}{N}}$

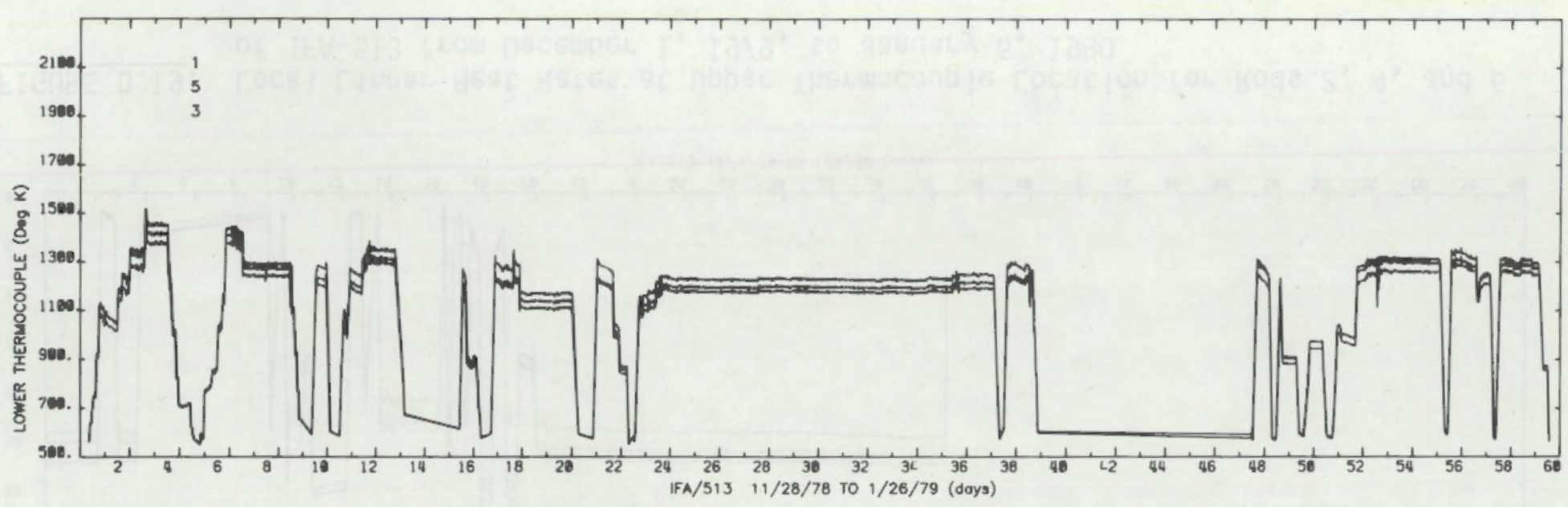

FIGURE 0.22 . Lower Thermocoup le Readings for Rods 1,3 , and 5 of IFA-513 from November 28, 1978, to January 26, 1979 


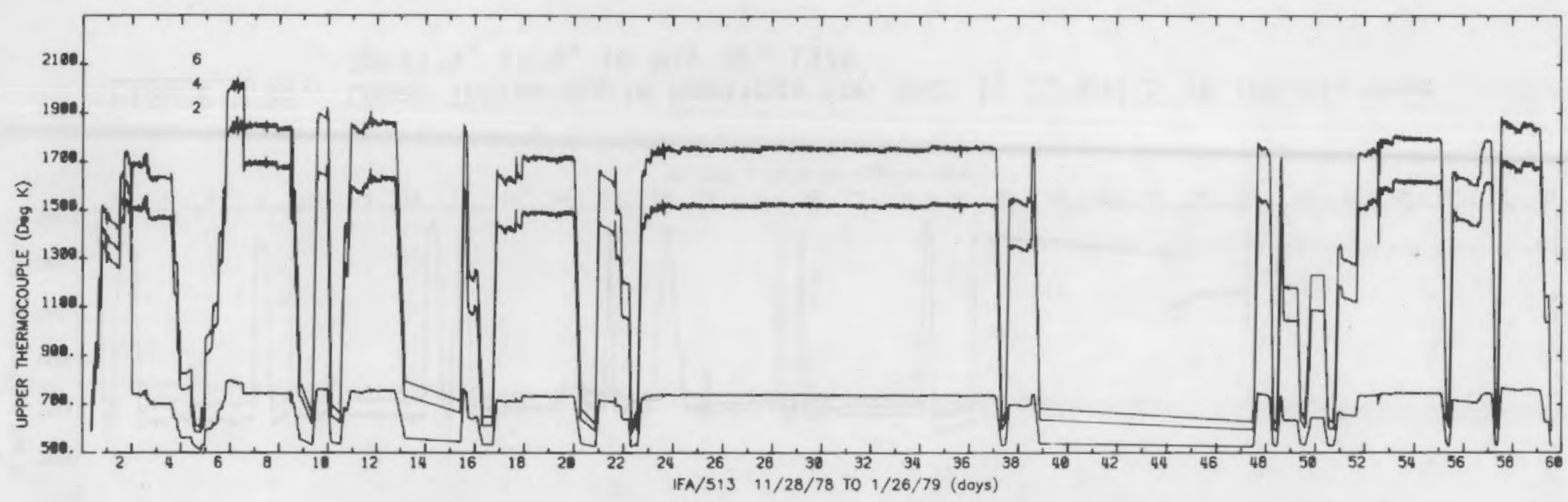

FIGURE D.23. Upper Thermocouple Readings for Rods 2, 4, and 6 of IFA-513 from November 28, 1978, to January 26, 1979

$\stackrel{\circ}{i}$

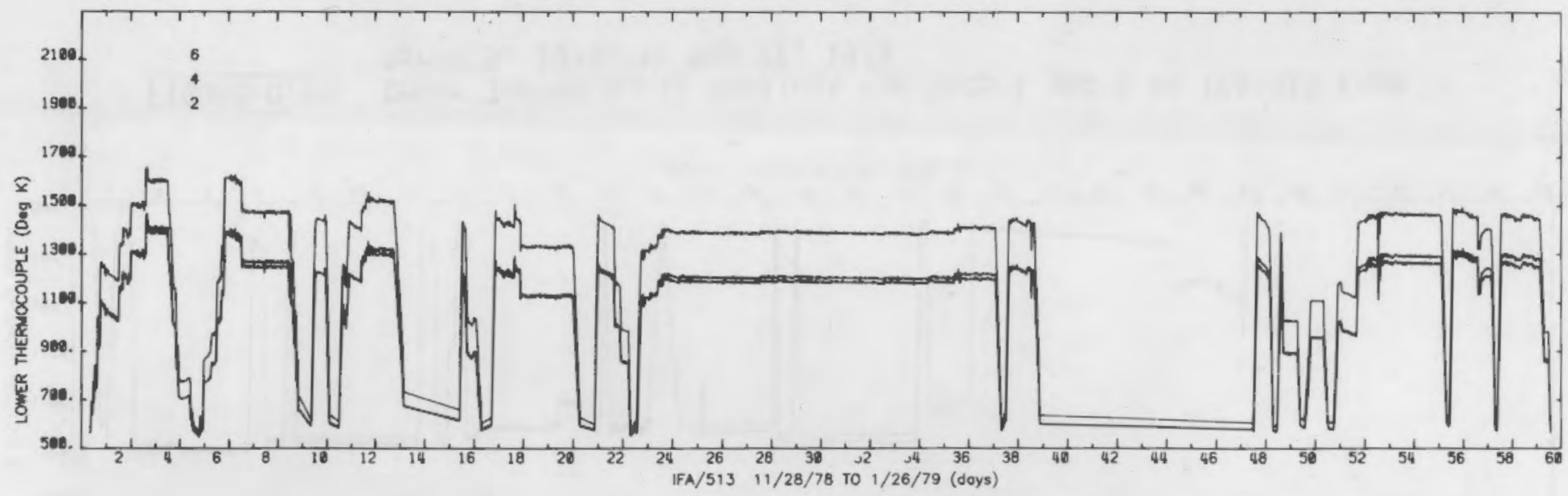

FIGURE 0.24 . Lower Thermocouple Readings for Rods 2, 4, and 6 of IFA-513 from November 28, 1978, to January 26, 1979 


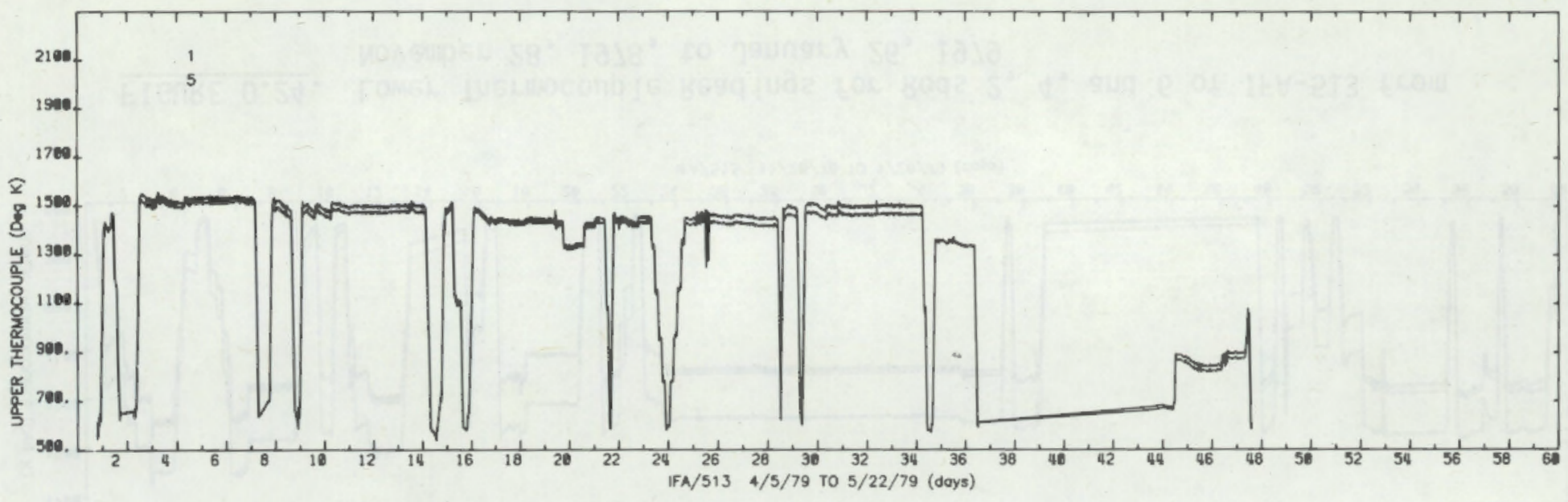

FIGURE 0.25 . Upper Thermocouple Readings for Rods 1 and 5 of IFA-513 from Apri] 5, 1979, to May 22, 1979

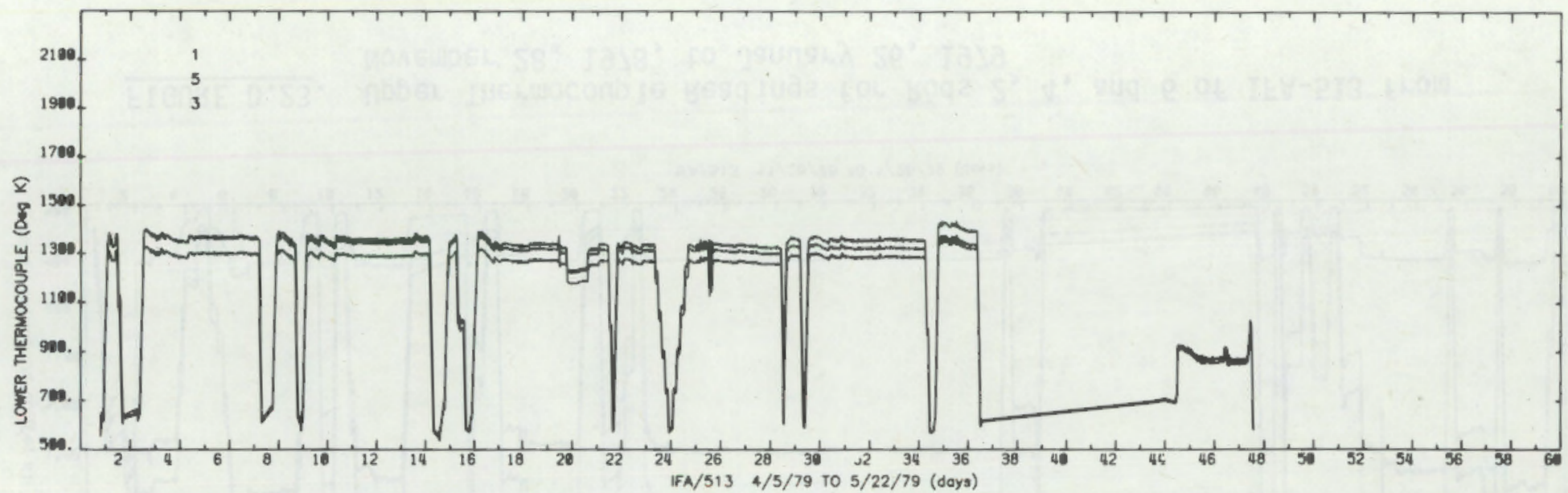

FIGURE D.26. Lower Thermocouple Readings for Rods 1, 3, and 5 of IFA-513 from April 5, 1979, to May 22, 1979 


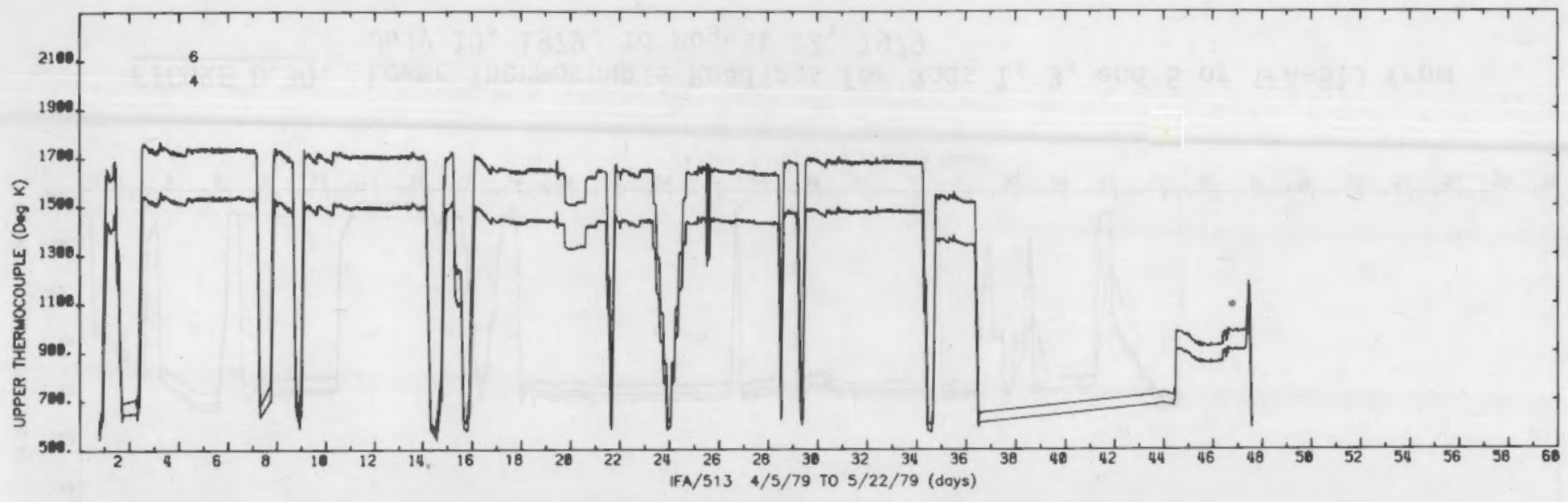

FIGURE 0.27 . Upper Thermocoup le Read ings for Rods 4 and 6 of, IFA-513 from April 5, 1979, to May 22, 1979

in

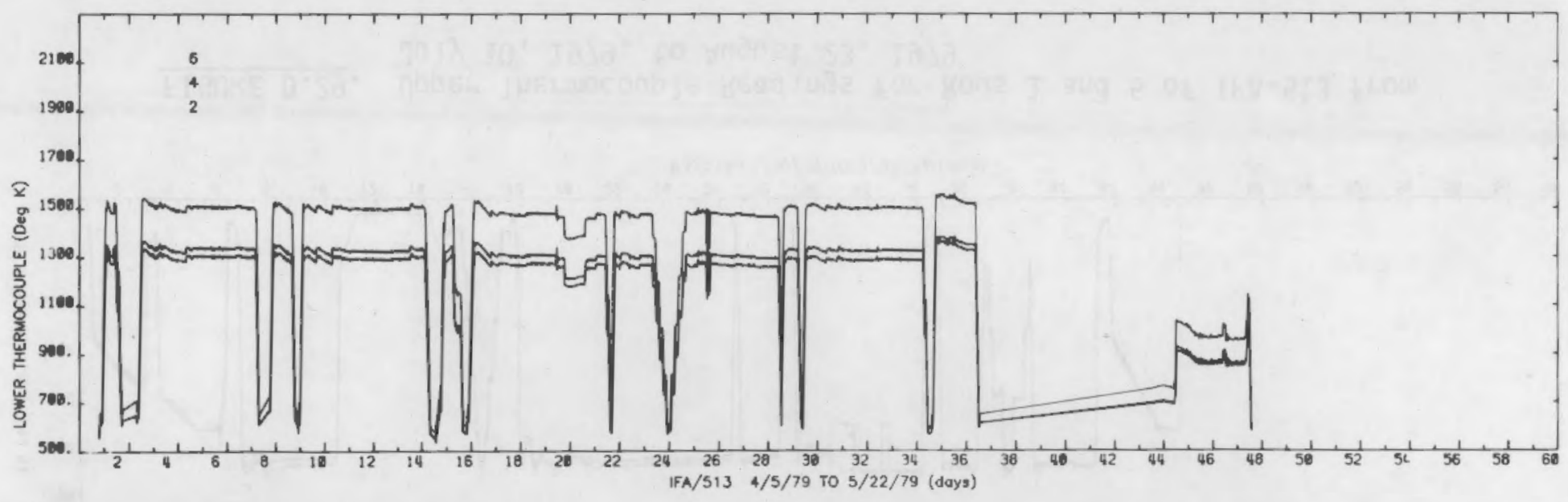

FIGURE 0.28. Lower Thermocouple Readings for Rods 2, 4, and 6 of IFA-513 from April 5, 1979, to May 22, 1979 


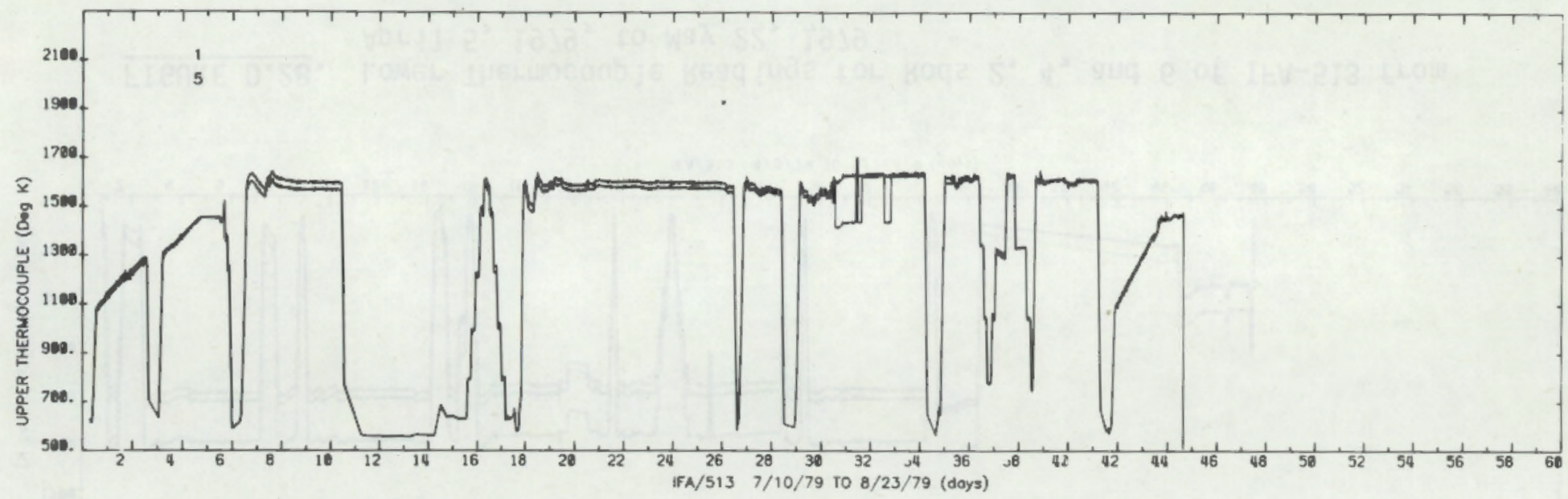

FIGURE D.29. Upper Thermocouple Readings for Rods 1 and 5 of IFA-513 from July 10, 1979, to August 23, 1979

ڤே

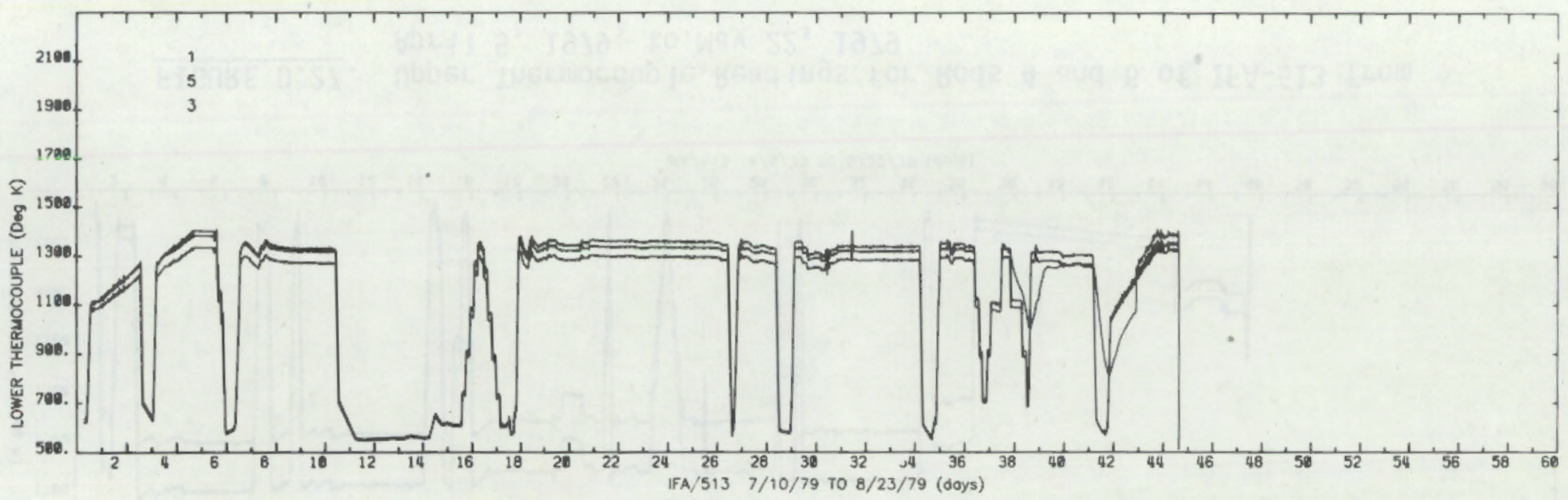

FIGURE 0.30 . Lower Thermocouple Readings for Rods 1, 3, and 5 of IFA-513 from July 10, 1979, to August 23, 1979 


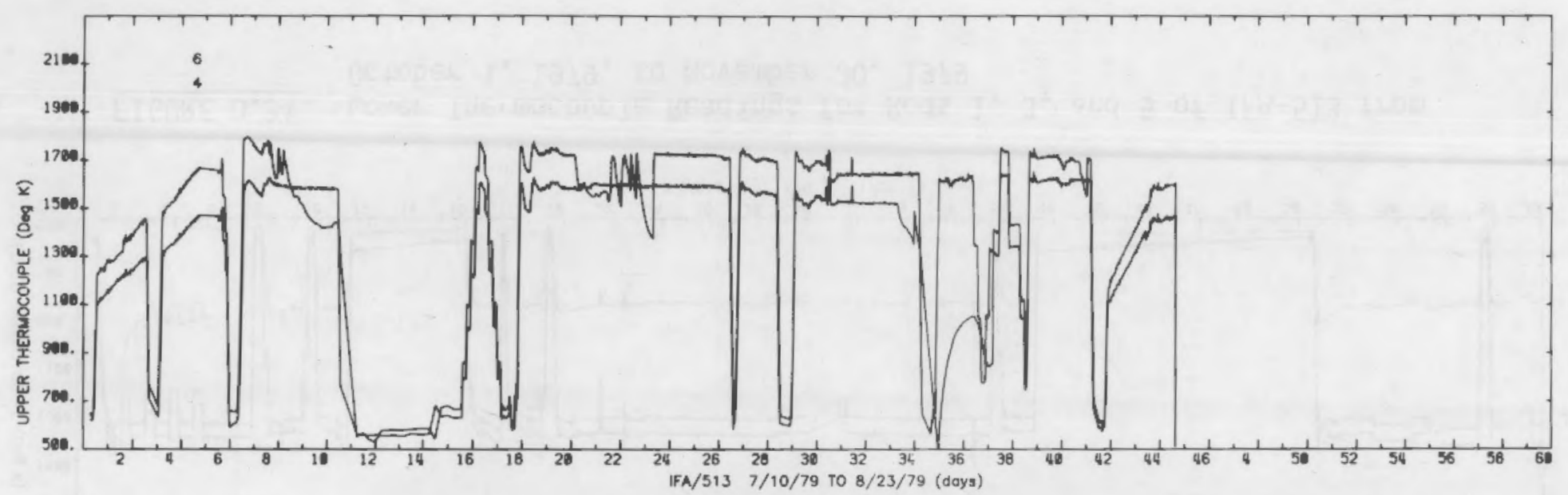

FIGURE D.31. Upper Thermocouple Readings for Rods 4 and 6 of IFA-513 from July 10, 1979, to August 23, 1979

$\stackrel{\square}{ }$

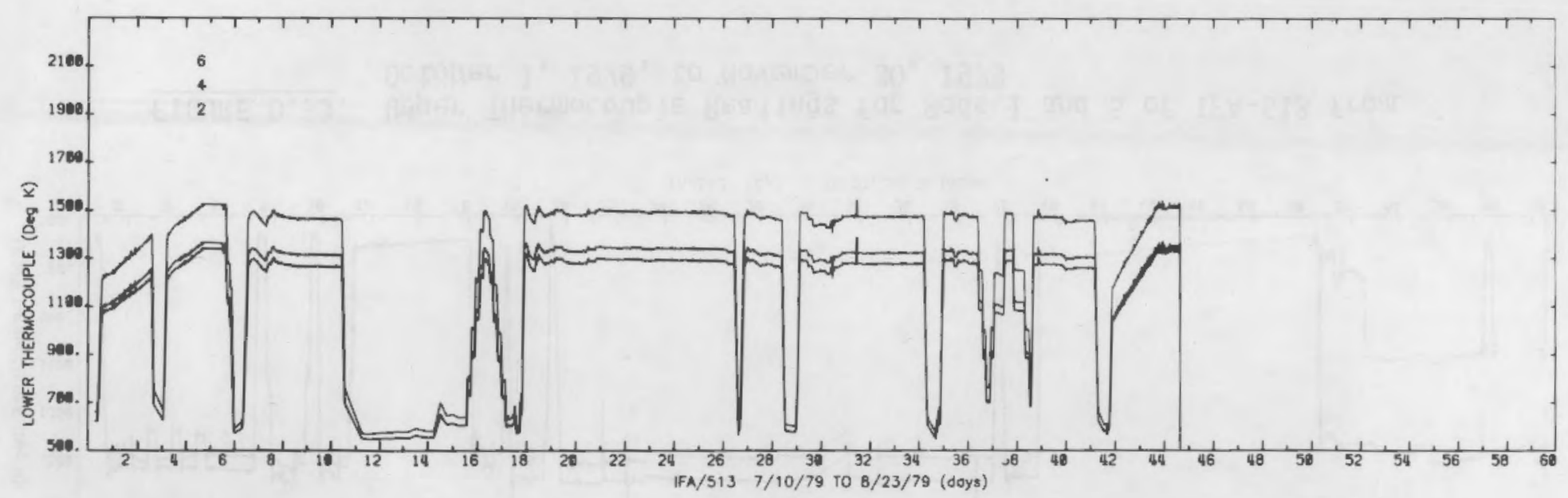

FIGURE D.32. Lower Thermocouple Readings for Rods 2, 4, and 6 of IFA-513 from July 10, 1979, to August 23, 1979 


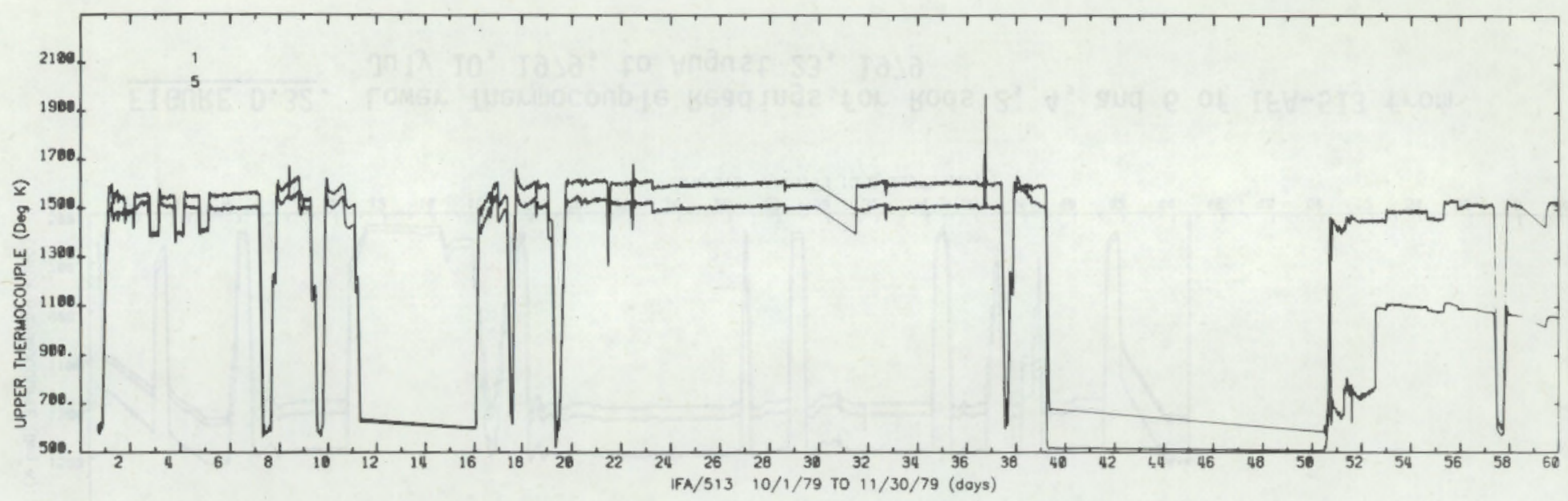

FIGURE 0.33. Upper Thermocouple Readings for Rods 1 and 5 of IFA-513 from October 1, 1979, to November 30, 1979

$\stackrel{\circ}{\infty}$

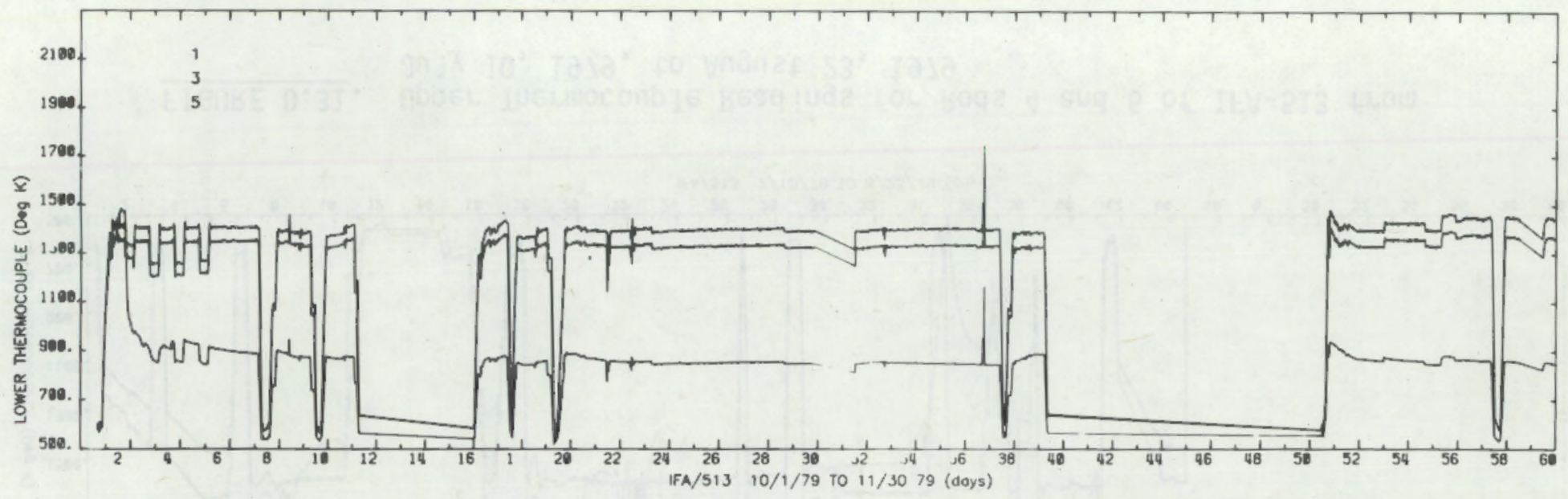

FIGURE 0.34. Lower Thermocouple Readings for Rods 1, 3, and 5 of IFA-513 from October 1, 1979, to November 30, 1979 


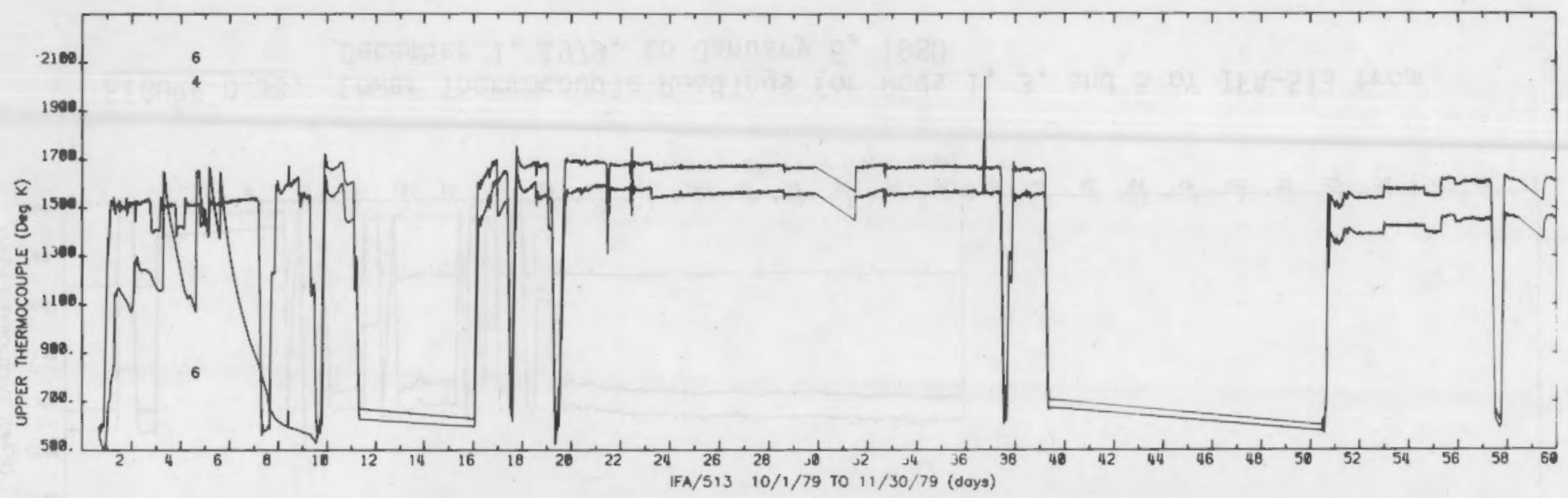

FIGURE D.35. Upper Thermocouple Read ings for Rods 4 and 6 of IFA-513 from October 1, 1979, to November 30,1979

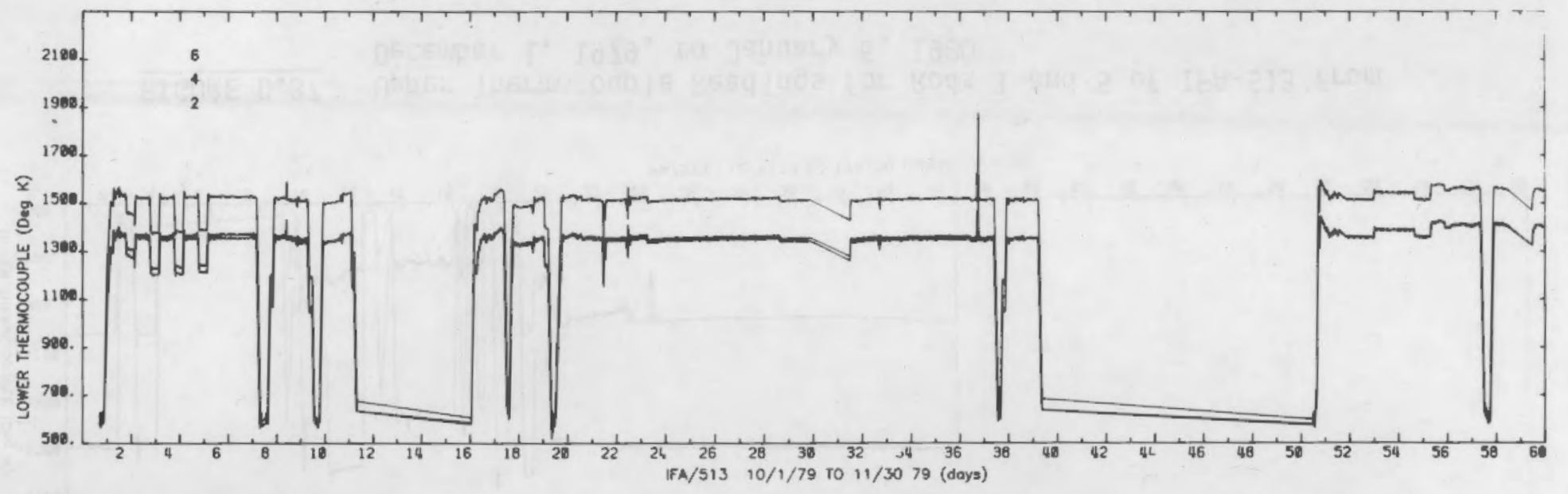

FIGURE 0.36 . Lower Thermocouple Readings for Rods 2, 4, and 6 of IFA-513 from October 1, 1979, to November 30, 1979 


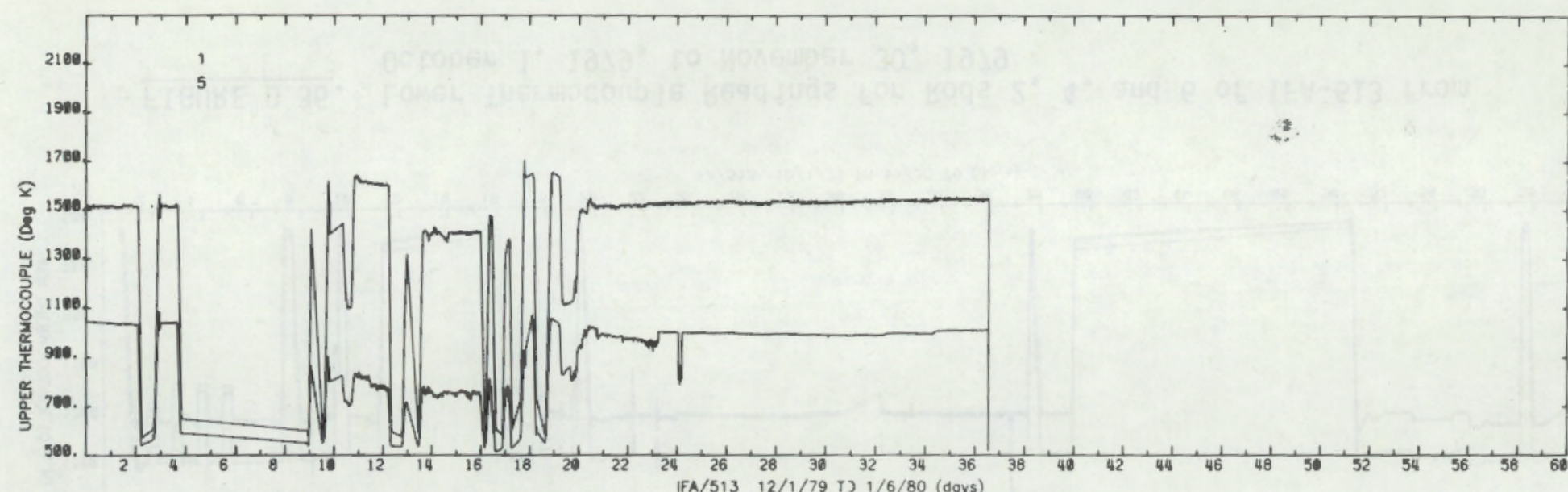

FIGURE 0.37. Upper Thermocouple Readings for Rods 1 and 5 of IFA-513 from December 1, 1979, to January 6, 1980

in

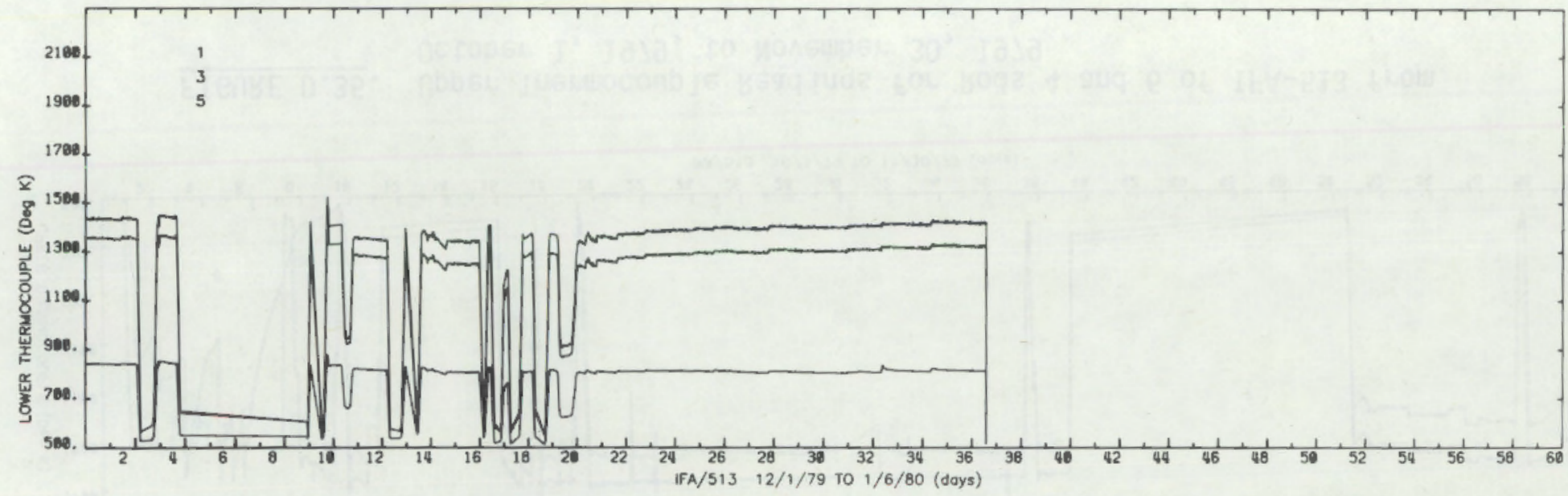

FIGURE D.38. Lower Thermocouple Readings for Rods 1, 3, and 5 of IFA-513 from December 1, 1979, to January 6, 1980 


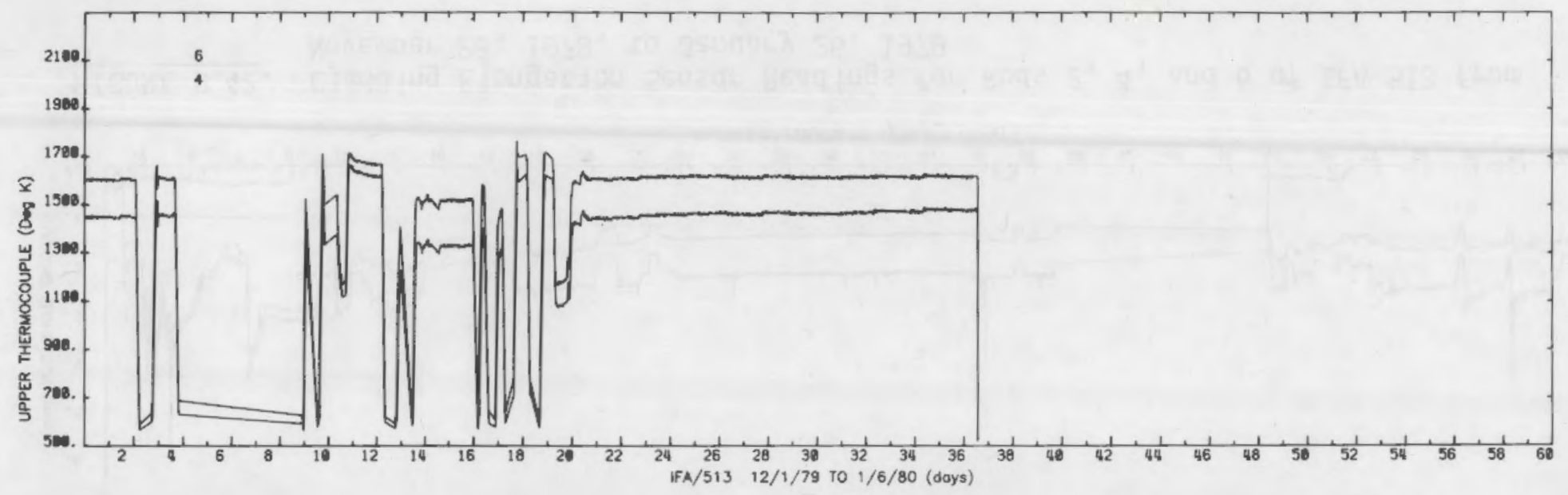

FIGURE D.39. Upper Thermocouple Readings for Rods 4 and 6 of IFA-513 from December 1, 1979, to January 6, 1980

$\stackrel{\square}{\sim}$

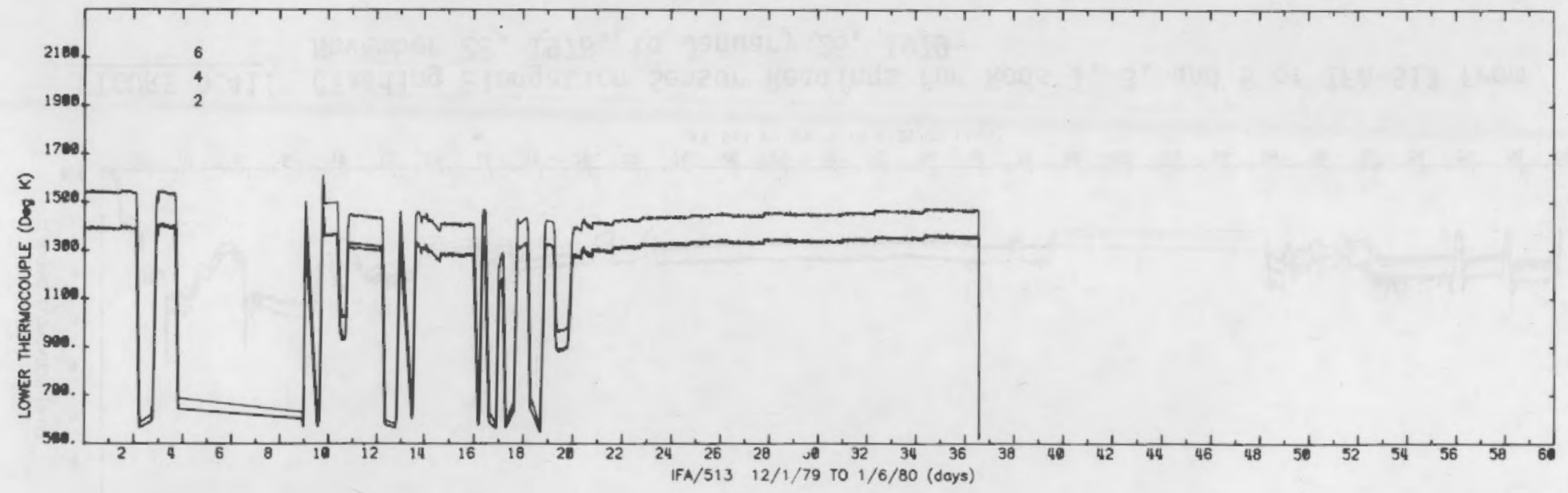

FIGURE 0.40 . Lower Thermocouple Readings for Rods 2, 4, and 6 of IFA-513 from December 1, 1979, to January 6, 1980 


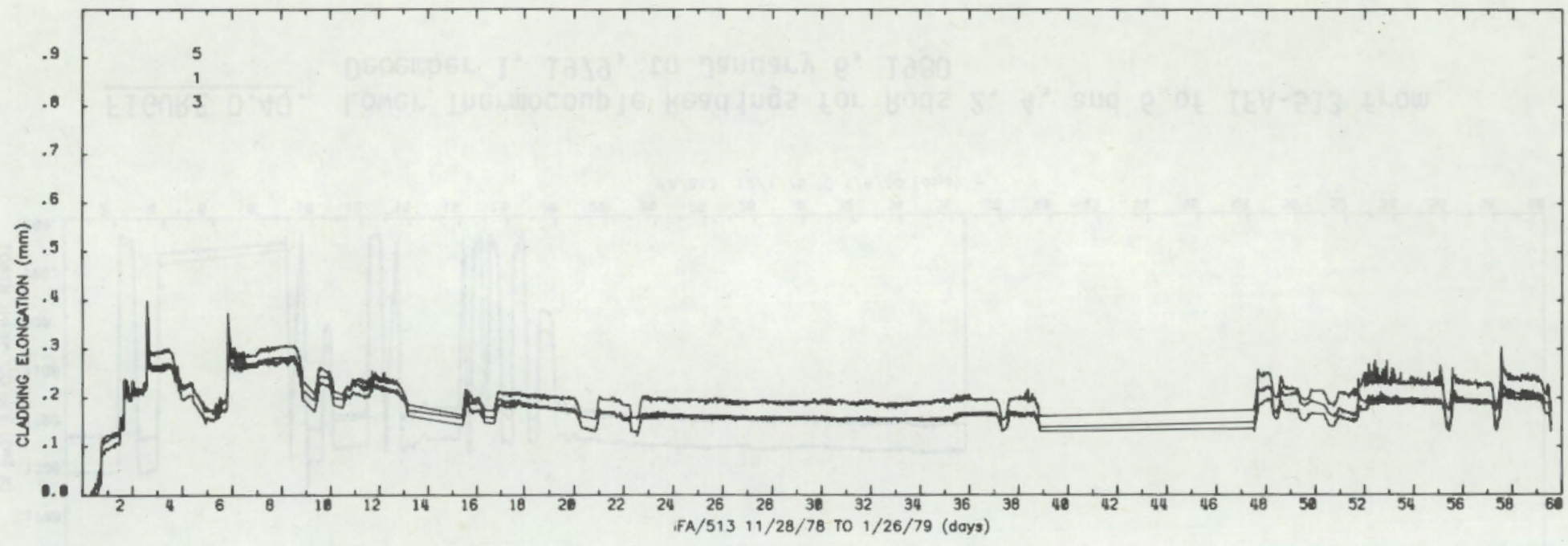

FIGURE D.41. Cladding Elangation Sensor Readings for Rods 1, 3, and 5 of IFA-513 from November 28, 1978, to January 26, 1979

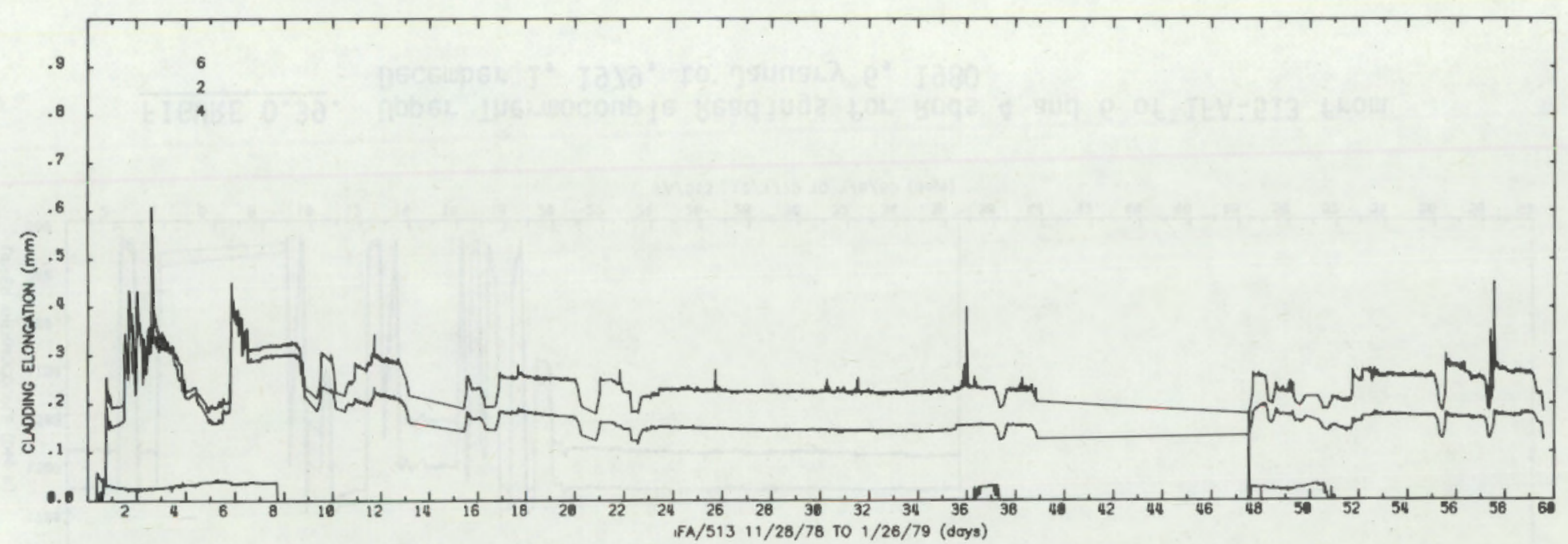

FIGURE 0.42. Cladding Elongation Sensor Readings for Rods 2, 4, and 6 of IFA-513 from November 28, 1978, to January 26, 1979 


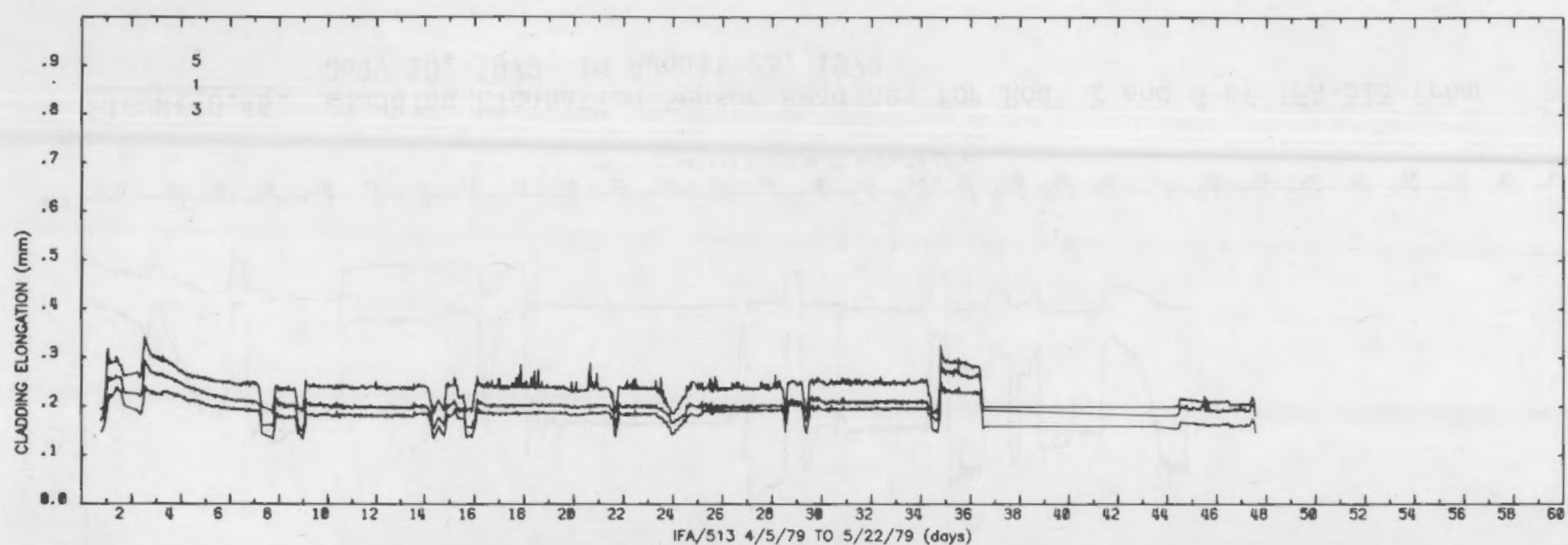

FIGURE 0.43 . Cladding Elongation Sensor Readings for Rods 1, 3, and 5 of IFA-513 from April 5, 1979, to May 22, 1979

$\stackrel{\square}{\omega}$

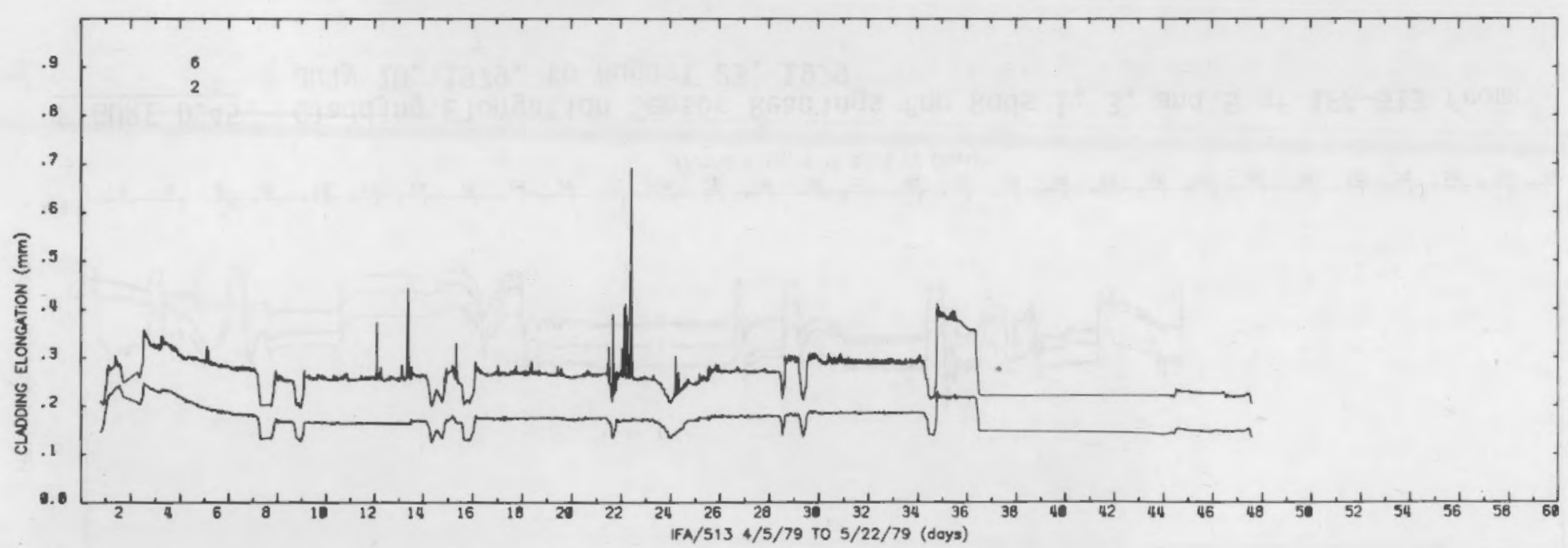

FIGURE 0.44. Cladding Elongation Sensor Readings for Rods 2 and 6 of IFA-513 from April 5, 1979, to May 22, 1979 


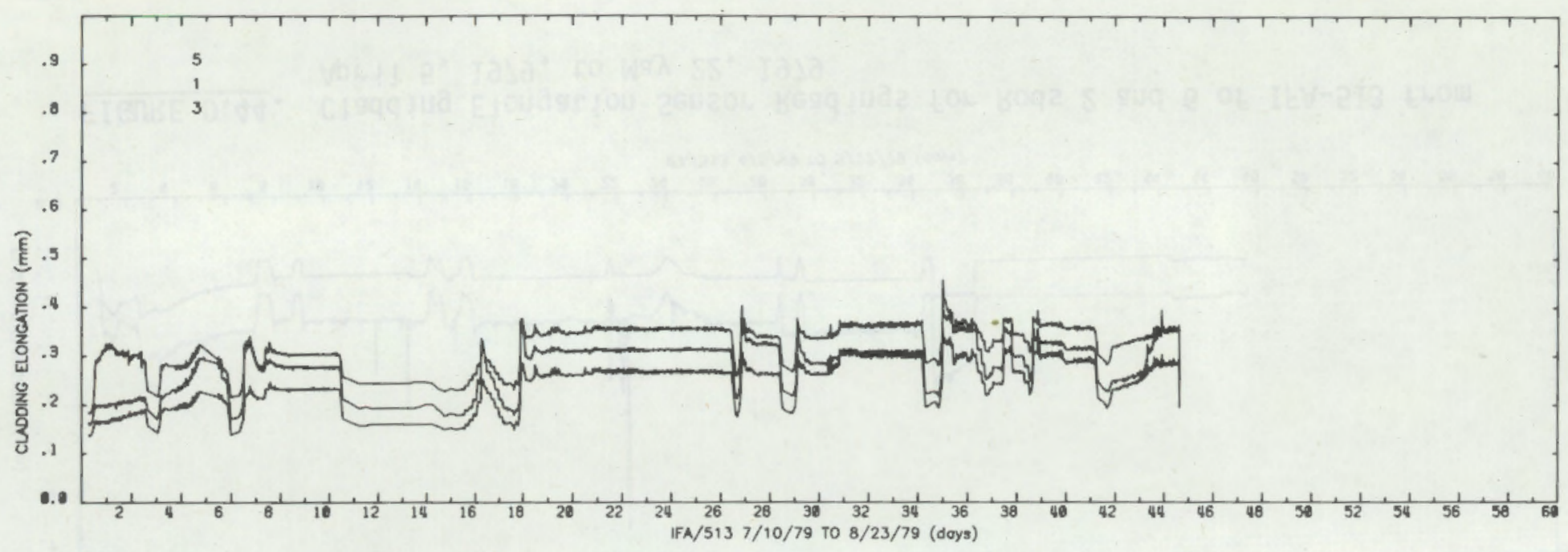

FIGURE 0.45 . Cladding Elongation Sensor Readings for Rods 1, 3, and 5 of IFA-513 from July 10, 1979, to August 23, 1979

$\stackrel{\square}{\rightarrow}$

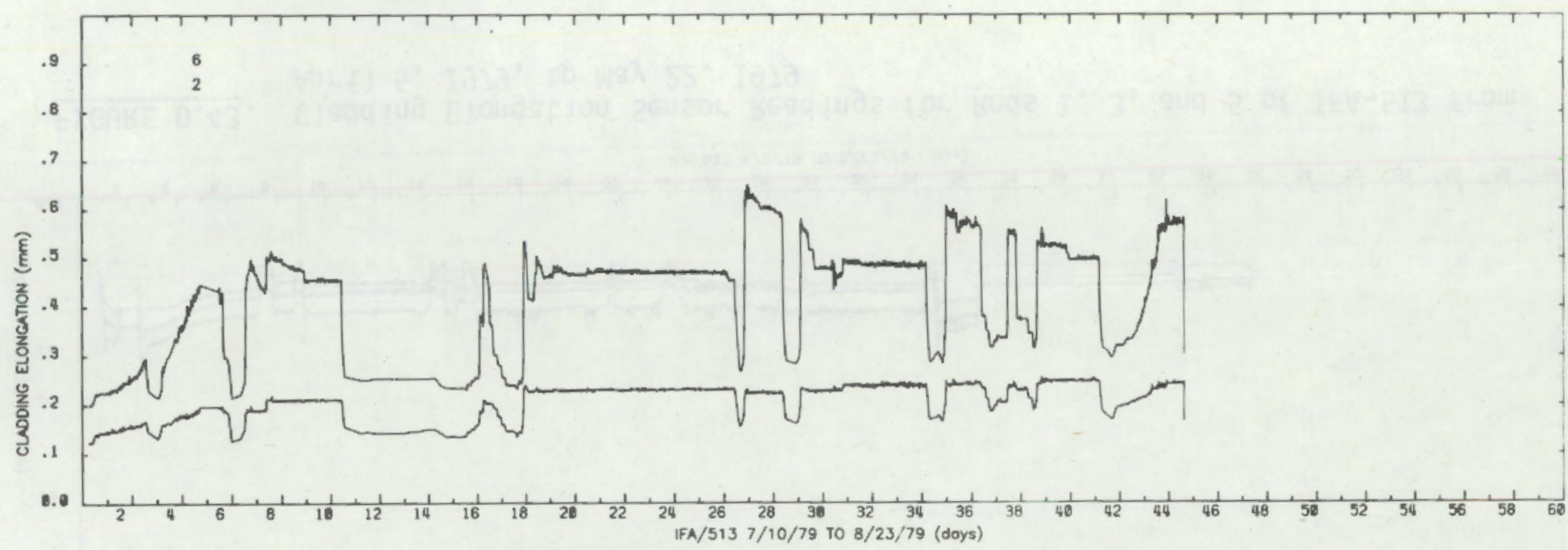

FIGURE D.46. Cladding Elongation Sensor Readings for Rods 2 and 6 of IFA-513 from Ju Ty 10, 1979, to August 23, 1979 


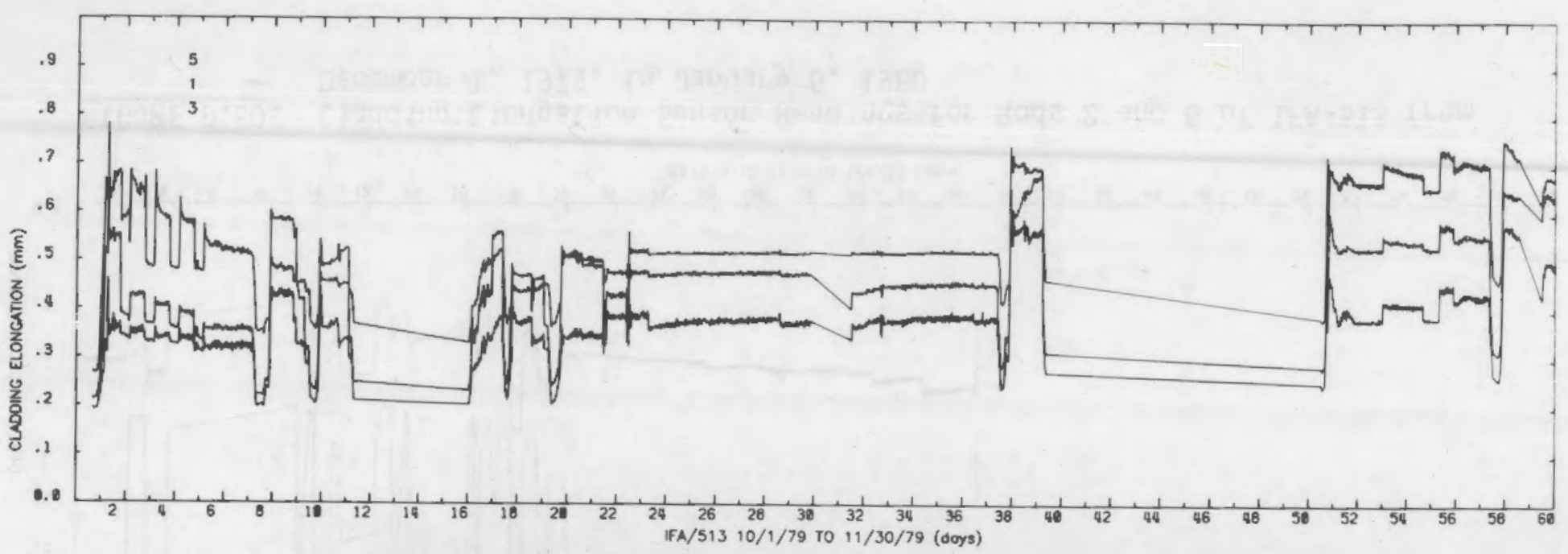

FIGURE 0.47. Cladding Elongation Sensor Readings for Rods 1, 3, and 5 of IFA-513 from October 1, 1979, to November 30, 1979

ஸั

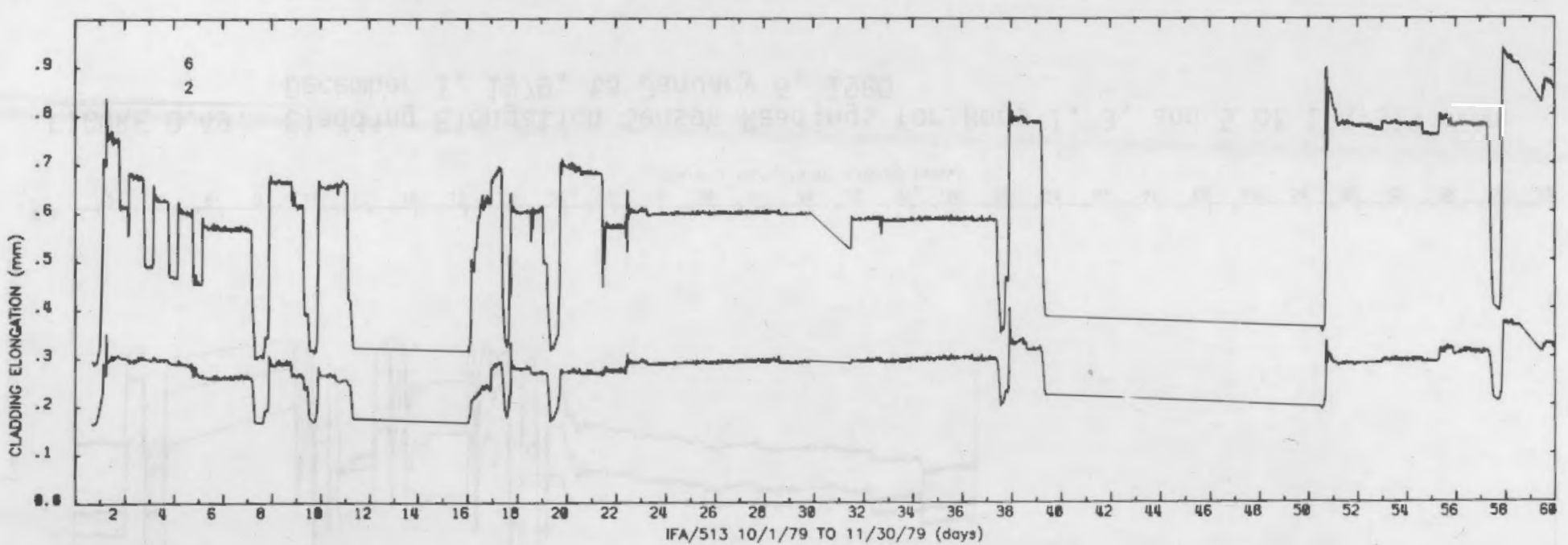

FIGURE D.48. Cladding Elongation Sensor Readings for Rods 2 and 6 of IFA-513 from October 1, 1979, to November 30, 1979 


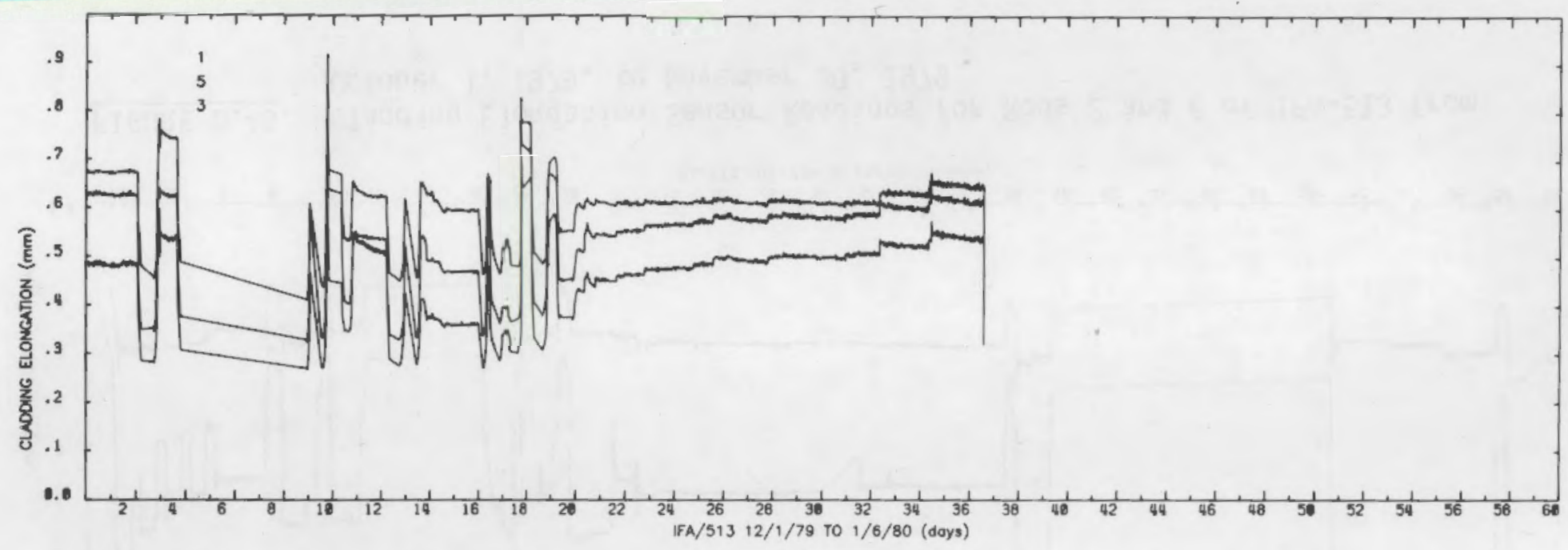

FIGURE 0.49. Cladding Elongation Sensor Readings for Rods 1, 3, and 5 of IFA-513 from December 1, 1979, to January 6, 1980

in

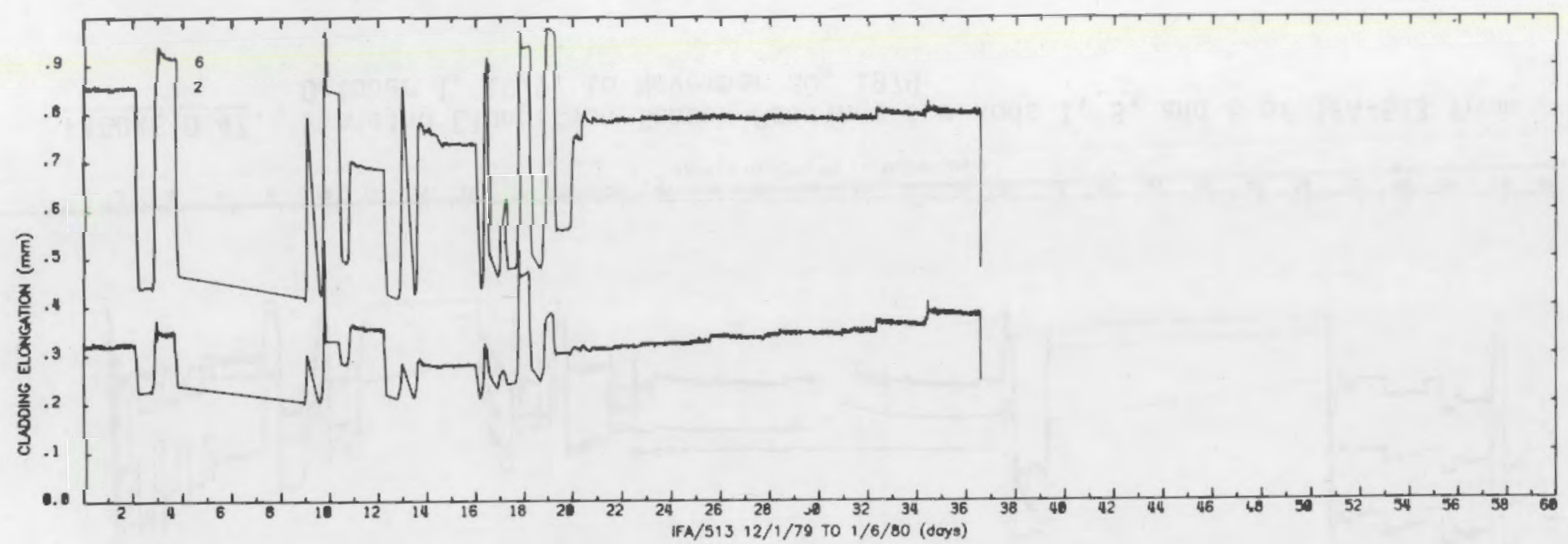

FIGURE 0.50. Cladding Elongation Sensor Readings for Rods 2 and 6 of IFA-513 from December 1, 1979, to January 6, 1980 


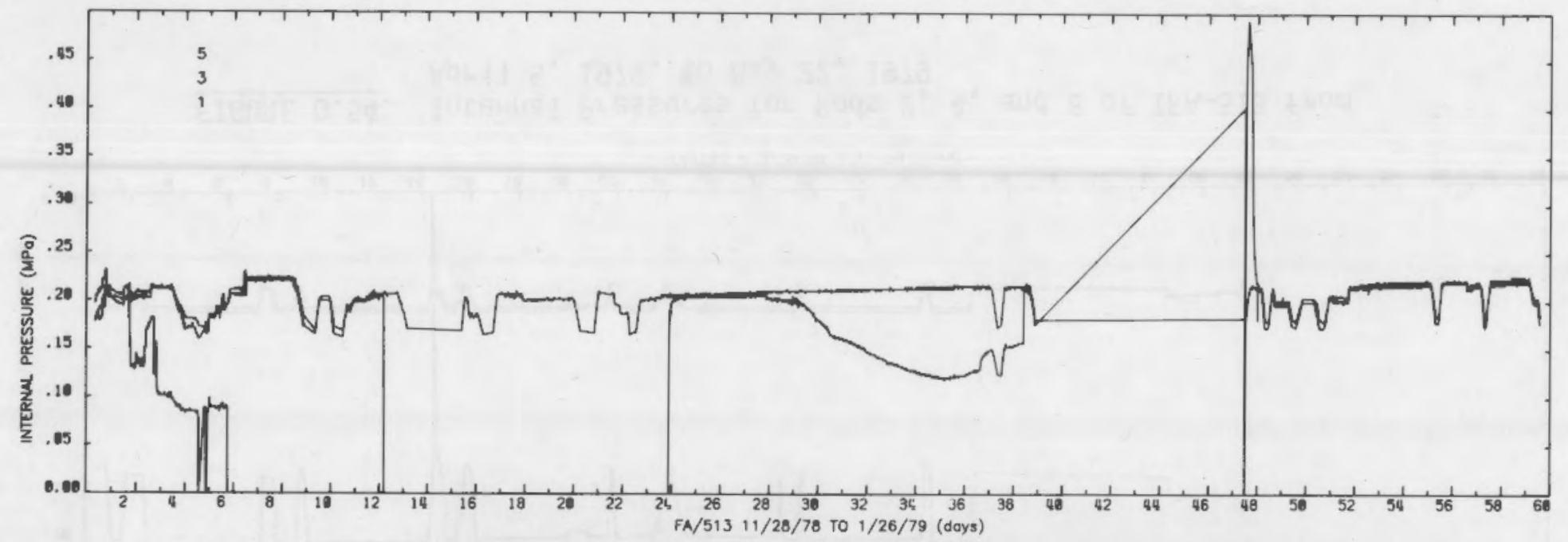

FIGURE 0.51 . Internal Pressures for Rods 1, 3, and 5 of IFA-513 from November 28, 1978, to January 26, 1979

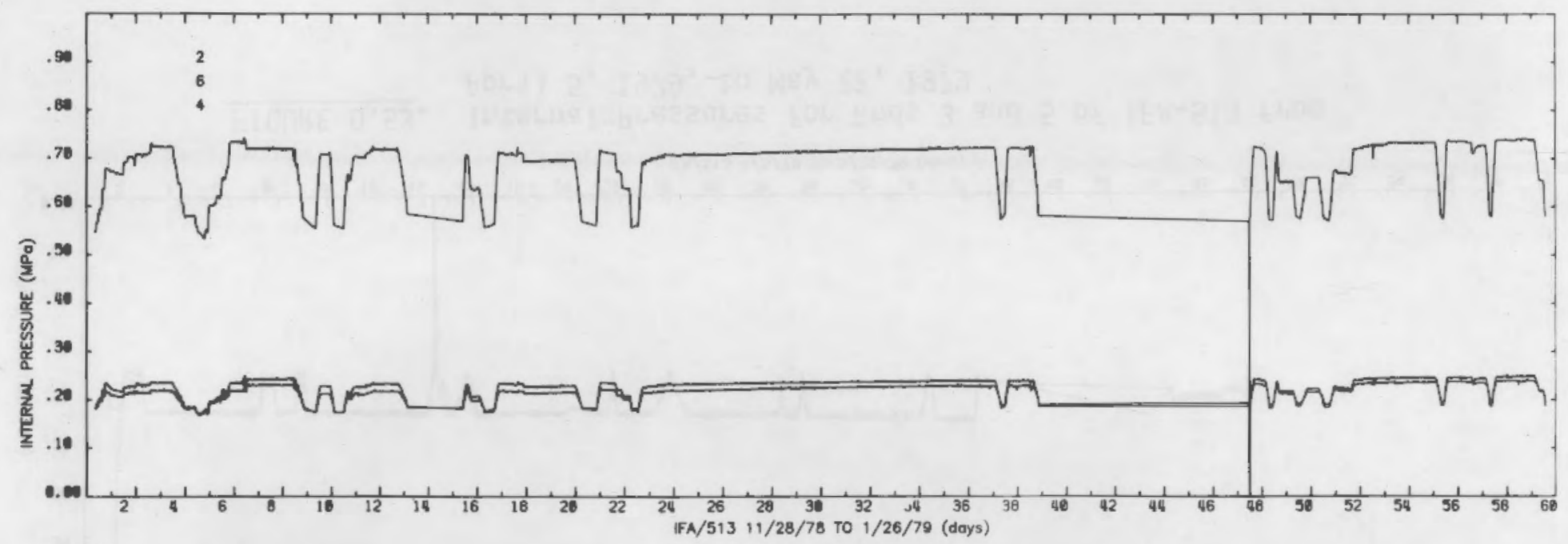

FIGURE D.52. Internal Pressures for Rods 2, 4, and 6 of IFA-513 from November 28, 1978, to January 26, 1979 


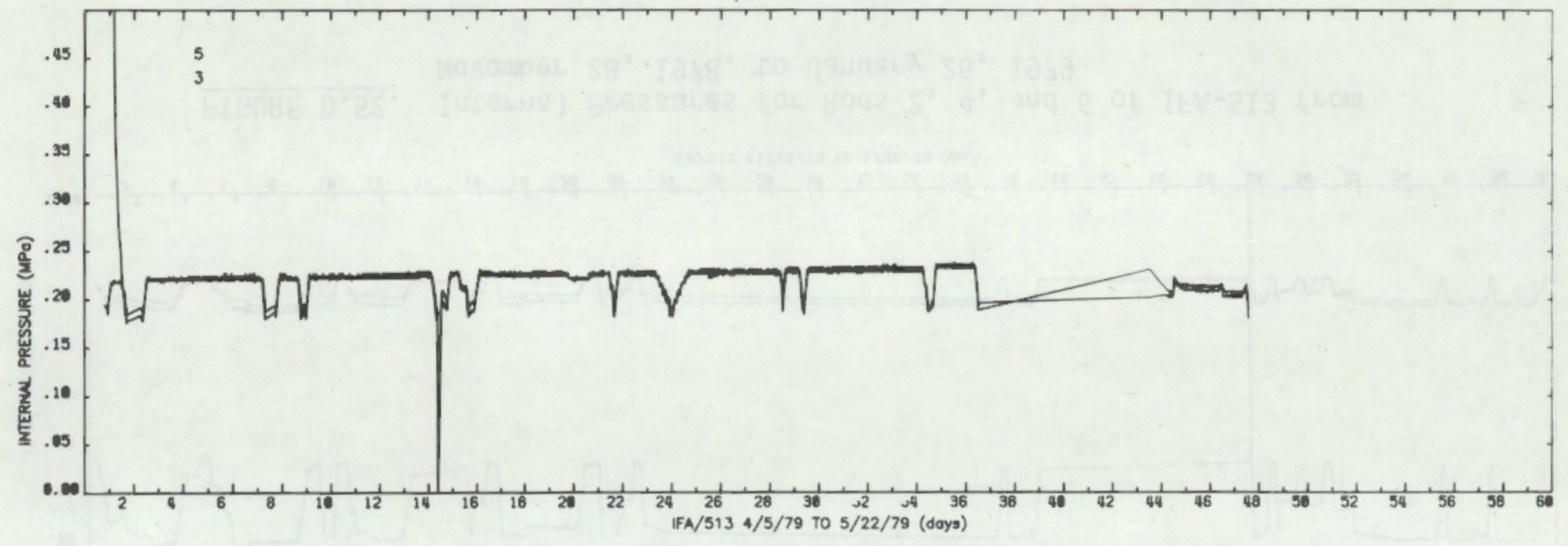

FIGURE 0.53. Internal Pressures for Rods 3 and 5 of IFA-513 from April 5, 1979, to May 22, 1979

$\stackrel{\infty}{\infty}^{\circ}$

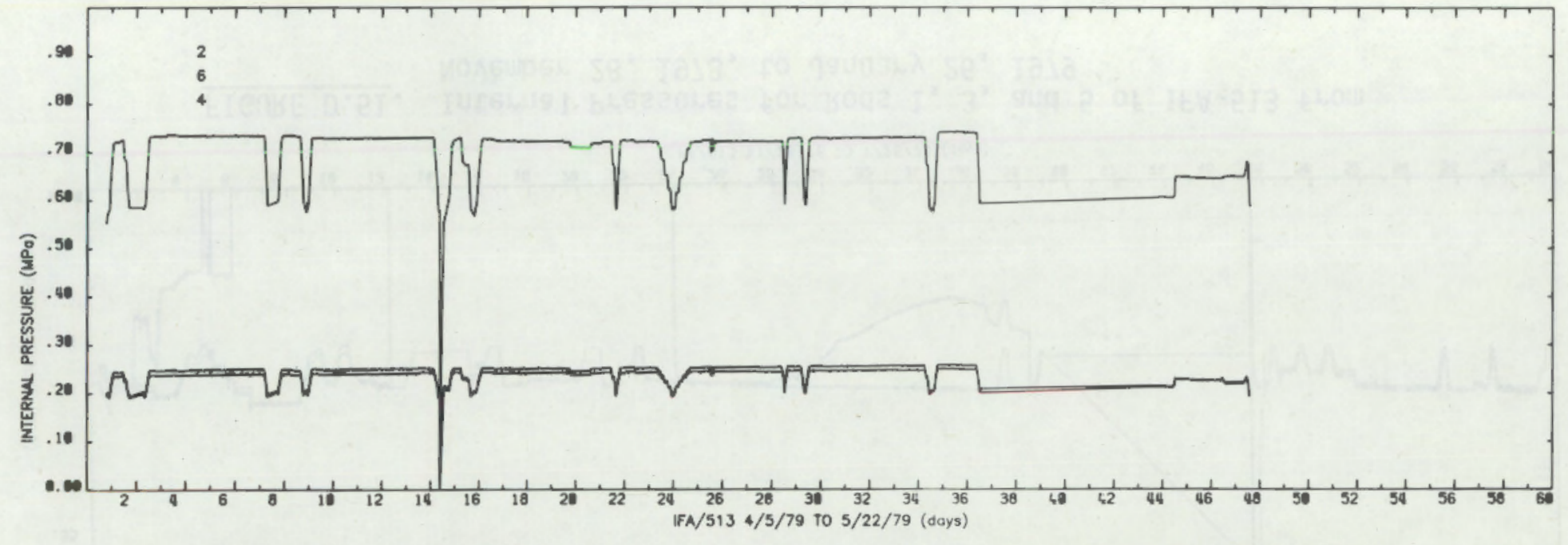

FIGURE 0.54. Internal Pressures for Rods 2, 4, and 6 of IFA-513 from Apri1 5, 1979, to May 22, 1979 


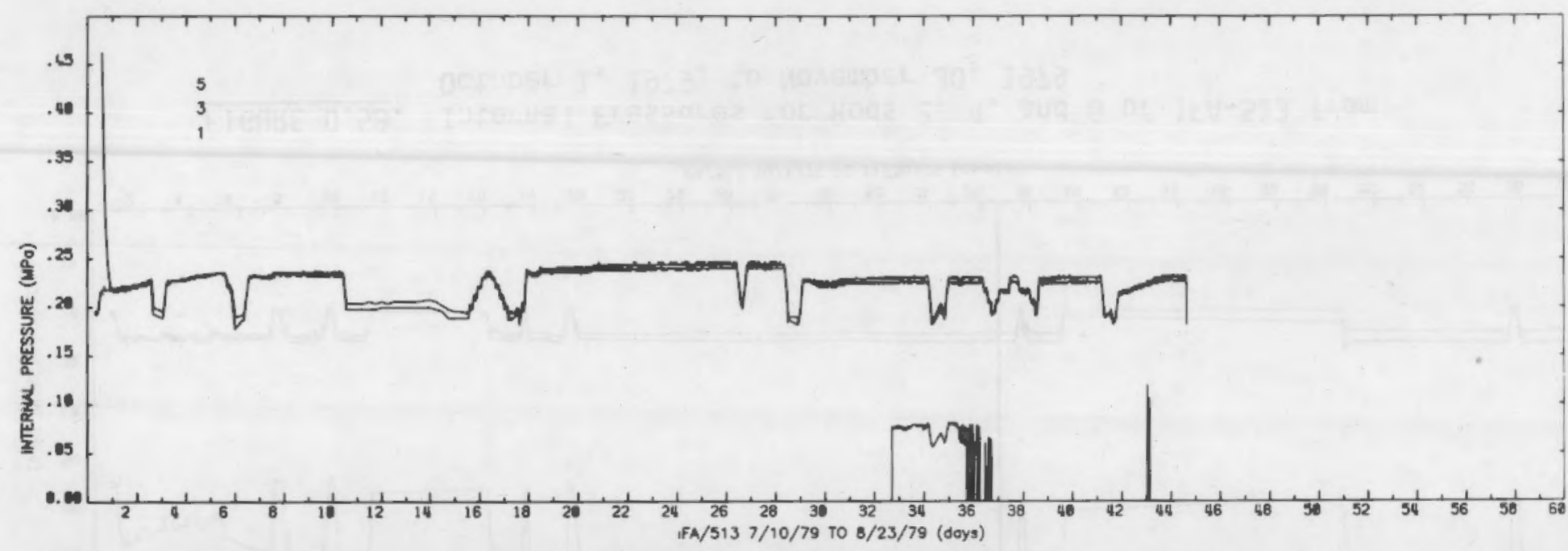

FIGURE 0.55 . Internal Pressures for Rods 1,3 , and 5 of IFA-513 from July 10, 1979, to August 23, 1979

$\stackrel{\bullet}{\text { iู }}$

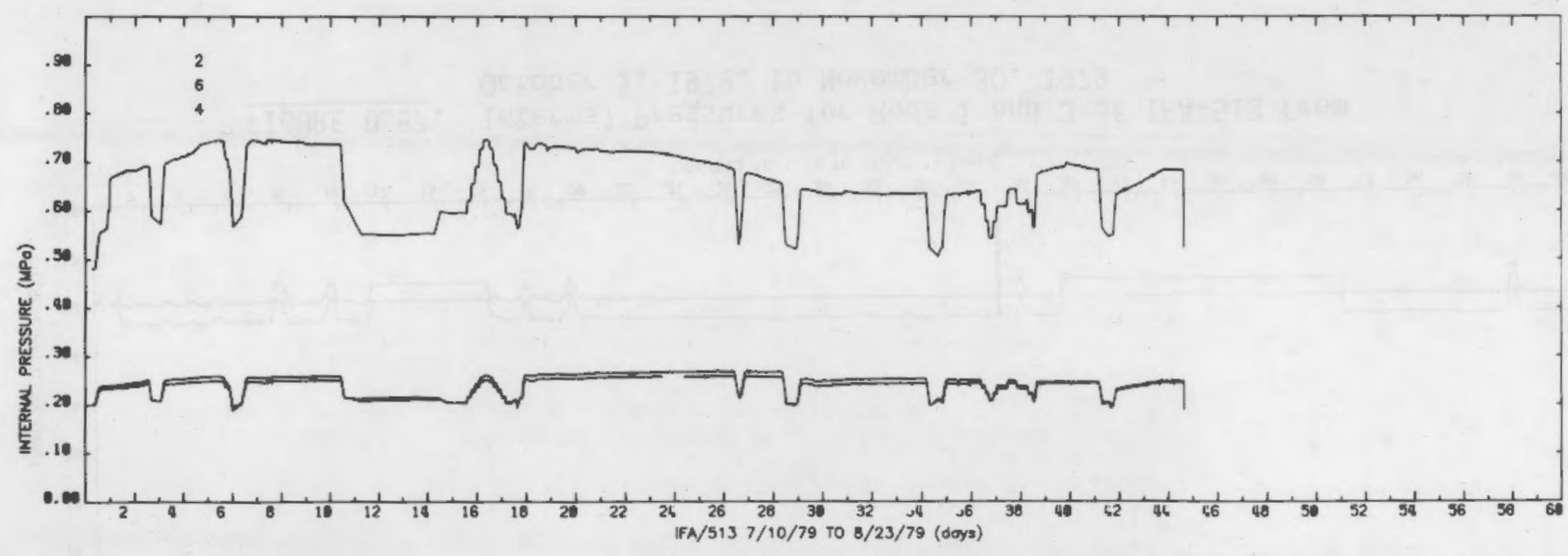

FIGURE D.56. Internal Pressures for Rods 2, 4, and 6 of IFA-513 from July 10, 1979, to August 23, 1979 


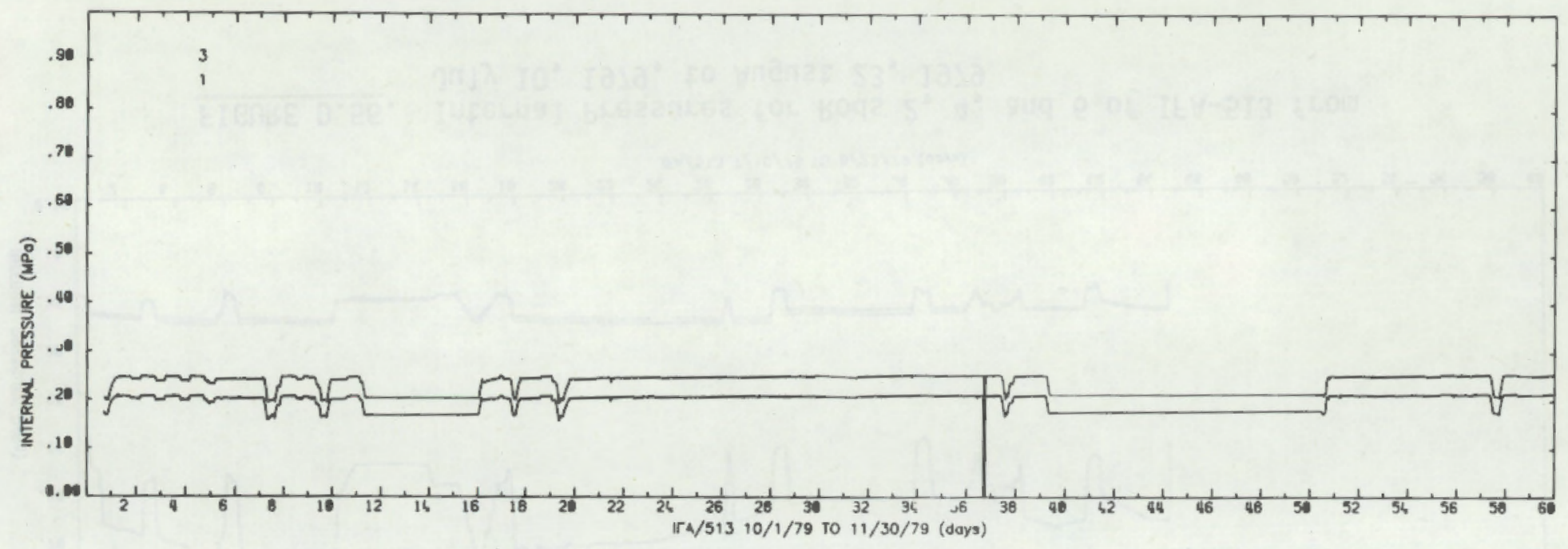

FIGURE 0.57. Internal Pressures for Rods 1 and 3 of IFA-513 from October 1, 1979, to November 30, 1979

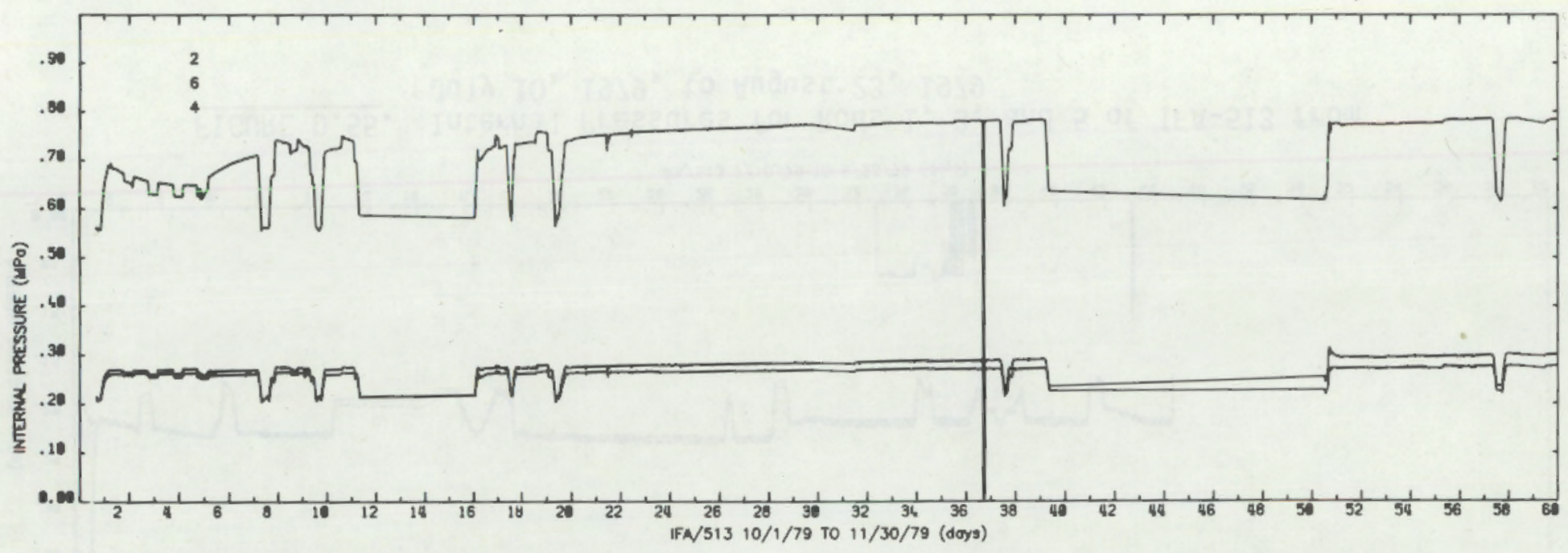

FIGURE D.58. Internal Pressures for Rods 2, 4, and 6 of IFA-513 from October 1, 1979, to November 30, 1979 


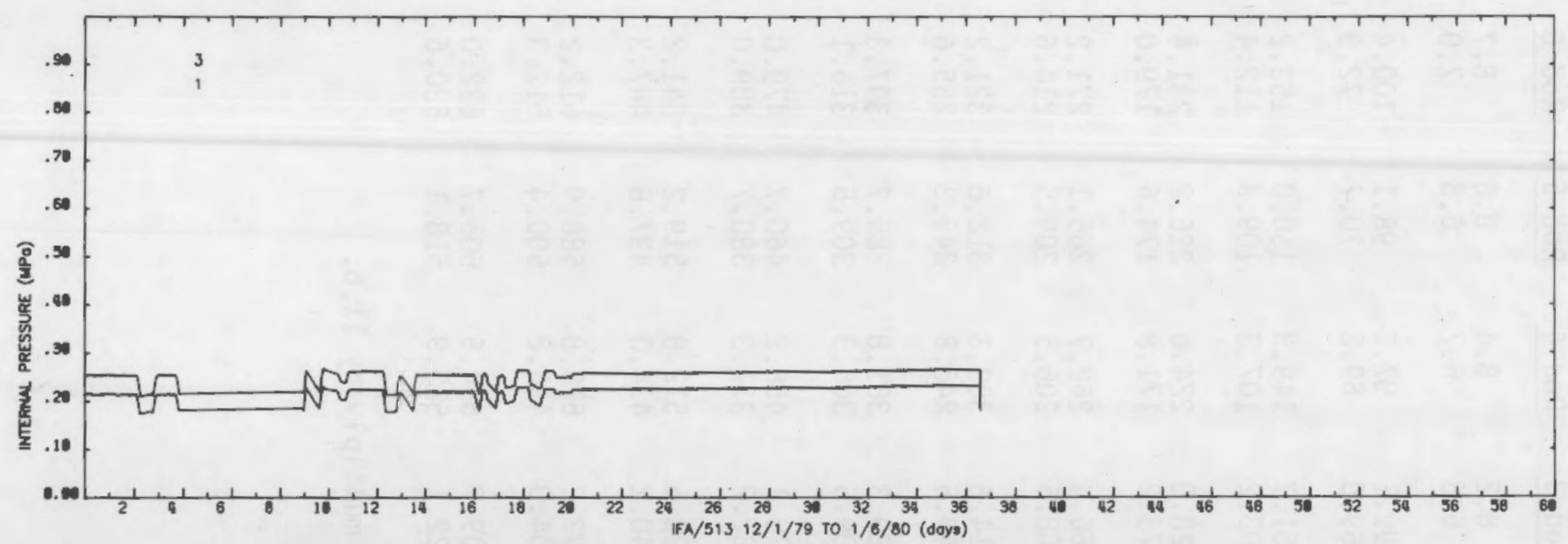

FIGURE D.59. Internal Pressures for Rods 1 and 3 of IFA-513 from December 1, 1979, to January 6, 1980

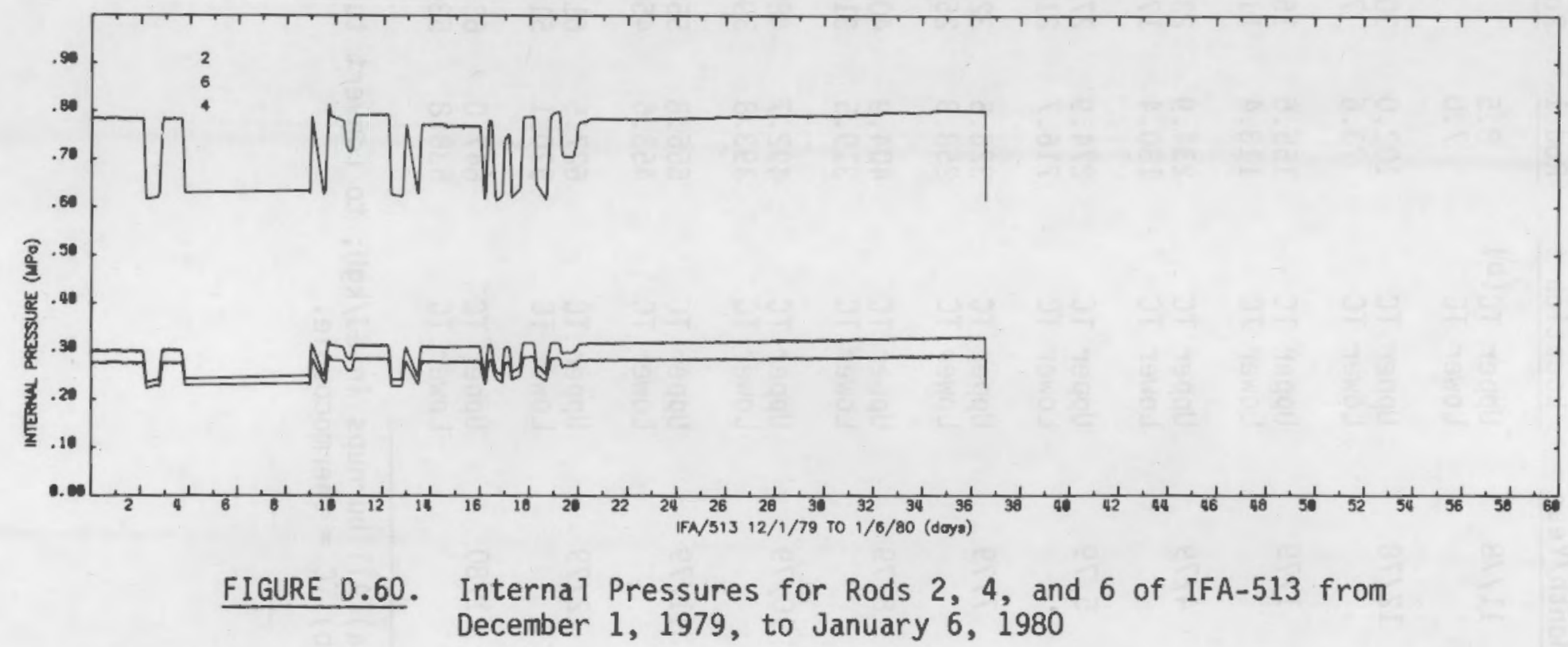


TABLE D.1. IFA-513 Burnup Data(a)

\begin{tabular}{|c|c|c|c|c|c|c|c|}
\hline Month/Year & Location & Rod 1 & Rod 2 & Rod 3 & Rod 4 & Rod 5 & Rod 6 \\
\hline $11 / 78$ & $\begin{array}{l}\text { Upper TC(b) } \\
\text { Lower TC }\end{array}$ & $\begin{array}{l}8.5 \\
7.0\end{array}$ & $\begin{array}{l}8.3 \\
6.9\end{array}$ & $\begin{array}{l}8.2 \\
6.8\end{array}$ & $\begin{array}{l}8.4 \\
6.7\end{array}$ & $\begin{array}{l}8.6 \\
6.8\end{array}$ & $\begin{array}{l}8.7 \\
7.0\end{array}$ \\
\hline $12 / 78$ & $\begin{array}{l}\text { Upper TC } \\
\text { Lower TC }\end{array}$ & $\begin{array}{r}102.0 \\
73.6\end{array}$ & $\begin{array}{r}101.4 \\
72.1\end{array}$ & $\begin{array}{l}99.1 \\
69.9\end{array}$ & $\begin{array}{l}97.5 \\
69.2\end{array}$ & $\begin{array}{l}98.1 \\
70.7\end{array}$ & $\begin{array}{r}100.4 \\
72.9\end{array}$ \\
\hline $1 / 79$ & $\begin{array}{l}\text { Upper TC } \\
\text { Lower TC }\end{array}$ & $\begin{array}{l}155.6 \\
113.4\end{array}$ & $\begin{array}{l}154.8 \\
111.3\end{array}$ & $\begin{array}{l}151.7 \\
108.2\end{array}$ & $\begin{array}{l}149.3 \\
107.3\end{array}$ & $\begin{array}{l}150.0 \\
109.3\end{array}$ & $\begin{array}{l}153.2 \\
112.4\end{array}$ \\
\hline $4 / 79$ & $\begin{array}{l}\text { Upper TC } \\
\text { Lower TC }\end{array}$ & $\begin{array}{l}234.9 \\
180.4\end{array}$ & $\begin{array}{l}233.2 \\
177.6\end{array}$ & $\begin{array}{l}228.0 \\
173.2\end{array}$ & $\begin{array}{l}224.6 \\
171.8\end{array}$ & $\begin{array}{l}226.2 \\
174.6\end{array}$ & $\begin{array}{l}231.4 \\
179.0\end{array}$ \\
\hline $5 / 79$ & $\begin{array}{l}\text { Upper TC } \\
\text { Lower TC }\end{array}$ & $\begin{array}{l}274.9 \\
216.7\end{array}$ & $\begin{array}{l}272.5 \\
213.6\end{array}$ & $\begin{array}{l}266.4 \\
208.5\end{array}$ & $\begin{array}{l}262.7 \\
206.5\end{array}$ & $\begin{array}{l}265.1 \\
209.5\end{array}$ & $\begin{array}{l}271.2 \\
214.6\end{array}$ \\
\hline $7 / 79$ & $\begin{array}{l}\text { Upper TC } \\
\text { Lower TC }\end{array}$ & $\begin{array}{l}326.5 \\
258.3\end{array}$ & $\begin{array}{l}323.2 \\
255.3\end{array}$ & $\begin{array}{l}314.6 \\
249.5\end{array}$ & $\begin{array}{l}309.3 \\
246.8\end{array}$ & $\begin{array}{l}312.6 \\
249.8\end{array}$ & $\begin{array}{l}321.2 \\
255.6\end{array}$ \\
\hline $8 / 79$ & $\begin{array}{l}\text { Upper TC } \\
\text { Lower TC }\end{array}$ & $\begin{array}{l}404.9 \\
319.5\end{array}$ & $\begin{array}{l}400.9 \\
316.2\end{array}$ & $\begin{array}{l}389.3 \\
309.6\end{array}$ & $\begin{array}{l}381.6 \\
306.3\end{array}$ & $\begin{array}{l}385.7 \\
309.5\end{array}$ & $\begin{array}{l}397.3 \\
316.1\end{array}$ \\
\hline $10 / 79$ & $\begin{array}{l}\text { Upper TC } \\
\text { Lower TC }\end{array}$ & $\begin{array}{l}492.7 \\
393.8\end{array}$ & $\begin{array}{l}488.3 \\
390.5\end{array}$ & $\begin{array}{l}470.1 \\
382.2\end{array}$ & $\begin{array}{l}456.2 \\
377.3\end{array}$ & $\begin{array}{l}460.7 \\
380.7\end{array}$ & $\begin{array}{l}479.0 \\
389.0\end{array}$ \\
\hline $11 / 79$ & $\begin{array}{l}\text { Upper TC } \\
\text { Lower TC }\end{array}$ & $\begin{array}{l}556.8 \\
453.6\end{array}$ & $\begin{array}{l}550.4 \\
450.0\end{array}$ & $\begin{array}{l}528.5 \\
440.2\end{array}$ & $\begin{array}{l}512.8 \\
434.0\end{array}$ & $\begin{array}{l}519.2 \\
437.6\end{array}$ & $\begin{array}{l}541.2 \\
447.3\end{array}$ \\
\hline $12 / 79$ & $\begin{array}{l}\text { Upper TC } \\
\text { Lower TC }\end{array}$ & $\begin{array}{l}627.5 \\
520.1\end{array}$ & $\begin{array}{l}617.5 \\
515.9\end{array}$ & $\begin{array}{l}592.2 \\
504.0\end{array}$ & $\begin{array}{l}576.8 \\
496.2\end{array}$ & $\begin{array}{l}586.9 \\
500.4\end{array}$ & $\begin{array}{l}612.2 \\
512.3\end{array}$ \\
\hline $1 / 80$ & $\begin{array}{l}\text { Upper TC } \\
\text { Lower TC }\end{array}$ & $\begin{array}{l}647.0 \\
538.8\end{array}$ & $\begin{array}{l}635.0 \\
534.5\end{array}$ & $\begin{array}{l}609.7 \\
522.1\end{array}$ & $\begin{array}{l}594.5 \\
513.9\end{array}$ & $\begin{array}{l}605.7 \\
518.1\end{array}$ & $\begin{array}{l}632.0 \\
530.6\end{array}$ \\
\hline
\end{tabular}

(a) All burnups in GJ/kgU; to convert to MWd/MTM multiply by 11.6 .

(b) $\mathrm{TC}=$ thermocouple. 


\section{STR IBUT ION}

No. of

Copies

OFFSITE

A. A. Churm

DOE Patent Division

$9300 \mathrm{~S}$. Cass Avenue

Argonne, IL 60439

400 U.S. Nuclear Regulatory Commission

Division of Technical Information and Document Control

7920 Norfolk Avenue

Bethesda, MD 20014

2 DOE Technical Information Center

4 Chief, Fuel Behavior Research Branch

Division of Reactor Safety Research

U.S. Nuclear Regulatory Commission Washington, D.C. 20555

H. H. Scott

Division of Reactor Safety Research

U.S. Nuclear Regulatory Commission Washington, D.C. 20555

G. P. Marino

Fuel Behavior Research Branch

Division of Reactor Safety Research

U.S. Nuclear Regulatory Commission Washington, D.C. 20555
No. of

Copies

ONSITE

50 Pacific Northwest Laboratory

W. J. Bailey

J. 0. Barner

E. R. Brad ley (7)

M. E. Cunn ingham (20)

S. K. Edler

M. D. Freshley

R. L. Goodman

R. J. Guenther

C. R. Hann

D. D. Lanning

R. K. Marsha 11

C. L. Mohr

C. Nealley

F. E. Panjisko

W. N. Rausch

R. E. Schreiber

M. S. Sinith

R. E. Williford

Technical Information (5)

Publishing Coordination $\mathrm{Fe}(2)$ 



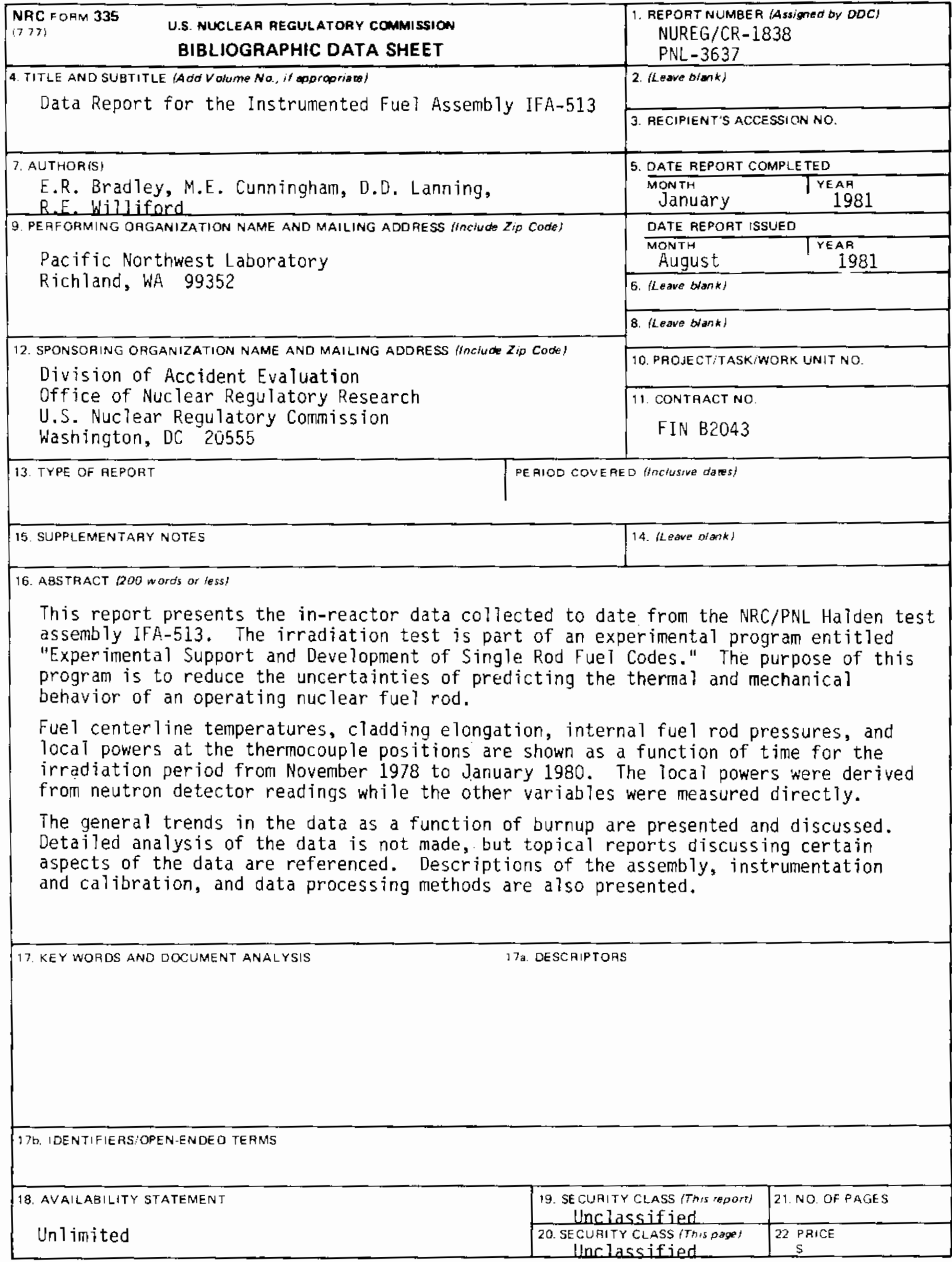


